\title{
Tensile properties of a novel fibre reinforced geopolymer composite with enhanced strain hardening characteristics
}

\begin{abstract}
Strain hardening cementitious concrete is a type of fibre reinforced concrete with enhanced mechanical properties, including strain hardening and ductility. Geopolymer (cement-free) materials represent promising more sustainable alternatives to ordinary Portland cement. Heat treatment however is crucial when using geopolymer materials, to provide comparable mechanical properties to conventional concrete, and there are a number of practical limitations in the application of heat curing in large-scale structures.

The main aim of this study is to develop and evaluate the mechanical properties of a novel, sustainable strain hardening fibre-reinforced geopolymer composite material, cured under ambient temperature and thus suitable for cast-in-place applications. In particular, the effect of incorporation of discontinuous fibres on the mechanical performance and on the microstructure of the composite geopolymer materials has been evaluated. The results indicate that room temperature cured, cement-free, strain hardening geopolymer concrete with superior deflection capacity can be produced using a ternary geopolymer binder mix reinforced by $2 \%$ PVA fibre or with $2 \%$ and $3 \%$ of $13 \mathrm{~mm}$ length steel fibre.
\end{abstract}

Keywords: Geopolymer; Strain hardening; Ambient curing; Steel fibres; PVA fibres; Glass fibres

\section{Introduction}

Fibre reinforced cementitious composites (FRCC) have been developed and extensively researched over the last two decades [1]. Generally, the addition of fibres to a concrete mix considerably enhances many of the mechanical properties of concrete such as flexural, impact, tensile and abrasion strength, and post cracking behaviour [2]. FRCCs with higher ductility, such as strain hardening cementitious composites, however need higher contents of cement than normal concrete in order to develop the interfacial bond characteristics and to account for the absence of coarse aggregates in the mixture design [3]. Using high cement amounts leads to increased heat of hydration, higher shrinkage and is more energy intensive [4]. In addition, use of a high ordinary Portland cement (OPC) content has negative environmental impacts associated with the cement manufacturing process production of 1 ton of cement generates 1 ton of greenhouse gas emissions [5,6]. Partial replacement of OPC by waste materials such as fly ash (FA) has been reported in some studies as a possible solution to this problem [7]. Yang et al. [8] examined the feasibility of creating an engineering cementitious composite, taking into account environmental sustainability considerations, by using high FA content (up to $85 \%$ by weight) cement. Their results showed that a high volume of FA can reduce the drying shrinkage, crack width, and improve tensile ductility, although this also reduced the 28 days compressive strength. Choi et al. [3] investigated the effect of partial replacement of cement by recycled materials on the mechanical properties of strain hardening cementitious material (SHCC). Alternative byproduct materials (FA, sand, and polyethylene terephthalate (PET) fibers) were used to 
partially replace cement, silica sand, and polyvinyl alcohol (PVA) fibers, respectively. The results from this study indicated that FA improves both bending and tensile behavior due to generation of stronger bonding between the PVA fibres and cement matrix. The SHCC containing PET fibres however performed relatively poorly in tensile and bending strength tests.

A new greener material with cementitious characteristics (termed geopolymer) has been developed in recent years. Geopolymer can be synthesised by mixing an alkaline solution with industrial aluminosilicate waste materials such as FA, ground granulated blast slag (GGBS), metakaolin, rice husk ash and silica fume (SF). The adoption of geopolymer materials could reduce the carbon dioxide emissions associated with the manufacturing of conventional Portland cement by up to $80 \%$ [9]. The "green" credentials of geopolymer compared with OPC, and the known positive impact of fibre incorporation on service life durability, mean that use of fibre reinforced geopolymer composites could play a key role in developing more sustainable infrastructure systems [10]. However, based on previous studies [11-13], FA-based geopolymer concretes require elevated temperature treatment to obtain comparable performance (in terms of physical, mechanical and durability characteristics) to conventional concrete. This heat treatment leads to increased cost, effects the material sustainability, and generates practical production and handling issues, preventing in situ application of geopolymer concrete at large scales $[12,14,15]$.

Geopolymer mortar has relatively poor tensile and bending strength compared to conventional Portland cement. This limitation could be overcome however by the inclusion of fibre [16]. The mechanical performance of fibre reinforced cementitious composites depends on the material parameters (both of the fibres themselves, and the cementitious matrix). These parameters include strength, aspect ratio, Poisson's ratio and shape of fibres; the stiffness, strength, and shrinkage of the matrix; and frictional bond properties and the physio-chemical interactions at the interface between the cementitious matrix and the fibres. Although geopolymer concretes are a growing area of research and development, there are as yet only a small number of studies examining fibre reinforced geopolymer composites in the open literature compared with traditional fibre reinforced cement concretes [16-18]. Aydin and Baradan [19] examined the effect of steel fibres on the mechanical characteristics and shrinkage behavior of alkali activated GGBS and SF mortar. Their results showed that incorporation of steel fibres led to improved flexural toughness and reduced drying shrinkage strain. Bernal et al. [17] evaluated the permeability and engineering properties of GGBS concrete reinforced with steel fibres. Their experimental results indicated that GGBS concrete reinforced with steel fibres exhibits better mechanical performance than conventional concrete. However, compressive strength of AAS concrete reduced with the fiber incorporation. Natali et al., [16] examined the effect of different fibre types on the flexural characteristics of fibre reinforced geopolymer composites (glass, carbon, polyvinyl Chloride (PVC), and polyvinyl Alcohol (PVA)), and showed that application of all fibre types significantly improved flexural strength and post-crack ductility. Alcaide et al. [20] mentioned that inclusion of carbon fibre in alkali activation slag failed to improve strength however it reduced the drying shrinkage. Finally, Zhang et al., [21] reported the flexural behavior of extruded PVA fibre reinforced geopolymer, manufactured by mixing metakaolin 
and FA /metakaolin blend with sodium silicate and sodium hydroxide as alkaline activator. Their results indicated that the flexural strength and failure mechanism varied as a function of matrix composition and fibre/matrix bonding.

Recently, the development of more user-friendly geopolymers has been proposed in order to enhance the strength of the geopolymer material as well as reduce costs and energy consumption, and promote easier handling application $[11,22]$. However, there are no published studies to date on user friendly geopolymer systems with strain hardening characteristics. In the current study, the development of a user-friendly geopolymer concrete with strain hardening characteristics, cured under ambient temperature and thus suitable for cast-in-place application, has been examined. The geopolymer matrix was produced using a ternary geopolymer binder (FA, GGBS and silica fume) mixed with a low content and concentration of potassium silicate alkaline activator. An extensive experimental programme was carried out to evaluate the effect of incorporation of variant volume fractions and aspect ratios of discontinuous steel (ST), polyvinyl alcohol (PVA), and glass fibres on the mechanical performance and microstructure of the composite, via compressive, flexural and direct tensile tests, and scanning electron microscopy. Flexural load-deflection curves have been used to determine flexural strength, residual strength and flexural toughness. The strength development of FRGC with curing time has been also examined.

\section{Experimental details \\ 2.1 Material and mix proportions}

The geopolymer mortar matrix adopted in the present work was based on a ternary blend geopolymer binder (FA, GGBS and silica fume), mixed with potassium silicate $\left(\mathrm{K}_{2} \mathrm{SiO}_{3}\right)$ with a molar ratio equal to 1.25 , and sand [23]. Silica sand with a particle size less than $0.5 \mathrm{~mm}$ was used as fine aggregate. Total binder and silica sand quantities of $775 \mathrm{~kg} / \mathrm{m}^{3}$ and 1054 $\mathrm{kg} / \mathrm{m}^{3}$ respectively were used for the mixes in the current investigation, values based on a previous study [22].

Fourteen different mixtures were prepared, with varying fibre type, fibre volume fractions and fibre aspect ratios (Table 1). Details of the fibres used are presented in Fig.1 and Table 2. A Zyklos high shear mixer (Pan Mixer ZZ 75 HE) was used to manufacture the fibrereinforced geopolymer composite. Geopolymer binder (SF, FA and GGBS) was placed first in the mixer, followed by alkaline liquid, and sand. The materials were dry mixed for 5 min before adding the water and alkaline activator. Mixing continued for a further 4 min before the fibres were added, and finally silica sand was added to give a total mixing time of 13 minutes. After demoulding, the samples were covered with plastic sheets to prevent moisture loss and cured at room temperature up to the testing date.

\subsection{Experimental equipment and test procedures}

Three different tests were conducted to measure the mechanical characteristics of the examined mixtures: compression tests, flexural strength tests and direct tensile tests. The development of compressive and tensile strength over curing time were also investigated. The microstructure of the mixtures was examined using scanning electronic microscopy (SEM). 
- Compressive strength values were determined at 28 days using four cubes with 100 $\mathrm{mm}$ sides, while examination of compressive strength development over curing time (3, 7 and 28 days) was conducted by using nine cubes with $50 \mathrm{~mm}$ sides for each mixture, using a Denison Avery $2000 \mathrm{KN}$ test machine with loading rate of $180 \mathrm{KN}$ per minute [24].

- Flexural strength was determined by testing standard prismatic specimens $(100 * 100 * 500 \mathrm{~mm})$ at 28 days using an Instron testing machine. A span length equal to $450 \mathrm{~mm}$ was used, with distance between the loading points set at 1/3rd of the span length [25]. The flexural test set-up is shown in Fig. 2. The testing machine was operated in a 'closed loop' mode to load the prisms at a fixed deflection rate of 0.24 $\mathrm{mm} / \mathrm{min}$. Two Linear Variable Displacement Transducers (LVDTs) were attached to a yoke frame which was used in order to eliminate any induced displacements at the supports during loading (see Fig. 2). The load deflection curve was used to characterize the ultimate load and its related deflection, ultimate flexural strength, toughness and residual strengths based on ASTM C1609 [26]

- Direct tensile strength was determined using 'dog bone' shaped samples of $13 \mathrm{~mm}$ (mid cross section) by $50 \mathrm{~mm}$ (Fig. 3a). The samples were manufactured to fit into a pair of clamps that were attached on both sides of the sample to measure displacement alongside the narrow cross section. The test was carried out to determine the tensile strength of geopolymer specimens reinforced with the micro fibres after 3, 7, 14 and 28 days curing. The setup shown in Fig.3b was used to determine the average displacement over a gauge length of $105 \mathrm{~mm}$. A constant loading rate of $0.4 \mathrm{~mm} / \mathrm{min}$ was used to control the tests and measurements were recorded until the ultimate load was achieved. The load carrying capacity behavior after cracking of the fibre reinforced sample was also examined [27].

- For microstructural analysis, Plain Geopolymer and FRGC samples were taken from the cracked samples after the end of the tensile tests. The fractured samples were sputtered with carbon and imaged using scanning electronic microscopy (SEM) (Zeiss; model LEO 1455VP).

\section{$3 \quad$ Results}

\subsection{Compressive Strength Test}

The compressive strength development of strain hardening geopolymer concrete over curing time was examined, using cubes with $50 \mathrm{~mm}$ side (Fig. 4). This cubic size was valid only for micro fibre mixtures as the macro fibre length exceeded the limit of the cube size. Each data point corresponds to an average of three specimens.

As can be seen from the results, the compressive strength of FRGC increased with increasing curing time for all examined mixtures. The 7 days compressive strength was enhanced by $31 \%, 64 \%, 48 \%$ and $80 \%$ for PG, 2ST6, 2ST13, 2PVA and 1Glass mixtures, respectively, compared with the respective compressive strength values at 3 days. This observation indicates similar behaviour to that reported in conventional ordinary Portland 
concrete, which undergoes a hydration process and develops strength over time. The maximum compressive strengths were achieved at 28 days, at $c a .45 \mathrm{MPa}, 59 \mathrm{MPa}, 57 \mathrm{MPa}$, $45 \mathrm{MPa}$, and $42 \mathrm{MPa}$ for PG, 2ST6, 2ST13, 2PVA and 1Glass mixtures, respectively. This overall trend in increasing compressive strength over time is due to the low strength of the geopolymer matrix at early ages, which weakens the interfacial bonds between the fibre and the geopolymer matrix. At later ages the compressive strength of FRGC significantly improves due to infilling of the porous microstructure of the geopolymer matrix by formation of more hydration products, leading to improvement in the fibre-matrix bond.

From the above observations, the compressive strength of all the examined mixtures at 28 days is compared in Fig. 5. Each column corresponds to an average of three cubic specimens with $100 \mathrm{~mm}$ sides while the scatter of the experimental results is also presented.

The compressive strength value of the plain geopolymer mortar without fibres was 43.7 $\mathrm{MPa}$. The incorporation of steel fibres increases the compressive strength by about 15 $25 \mathrm{MPa}$ depending on the fibre aspect ratio, shape and dosage rates. The resistant capacity of the ST13 mixture under compression increased by increasing the fibre dosage rates, although this trend was not apparent for the ST6 mixtures, where the compressive strength decreased with increasing fibre content. This is due to high number of short steel fibre at high volume fraction $\left(V_{f}\right)(3 \%)$ (double of the ST13 fibre at the same $V_{f}$ ), leading to redistribution of voids structure, and weaken the interfacial bonding between the fibre and geopolymer binder grains under compression. The 3ST13 mixture had the highest strength value, of around $70 \mathrm{MPa}$. The increase in compressive strength for the geopolymer with macro hooked end fibres was ca. $13 \mathrm{MPa}$. The hybrid macro and micro steel fibre (ST13) also showed improvement in compressive strength, depending on the dosage of straight ST13 fibres. The compressive strength of HE1050 fibres with a straight aspect improved the compressive strength to 62 $\mathrm{MPa}$ and $67 \mathrm{MPa}$ for 1HE-1ST13 and 1HE-2ST13. This increment in the compressive strength is due to the ability of steel fibre to restrain the extension of cracks, reduce the stress concentration at the tip of cracks, and change the direction of cracks leading to a delay in their growth rate [28]. However, the geopolymer composite reinforced with glass and PVA fibres did not significantly alter the compressive strength value compared to ordinary Portland cement and the geopolymer control sample. The compressive strength of 1PVA, 2PVA and 1Glass mixtures was $39 \mathrm{MPa}, 42 \mathrm{MPa}$ and $34 \mathrm{MPa}$.

\subsection{Flexural strength test}

\subsubsection{Flexural specifications (criterion or boundary) of FRGC.}

The flexural performance of FRC is classified as either deflection softening or hardening behaviours, based on the change in load carrying capacity after first cracking [29, 30]. According to ASTM C1609/C [26], the first cracking of FRGC is determined as the point where nonlinearity in the load-deflection relationship becomes evident. The load initiating the first crack in the specimens is named as the first peak load $\left(\mathrm{P}_{1}\right)$, while the second peak load represent the greatest value of the load on the load deflection curve of the FRGC. 
The ASTM C1609 standard defines the residual load values $\left(\mathrm{P}_{600}^{D}\right.$ and $\left.\mathrm{P}_{150}^{D}\right)$ and corresponding residual strength $\left(f_{600}^{D}\right.$ and $\left.f_{150}^{D}\right)$, determined at net deflections of $\mathrm{L} / 600$ and $\mathrm{L} / 150$ for a beam with a depth of $\mathrm{D}$. Toughness $\mathrm{T}_{600}$ and $\mathrm{T}_{150}$ were identified as the area under the load-deflection curve up to the deflection points $\mathrm{L} / 600$ and $\mathrm{L} / 150$, respectively (Fig. 6). Toughness up to the peak load $\left(T_{p}\right)$ and toughness peak indices $\left(I_{\text {peak }}\right)$ (the ratio of $T_{p}$ to the first cracking load-deflection area) [29] were also examined.

\subsubsection{Flexural load versus deflection response}

The primary advantage of using fibres is that they improve ductility in the load carrying capacity after cracking, which can be determined from load-deflection measurement. The effect of different volume fractions and fibre types on the load-deflection relationships are presented in Fig. 7 and Fig. 8, respectively. The flexural response of all examined mixtures for loads, bending strength and toughness using load-deflection relationships are summarized in Table 3, and Fig. 9.

For the geopolymer composite without fibres, cracking occurred at the midspan and propagated quickly to the top, and the specimens fractured into two pieces (Fig. 7a). Addition of steel fibres positively affected the post cracking behaviour of all the geopolymer mixtures. The load-deflection curves of all the fibre reinforced geopolymer mixtures were similar as the load linearly increased up to the first peak, the nonlinear increased up to the ultimate load. After the ultimate load points, the load deflection curves gradually decrease up to failure.

The load carrying capacity and related deflection of the fibre reinforced geopolymer concrete were improved dramatically by increasing steel fibre dosage rates and aspect ratios (Fig.7 bc). The deflections at first cracking were $0.12 \mathrm{~mm}, 0.25 \mathrm{~mm}$ for 2ST6 and 3ST6 mixtures, respectively. Increasing the steel fibre aspect ratio increased the first crack deflection to 0.171 $\mathrm{mm}, 0.3$ and $0.6 \mathrm{~mm}$ for 1ST13, 2ST13 and 3ST13, respectively (Table 3 and Fig. 11). The ultimate flexural load of SFRGC was improved by 30\%, 56\% for the mixture reinforced by ST6 and $175 \%, 240 \%$ for the mixture reinforced by ST13 at 2\% and 3\% volume fraction, respectively, compared with the plain geopolymer mixture. The deflection of ST13 mixtures at the peak load increased by 5.7 times and 2.8 times over the ST6 mixture with $2 \%$ to $3 \%$ volume fraction, respectively. The peak load deflections of 2ST13 and 3ST13 mixtures provide almost 13 and 19 times higher deflection than the plain geopolymer mixture, respectively.

Fig. 7d presents the load-deflection curve of a geopolymer composite with macro hooked end fibre HE1050. When only hooked end fibres were utilized, the load-deflection relation clearly divided into three sections; a linear section, a strain hardening section and a strain softening section with low flexural strength to around 3.8 MPa. Hybrid micro straight steel fibres with hooked end steel fibres considerable improved the flexural load and deflections of SFRGC depending on the volume fraction of ST13. The first cracking load of 1HE-1ST13 and 1HE2ST13 mixtures increased by $73 \%$ and $160 \%$ and the corresponding deflection increased by $100 \%$ and $250 \%$, respectively compared with first cracking load and deflection of the $1 \mathrm{HE}$ mixture (Table 3). This behaviour can be explained as the stress in the hybrid SFRGC is well 
distributed and its mechanical properties improved due to short steel fibres efficiently resisting the micro cracks, at the point when the micro cracks are just initiated in the geopolymer specimen. As the micro cracks develop and merge into larger macro cracks, long hooked end steel fibres become more active in crack bridging.

In the case of PVA-FRGC, the geopolymer composite showed high deflection capacity (Fig. 7 e) and first and second peak loads can be clearly observed in the load-deflection curve. Increasing the PVA fibres volume fraction did not affect the ultimate flexural load. However, deflection at the first and second peaks significantly increased from $0.17 \mathrm{~mm}$ and $2.19 \mathrm{~mm}$ to 0.18 and $5.5 \mathrm{~mm}$ for 1PVA and 2PVA mixtures, respectively. The deflection capacity of the 2PVA mixture at the second peak load is much higher than all geopolymer composites containing steel fibre (Fig. 8 and Fig. 9). The load deflection curve showed that after the initial cracking, load increased with deflection with a low slope due to the fibre bridging action at the interface of cracks, up to the point at which slip between the fibres and matrix happened. Tension softening and load moderately decreased after the second peak load at the crack surface was achieved. This is due to strong bonds between fibres and matrix. The maximum flexural load value of PVA-containing samples was close to the flexural load of the $13 \mathrm{~mm}$ steel fibre mixture (at around $20 \mathrm{MPa}$ ) at the same volume fraction. In addition, the experimental test showed bendable behaviour of the composite, with self-healing performed as the beam returned to the initial beam shape after finalization of the flexural test.

The load-deflection relationship of the glass fibre reinforced geopolymer specimen is plotted in Fig. 7f. It can be seen that glass fibre improves the peak load by $50 \%$ compare with the plain geopolymer. However, the 1Glass peak load is lower than steel and PVA at the same volume fraction and strain-softening failure can be recognized in the post crack behaviour with small deflection capacity. This is due to the weak bond between the glass fibre and the geopolymer matrix (See Section 3.3).

As can be seen from Fig. 8 and Fig. 9, all fibre reinforced geopolymer mixtures apart from the 2ST6 mixture confirm strain hardening behaviour as the second peak load is greater than that at the first cracking load. However, the fibre reinforced geopolymer mixture reinforced by PVA, ST13 and hybrid ST13 with HE fibre has the greatest gap between first and second peak loads and deflections. This superior deflection could be due to the fineness of the geopolymer binder and the high strength of the geopolymer matrix, resulting in high interfacial bond strength between the geopolymer matrix and the fibre.

\subsubsection{Flexural toughness}

Flexural toughness is a vital parameter in evaluating the influence of fibres on the fracture energy absorption capacity of the fibre-reinforced geopolymer composites. The toughness residual strength have been determined at $\mathrm{f}_{600}$ and $\mathrm{f}_{150}$ according to ASTM standard C1609 (fig. 10a). Toughness and toughness indices up to the peak load $\mathrm{I}_{\text {peak }}$ were also obtained as noted earlier to identify the toughness capacity of SHGC with different load deflection curve shapes (Fig. 10b). 
As shown in Fig. 10a, the residual flexural strength $\mathrm{f}_{600}, \mathrm{f}_{150}$ and the toughness parameters $\mathrm{T}_{600}$ and $\mathrm{T}_{150}$ were considerably altered by utilizing different types of fibre. The lowest values of toughness $\mathrm{T}_{600}$ (4.7 joules) were shown for the 1HE-1ST13 mixture. The toughness of SFRGC before and after the second peak load was also considerably influenced by fibre volume and aspect ratio. The experimental results indicate that the aspect ratio of the steel fibres influenced the post-crack behaviour, as with increasing steel fibre volume content and aspect ratio an increase in the values of toughness is observed. Fibre reinforced geopolymer with 3ST13 gave the highest toughness $\mathrm{T}_{150}$ value of 60 joules. When combining two different steel fibre lengths (of $13 \mathrm{~mm}$ and $6 \mathrm{~mm}$ ), the toughness values were close to the toughness of the 3ST13 mixture. The toughness of hooked end fibre reinforced geopolymer mixtures increased with the inclusion of straight $13 \mathrm{~mm}$ steel fibre. Toughness $\mathrm{T}_{150}$ of the HE fibre mixture increased with increasing straight steel fibre content from 36 joules to 54 joules for 1HE-1ST13 to 1HE-2ST13, respectively.

Toughness and toughness indices up to the peak load were also examined to evaluate the effect of fibre types and aspect ratios on the ultimate load-deflection values (Fig. 10b). For non-reinforced geopolymer concrete, toughness indices are taken as 1.0 due to the plain mortar flexural test specimens failing directly after the formation of the first crack. Toughness indices $I_{\text {peak }}$ and peak toughness increased with increasing steel fibre volume fractions and aspect ratios. This is due to higher frictional surface area between the steel fibres and the geopolymer matrix, resulting in stronger crack bridging by the long steel fibres and thus a more efficient load transfer mechanism. Toughness, and toughness indices at the peak load, of PVA fibre reinforced geopolymer significantly improved by increasing the fibre volume fraction from $1 \%$ to $2 \%$. 2PVA-FRGC exhibited highest toughness indices values of 84 at $\mathrm{I}_{\text {peak }}$ proving the superior deflection hardening behaviour of this composite material. The strong bond between PVA and steel fibre with the geopolymer matrix is the major toughening mechanism in the geopolymer composite as indicated by the microstructural analysis (SEM section, below) in this study. Toutanji et al. [31] have noted that adding fibres to the matrix changes the behaviour from plain linear, where the energy absorption capacity relates to fracture and initiation of cracking, to a ductile behaviour, where the energy absorption is measured by micro-crack development and progressive fibre de-bonding up to failure.

\subsection{Direct tensile test}

Direct tensile tests were executed in order to examine the effect of fibre types, aspect ratios, volume fractions and curing time on the tensile strength of the examined mixes. The effect of curing age on the tensile stress-strain relationship of FRGC are evaluated by examined geopolymer specimens at 3, 7, 28 and 90 days (Fig. 11 and Table 4).

Fig. 11 and Table 4 show that curing time significantly affected the ultimate tensile strength and post cracking behaviour in the stress-strain curves. At early ages ( 3 and 7 days), tensile performance of the 2ST6 mixture cured under ambient temperature is about $0.7 \mathrm{MPa}$ and $0.85 \mathrm{MPa}$, respectively. This early strength is low compared to the specimens reinforced with 2ST13 (at about 1.3 and 1.43, respectively). 2PVA-FRGC specimens show higher tensile strength than all specimens reinforced with both aspect ratios of steel fibre. At 7 days, 
the tensile strength of 2PVA-FRGC is about 2.13, which is greater than the tensile strength of SFRGC (which is $0.85 \mathrm{MPa}$ and $1.3 \mathrm{MPa}$ for $6 \mathrm{~mm}$ and $13 \mathrm{~mm}$ fibre length, respectively). This is due to a relatively strong early interfacial bond forming between the PVA fibres and the geopolymer matrix compared with the steel fibre reinforced composite. For all SFRGC specimens, the tensile strength was significantly improved after 7 days. The results show the same trend with high values for all geopolymers reinforced with different fibres observed compared to their respective values at early ages. At 28 days tensile strength increased by $104 \%, 95 \%, 65 \%$ and $77 \%$ for 2ST6, 2ST13, 2PVA and 1Glass mixtures, respectively compared to the respective mixtures at 7 days. Under room temperature curing, geopolymerization improved with curing time, leading to improvements in the strength of the geopolymer matrix, and enhancement of the bond between the geopolymer matrix and the reinforcement fibres. Fig. 11 also shows that curing time effects the post cracking behaviour of FRGC. However, the type of failure is still the same for all curing ages, i.e. softening strain for short lengths of steel fibre and strain hardening failure for PVA and ST13 fibre reinforced geopolymer mixtures.

The effect of fibre aspect ratios, volume fractions and type in the 28 days tensile stress-strain relationship for FRGC are evaluated in Fig. 12

As can be observed from the results, the tensile stress-strain relationship of the plain geopolymer mortar (See Fig. 12a) is represented by linear build up to the ultimate stress, which then drops suddenly after formation of the first crack. However, the initial linear elastic phase of steel fibre reinforced geopolymer concrete is followed by a non-linear strainhardening behaviour up to the peak load only in the case of specimens with $13 \mathrm{~mm}$ long steel fibres or hybrid specimens with $6 \mathrm{~mm}$ and $13 \mathrm{~mm}$ long fibres. In specimens with $6 \mathrm{~mm}$ length steel fibre only, there was no strain hardening after the linear part of the curve, which is attributed to the lower surface friction between the geopolymer matrix and the short steel fibres (Fig. 12b). The highest strength and strain hardening behaviour in the post peak stress values of SFRGC mixtures was achieved in the specimens using $13 \mathrm{~mm}$ length fibres, where a longer friction surface between the fibres and the matrix is provided (Fig. 12c).

Inclusion of PVA and glass fibres in the FRGC showed different performance from SFRGC (Fig. 13). PVA-FRGC samples displayed strain-hardening behaviour accompanied by multiple cracking behaviour. Strain hardening was observed after first cracking and the stress-strain curve was almost horizontal. As displacement increased, PVA fibres started to be fractured; the strain-hardening trend gradually disappeared. On the other hand, the effect of glass fibre on the post crack behaviour of fibre reinforced geopolymer composites was less pronounced, and soft hardening failure occurred after the ultimate tensile strength was reached.

The failure pattern and crack distribution of FRGC vary under tension loading with the different fibres used. In the case of steel and glass fibre, most of the specimens failed by initiation of cracks in one or two locations in the narrow cross section of the specimens, and the crack opening became wider up to failure. Different behaviour was seen within PVAFRGC samples as multiple cracks were noticed during loading, the strain increased at the same stress value and many of the microcracks closed after unloading the specimens. This 
multiple cracking improves the composite characteristics in terms of ductility, fracture energy, strain hardening, and deformation capacity under tension and compression [32].

\subsubsection{Tensile stress-strain models of fibre reinforced geopolymer concrete}

Based on the tensile stress-strain performance of varying FRGC mixtures with strain hardening or softening behaviour (Fig. 12 and Fig. 13), two stages of FRGC response before destruction under tension load are defined in Fig. 14. The first stage represents the stress distribution during the elastic range before first cracking $\mathrm{E}$, and the second stage corresponding to the post-cracking modulus $\mathrm{E}_{\mathrm{cr}}$.

The effect of fibre type, volume fractions and aspect ratios on the tensile bond characteristics results of steel, PVA and glass fibres are shown in Table 5.

As shown in Table 5, the elastic behaviour of fibre-reinforced geopolymer is considerably affected by the fibre type and volume fraction used in the geopolymer mixture. The modulus of elasticity of 2ST13 was almost $60 \%$ higher than in the 2ST6 mixture. Increasing the volume fraction of steel fibre from $2 \%$ to $3 \%$ considerably improved the elastic modulus to $16 \mathrm{GPa}$ and $23.9 \mathrm{GPa}$ for the ST13 mixture, respectively. Inclusion of PVA fibres in the geopolymer mixture gave a high elastic modulus, and increasing the PVA volume fraction from $1 \%$ to $2 \%$ increase the elastic modulus from $16 \mathrm{GPa}$ to $24 \mathrm{GPa}$.

After the elastic modulus, the stress-strain relationships indicate yielding of FRGC in nonlinear mode, defined as a plastic state of the material. The nonlinear region is a function of the microcracks formed in the geopolymer binding matrix. The geopolymer reaches maximum stress through nonlinear strain hardening followed by strain softening once microcracks accumulate in a significant amount in the concrete. According to the experimental stress-strain relationships of FRGC, a low volume fraction of short steel fibre reinforced geopolymer performed as a strain softening material. However, increasing steel fibre length from $6 \mathrm{~mm}$ to $13 \mathrm{~mm}$ changed the geopolymer composite performance to a strain hardening behaviour. The effect of PVA fibres on load carrying capacity after cracking of FRGC is noticeable, as shown in Fig. 12e. The post cracking modulus of 2PVA fibre reinforced geopolymer concrete is 14 times higher than in the 2ST13 mixture. Furthermore, the residual tensile strength at the plateau zone is not the same for different fibre types. This behaviour illustrates that geopolymer reinforced with PVA, 3ST13 and hybrid ST13-ST6 exhibited higher strain hardening with the geopolymer matrix than glass and short steel fibre.

\subsubsection{Analysis - Prediction of Stress-Strain tensile response of FRGC.}

To predict the tensile behaviour of fibre reinforced geopolymer concrete, the method proposed by Vandewalle et al. [33] was used in approximating the tensile stress-strain parameters based on the stress deflection data established from flexural beam tests of the same mixtures. Fig. 15 represents the bi-linear uniaxial stress strain diagram up to the ultimate tensile strength.

The points defined in fig. 15 are measured from the following relations: 


$$
\sigma_{1}=\mathrm{C}_{1}(1.6-\mathrm{h}) \mathrm{f}_{\mathrm{ctm}, \mathrm{fl}} \quad \sigma_{2}=\mathrm{C}_{2} \mathrm{~F}_{\mathrm{fl}, \mathrm{ult}} \quad \varepsilon 2=\varepsilon 1+0.01 \% \text { o }
$$

Where $f_{c t m, f l}, f_{f l, u l t}$ and $E_{c}$ are the first crack and ultimate flexural tensile strength and modulus of elasticity of fibre reinforced geopolymer concrete (in MPa), respectively, $h$ is the depth of the flexural beam (in $\mathrm{m}$ ), 1 and 2 represent the first crack strain which is obtained from experimental work and ultimate tensile strains, respectively.

In the case of geopolymer materials, there is no relation are available for predicting tensile strength of FRGC. Using the $\mathrm{f}_{\mathrm{ctm}, \mathrm{fl}}$ and $\mathrm{f}_{\text {ult }}$ values obtained from flexural experimental tests, the tensile stress strain diagram of geopolymer concrete reinforced with different aspect ratios, volume fractions and types of straight fibres was characterized following RILEM TC 162-TDF recommendations [33]. The relation was calculated and plotted between the experimental and the predicted bi-linear tensile strength values as shown in Table. 6 and Fig. 16.

Table 6 shows that using the average of the experimental tensile stress strain of fibre reinforced geopolymer within the constitutive law proposed by RILEM TC 162-TDF and using the proposed coefficients $\left(\mathrm{C}_{1}=0.7\right.$ and $\left.\mathrm{C}_{2}=0.45\right)$, higher predicted tensile values than those recorded in the experimental results were obtained. A trial was employed to modify stress coefficients $\mathrm{C}_{1}$ and $\mathrm{C}_{2}$ from the values presented in RILEM TC 162-TDF [33] using the experimental data to achieve a better fitting tensile behaviour. The strain at the ultimate tensile value considerably changed with fibre content and aspect ratios. The ultimate strain increased with increasing aspect ratio and volume fraction of steel and PVA fibres. The largest gap between the first crack strain and the peak tensile strain was determined in the 3ST13 and 2PVA mixtures, which confirms the strain hardening performance of these mixtures.

\subsection{Comparative performance of flexural strength and tensile strength tests in FRGC.}

It is well known that there are a correlation between tensile and flexural strength for the conventional steel fibre reinforced concrete [34]. In general, tensile strength can either be determined by splitting tensile strength, direct tensile test or flexural strength tests. Comparison among the flexural test and direct tensile strength values data at the first cracking load and maximum load of fibre reinforced geopolymer concrete was carried out (Fig. 17).

The results show that direct tensile strength values are in broad agreement with the flexural strength performance (Fig. 17a). However, FRGC shows a higher bending strength values alongside the specimens comparable to the tensile strength values across the geopolymer material. The main conclusions that can be drawn from the experimental results is that there is an agreement between the tensile strength and flexural strength behavior for all the examined fibre reinforced geopolymer concrete mixtures. The first crack tensile strength and first crack flexural strength increased when fibre volume fraction increased and, at the same fibre content, when fibre aspect ratio increases. The 3ST13 mixture shows the highest first crack flexural and tensile strength followed by 2ST13 and 2PVA mixtures over all the examined mixtures. Fig $17 \mathrm{~b}$ illustrates that the ultimate flexural and tensile strength is in agreement with the first crack strength results with the different fibres examined. Increasing 
the fibre aspect ratio and volume fraction leads to an increase in the gap between the first and second peak of the flexural and tensile strength, and improves the strain hardening behavior of the fibre reinforced geopolymer concrete. To conclude, both tensile and flexural data confirm strain hardening behavior for the 2ST13, 3ST13 and 2PVA geopolymer mixtures.

\subsection{Scanning Electronic Microscopy (SEM)}

Scanning electron microscope (SEM) examination of fibre surface texture and fibrematrix interfaces was carried out in order to evaluate the fibre-geopolymer matrix bond characteristics. The SEM images of the plain geopolymer mortar and fibre reinforced geopolymer composite containing steel, PVA and glass fibres are shown in Fig.18 (a-h), respectively. SEM photographs in Fig.18a show the plain geopolymer mortar, and the images show a dark, well-connected structure and dense geopolymer microstructure. This mixture represents an optimum ternary geopolymer mixture based on earlier published studies [22]. Combining GGBS as a source of calcium, with FA and silica fume as source of silica leads to an increase in the formation of the geopolymerization product of a calcium alumino-silicate hydrate $(\mathrm{C}-\mathrm{A}-\mathrm{S}-\mathrm{H})$ gel.

Images of the fracture surfaces of the FRGC after the completion of tensile tests are shown in Fig. 18 (c-h). It can be observed that the geopolymerization process has successfully occurred and all the examined samples had a similar well-connected geopolymer matrix regardless of the fibre type used.

The SEM images show the steel fibre surface covered with geopolymer matrix at the fracture surface. This indicates relatively good bonding between the geopolymerization product and the steel fibres, which resists pull-out failure of fibre in the FRGC sample. In the case of the PVA-FRGC mixture, PVA fibres have a coarser surface, and thickening of the fibres is observed resulting from build-up of geopolymer hydration products on the surface of the PVA fibres, indicating the strong bond between PVA fibres and the geopolymer matrix. This is in agreement with the experimental results as PVA has high post crack resistance with strain hardening behaviour. On the other hand, glass fibre shows a relatively smooth surface within the geopolymer composite. These fibre-matrix interface observations are clearly consistent with the mechanical behaviour of FRGC. The tensile strength and post crack behaviour are significantly improved by inclusion of PVA and steel fibres while the effect of glass fibre was less pronounced. In addition, the unchanged diameter of the fibres indicates negligible degradative effect of the alkaline geopolymer matrix on the steel fibres.

\section{Conclusion}

Novel fibre reinforced geopolymer concretes with improved strain hardening performance and cured at ambient temperature have been developed in this research. The geopolymer matrix was produced by using a ternary binder (FA, GGBS and SF) mix with potassium silicate alkaline activator. The effects of fibre type, volume fraction, and fibre aspect ratio on the mechanical properties of FRGC were examined. The mechanical properties of FRGC were determined by compressive strength, tensile strength and flexural strength tests. Scanning Electronic Microscopy (SEM) was also used to assess the microstructure of the 
examined geopolymer mixtures. The following main outcomes can be drawn from the experimental results outlined here.

- The compressive strength of the examined specimens increased by 15-25 $\mathrm{MPa}$ when steel fibres were added to the mix. Using PVA and glass fibres did not give the same pronounced improvement in compressive strength.

- Increasing steel fibre content and aspect ratio significantly affected the compressive strength of SFRGC. Highest compressive strength values were achieved when 3\% of steel fibres with $13 \mathrm{~mm}$ length were used, with the compressive strength value in this case found to be around $70 \mathrm{MPa}$.

- Longer straight steel fibres and higher dosage rates resulted in better mechanical performance in terms of compressive strength, tensile strength and post crack behaviour.

- The deflection hardening behaviour of a SFRGC specimen with 3\% dosage of steel fibre with $13 \mathrm{~mm}$ length gave almost twenty times higher deflection at the peak load than specimens without fibre and 4 times that of $3 \%$ of steel fibre with $6 \mathrm{~mm}$ length.

- At the second peak load, PVA-fibre reinforced geopolymer exhibited the highest energy absorption capacity. The order of performance of different fibre types at this deflection level was as follows: PVA-fibres $>$ ST13-fibers $>$ glass-fibres

- The ultimate flexural strengths of SFRGC reinforced with $13 \mathrm{~mm}$ steel fibres was higher than that of ST6, PVA and glass fibre.

- Increasing micro steel fibre content in a hybrid system with macro steel fibres leads to enhancements in strength and deflection compared to the single macro steel fibre type. The bridging action of micro fibres leads to higher flexural strength, and can contribute towards production of better performing steel fibre-reinforced concretes. Specifically,

(1) Deflections of hybrid $1 \% \mathrm{~V}_{\mathrm{F}} \mathrm{HE}$ fibre with micro fibre (1\% and $\left.2 \% \mathrm{~V}_{\mathrm{f}}\right)$ are 2 and 4 times larger than the deflection of macro $1 \% \mathrm{HE}$ alone.

(2) Toughness of the hybrid $1 \% \mathrm{~V}_{\mathrm{F}}$ HE fibre with micro fibre ( $1 \%$ and $\left.2 \% \mathrm{~V}_{\mathrm{f}}\right)$ is $3-14$ times higher for the first cracking and 3.6-5.3 times higher at second cracking than for specimens containing macrofibres alone.

- SEM analysis show that the geopolymer matrix is compacted, well connected and that the strength bonding between fibre and matrix (with the exception of glass fibres) was good.

In summary, this study shows that inclusion of steel and PVA fibres in the examined geopolymer matrix significantly improved the flexural and tensile strength, even without elevated temperature treatment, which makes the FRGC potentially valid for in situ (cast-inplace) applications. These findings warrant further research on the durability properties of this sustainable strain hardening geopolymer composite, and its suitability as a structural element. 


\section{Acknowledgments}

Iraqi Ministry of Higher Education and Scientific Research is gratefully acknowledged by the lead author for the financial support provided for this study which is part of a $\mathrm{PhD}$ Scholarship.

\section{Reference}

[1] F. U. A. Shaikh, and A. Hosan, "Mechanical properties of steel fibre reinforced geopolymer concretes at elevated temperatures," Construction and Building Materials, vol. 114, pp. 1528, 2016.

[2] T. Uygunoğlu, "Investigation of microstructure and flexural behavior of steel-fiber reinforced concrete," Materials and Structures, vol. 41, no. 8, pp. 1441-1449, 2008.

[3] W.-C. Choi, H.-D. Yun, J.-W. Kang, and S.-W. Kim, "Development of recycled strain-hardening cement-based composite (SHCC) for sustainable infrastructures," Composites Part B: Engineering, vol. 43, no. 2, pp. 627-635, 2012.

[4] N. M. Altwair, M. A. Megat Johari, and S. F. Saiyid Hashim, "Flexural performance of green engineered cementitious composites containing high volume of palm oil fuel ash," Construction and Building Materials, vol. 37, pp. 518-525, 2012.

[5] L. K. Turner, and F. G. Collins, "Carbon dioxide equivalent (CO2-e) emissions: A comparison between geopolymer and OPC cement concrete," Construction and Building Materials, vol. 43, pp. 125-130, 2013.

[6] E. Gartner, "Industrially interesting approaches to "low-CO2" cements," Cement and Concrete Research, vol. 34, no. 9, pp. 1489-1498, 2004.

[7] B. Nematollahi, J. Sanjayan, and F. U. Ahmed Shaikh, "Tensile Strain Hardening Behavior of PVA Fiber-Reinforced Engineered Geopolymer Composite," Journal of Materials in Civil Engineering, vol. 27, no. 10, pp. 04015001, 2015.

[8] S. A. Bernal, R. Mejía de Gutiérrez, and J. L. Provis, "Engineering and durability properties of concretes based on alkali-activated granulated blast furnace slag/metakaolin blends," Construction and Building Materials, vol. 33, pp. 99-108, 2012.

[9] G. S. Ryu, Y. B. Lee, K. T. Koh, and Y. S. Chung, "The mechanical properties of fly ash-based geopolymer concrete with alkaline activators," Construction and Building Materials, vol. 47, no. 0, pp. 409-418, 10//, 2013.

[10] A. R. Sakulich, "Reinforced geopolymer composites for enhanced material greenness and durability," Sustainable Cities and Society, vol. 1, no. 4, pp. 195-210, 12//, 2011.

[11] J. Davidovits, Geopolymer Chemistry and Applications, 3 ed.: Geopolymer Institute, 2011, 2011.

[12] P. S. Deb, P. Nath, and P. K. Sarker, "The effects of ground granulated blast-furnace slag blending with fly ash and activator content on the workability and strength properties of geopolymer concrete cured at ambient temperature," Materials \& Design, vol. 62, no. 0, pp. 32-39, 10//, 2014.

[13] A. Islam, U. J. Alengaram, M. Z. Jumaat, and I. I. Bashar, "The development of compressive strength of ground granulated blast furnace slag-palm oil fuel ash-fly ash based geopolymer mortar," Materials \& Design, vol. 56, no. 0, pp. 833-841, 4//, 2014.

[14] N. K. Lee, and H. K. Lee, "Setting and mechanical properties of alkali-activated fly ash/slag concrete manufactured at room temperature," Construction and Building Materials, vol. 47, no. 0, pp. 1201-1209, 10//, 2013.

[15] P. Nath, and P. K. Sarker, "Effect of GGBFS on setting, workability and early strength properties of fly ash geopolymer concrete cured in ambient condition," Construction and Building Materials, vol. 66, no. 0, pp. 163-171, 9/15/, 2014. 
[16] A. Natali, S. Manzi, and M. C. Bignozzi, "Novel fiber-reinforced composite materials based on sustainable geopolymer matrix," Procedia Engineering, vol. 21, no. 0, pp. 1124-1131, //, 2011.

[17] S. Bernal, R. De Gutierrez, S. Delvasto, and E. Rodriguez, "Performance of an alkali-activated slag concrete reinforced with steel fibers," Construction and Building Materials, vol. 24, no. 2, pp. 208-214, 2//, 2010.

[18] C. Duran Atiş, C. Bilim, Ö. Çelik, and O. Karahan, "Influence of activator on the strength and drying shrinkage of alkali-activated slag mortar," Construction and Building Materials, vol. 23, no. 1, pp. 548-555, 1//, 2009.

[19] S. Aydın, and B. Baradan, "The effect of fiber properties on high performance alkali-activated slag/silica fume mortars," Composites Part B: Engineering, vol. 45, no. 1, pp. 63-69, 2//, 2013.

[20] A. E. Alcaide JS, Puertas F, Lapuente R, Garces P. , "Carbon fiber-reinforced, alkali-activated slag mortars.," Materiales de Construcción, vol. 57, no. 288, pp. 33-48, 2007.

[21] Z. Yunsheng, S. Wei, L. Zongjin, Z. Xiangming, Eddie, and C. Chungkong, "Impact properties of geopolymer based extrudates incorporated with fly ash and PVA short fiber," Construction and Building Materials, vol. 22, no. 3, pp. 370-383, 3//, 2008.

[22] M. H. Al-Majidi, A. Lampropoulos, A. Cundy, and S. Meikle, "Development of geopolymer mortar under ambient temperature for in situ applications," Construction and Building Materials, vol. 120, pp. 198-211, 2016.

[23] M. H. Al-Majidi, A. Lampropoulos, A. Cundy, "Experimental investigation of the effect of silica fume on geopolymer mortar cured under ambient temperature."

[24] "ASTM C109/C109M. Standard test method for compressive strength of hydraulic cement mortars (using 50 mm [2 in.] cube specimens). United States: ASTM Standards; 2007.."

[25] "ASTM C1018-97, Standard Test Method for Flexural Toughness and First-Crack Strength of Fiber-Reinforced Concrete (Using Beam With Third-Point Loading)," (Withdrawn 2006).

[26] "ASTM C1609 / C1609M-12, Standard Test Method for Flexural Performance of FiberReinforced Concrete (Using Beam With Third-Point Loading), ASTM International, West Conshohocken, PA, 2012,."

[27] A. M. T. Hassan, S. W. Jones, and G. H. Mahmud, "Experimental test methods to determine the uniaxial tensile and compressive behaviour of ultra high performance fibre reinforced concrete (UHPFRC)," Construction and Building Materials, vol. 37, pp. 874-882, 2012.

[28] V. Afroughsabet, and T. Ozbakkaloglu, "Mechanical and durability properties of highstrength concrete containing steel and polypropylene fibers," Construction and Building Materials, vol. 94, pp. 73-82, 9/30/, 2015.

[29] F. U. A. Shaikh, "Deflection hardening behaviour of short fibre reinforced fly ash based geopolymer composites," Materials \& Design, vol. 50, no. 0, pp. 674-682, 9//, 2013.

[30] D. J. Kim, S. H. Park, G. S. Ryu, and K. T. Koh, "Comparative flexural behavior of Hybrid Ultra High Performance Fiber Reinforced Concrete with different macro fibers," Construction and Building Materials, vol. 25, no. 11, pp. 4144-4155, 2011.

[31] X. B. Toutanji H, Gilbert J, Lavin T. , "Properties of poly(vinyl alcohol) fiber reinforced highperformance organic aggregate cementitious material: Converting brittle to plastic," Construction and Building Materials, vol. 24, pp. 1-10, 2010.

[32] H. M. Takashi Matsumoto, "DFRCC Terminology and Application Concepts," Journal of Advanced Concrete Technology, vol. 1, no. 2, pp. 335-340, 2003.

[33] Vandewalle et al., "Test and design methods for steel fiber reinforced concrete $-\sigma-\varepsilon$ design method - final recommendation," Material and structures, vol. 36, no. 262, pp. 560 - 567, 2003.

[34] B. W. Xu, and H. S. Shi, "Correlations among mechanical properties of steel fiber reinforced concrete," Construction and Building Materials, vol. 23, no. 12, pp. 3468-3474, 2009. 


\section{List of figures' captions}

Fig. 1. Geometry and shape of fibre used in this study.

Fig. 2. Bending specimen geometry (a); and test set-up (b).

Fig. 3. Direct tensile specimen geometry (a); and test set-up (b).

Fig. 4. Compressive strength development of FRGC over the curing time $(50 \mathrm{~mm}$ cubic specimens).

Fig. 5. 28d-Compressive strength of plain and fibre reinforced geopolymer composite (100 mm cubes).

Fig. 6. Typical load-deflection curve for fibre reinforced concrete and flexural performance evaluation based on ASTM C1609-05.

Fig. 7. Load-deflection relationships: plain geopolymer mortar and OPC mortar (a); 2ST6 and 3ST6 mixtures (b); 1ST13, 2ST13 and 3ST13 mixtures (c); 1HE, 1HE-1ST13 and 1HE2ST13 mixtures (d); 1PVA and 2PVA mixtures (e); and 1Glass mixture (f).

Fig. 8. Comparisons of load-deflection relationships for varying fibre types within the same volume fraction: 1Glass, 1ST13, and 1PVA mixtures (a); 2ST6, 2ST13 and 2PVA mixtures (b); and 3ST13 and 3ST6 (C).

Fig. 9. Flexural strength and deflection at the first crack and second peak load.

Fig. 10. Average flexural toughness of SHGC: Toughness and residual strength at deflections $\mathrm{L} / 600$ and $\mathrm{L} / 150$ (a); peak load toughness $\left(\mathrm{T}_{\mathrm{p}}\right)$ and peak toughness indices $\mathrm{I}_{\text {peak }}(\mathrm{b})$.

Fig. 11. Effect of curing time on the stress strain relation under tensile strength: 2ST6 mixtures (a); 2ST13 mixtures (b); 3ST13 mixture (c); 3[ST6-ST13] mixture (d); 2PVA mixture (e); 1Glass mixture (f).

Fig. 12. Effect of volume fraction on tensile stress-strain relationships: plain geopolymer mortar (a); 2ST6 and 3ST6 mixtures (b); 1ST13, 2ST13 and 3ST13 mixtures (c); 1Glass mixture (d); and 1PVA and 2PVA mixtures (e).

Fig. 13. Stress-strain relationships of FRGC for variant fibre types with the same volume fraction: 1Glass, 1ST13, and 1PVA mixtures (a); 2ST6, 2ST13 and 2PVA mixtures (b); and 3ST13 and 3ST6 (c).

Fig. 14. Effect of fibre type on tensile bond characteristics of FRGC.

Fig. 15. Stress-strain diagram of the behaviour of fibre reinforced concrete up to the ultimate strength.

Fig. 16. Experimental and modelled stress-strain responses of SFRGC.

Fig. 17. Comparison of flexural and tensile strength; strength at the first crack (a); at the ultimate strength (b). 
Fig. 18. SEM micrographs of plain geopolymer mortar (a); image perpendicular to the fracture surface of steel fibre/geopolymer composites (b); image perpendicular to the fracture surface of PVA fibre/geopolymer composites (c), and image perpendicular to the fracture surface of glass fibre/geopolymer composites (d). 

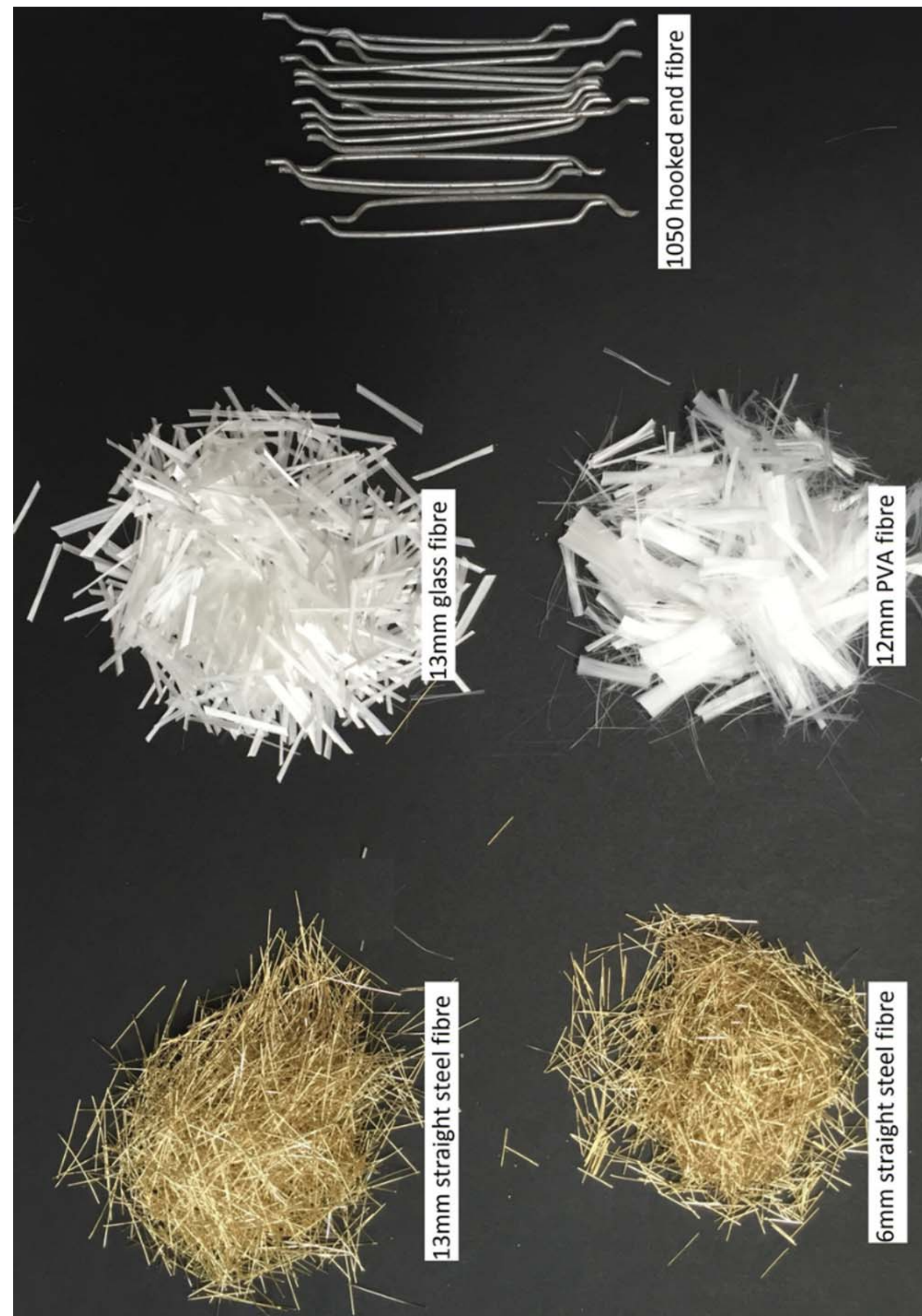


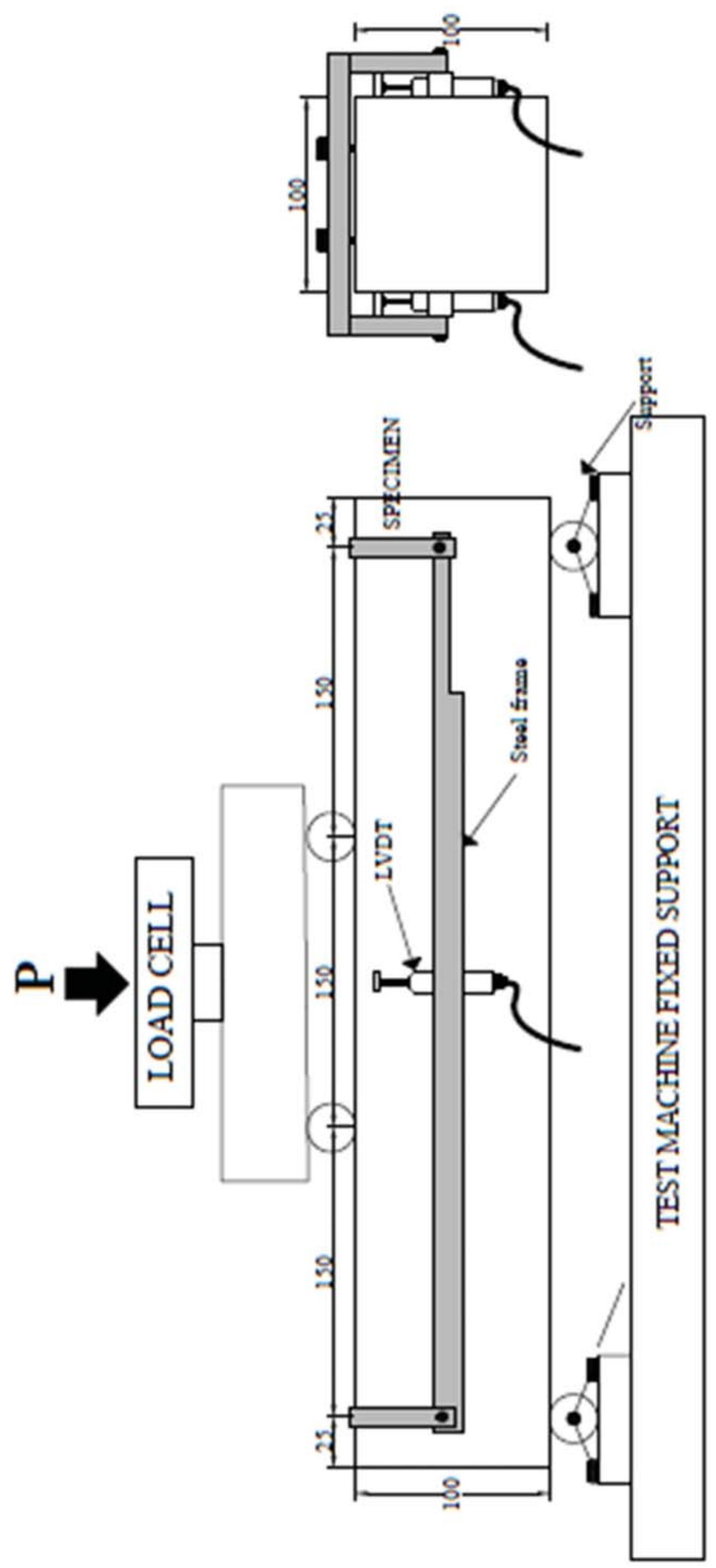




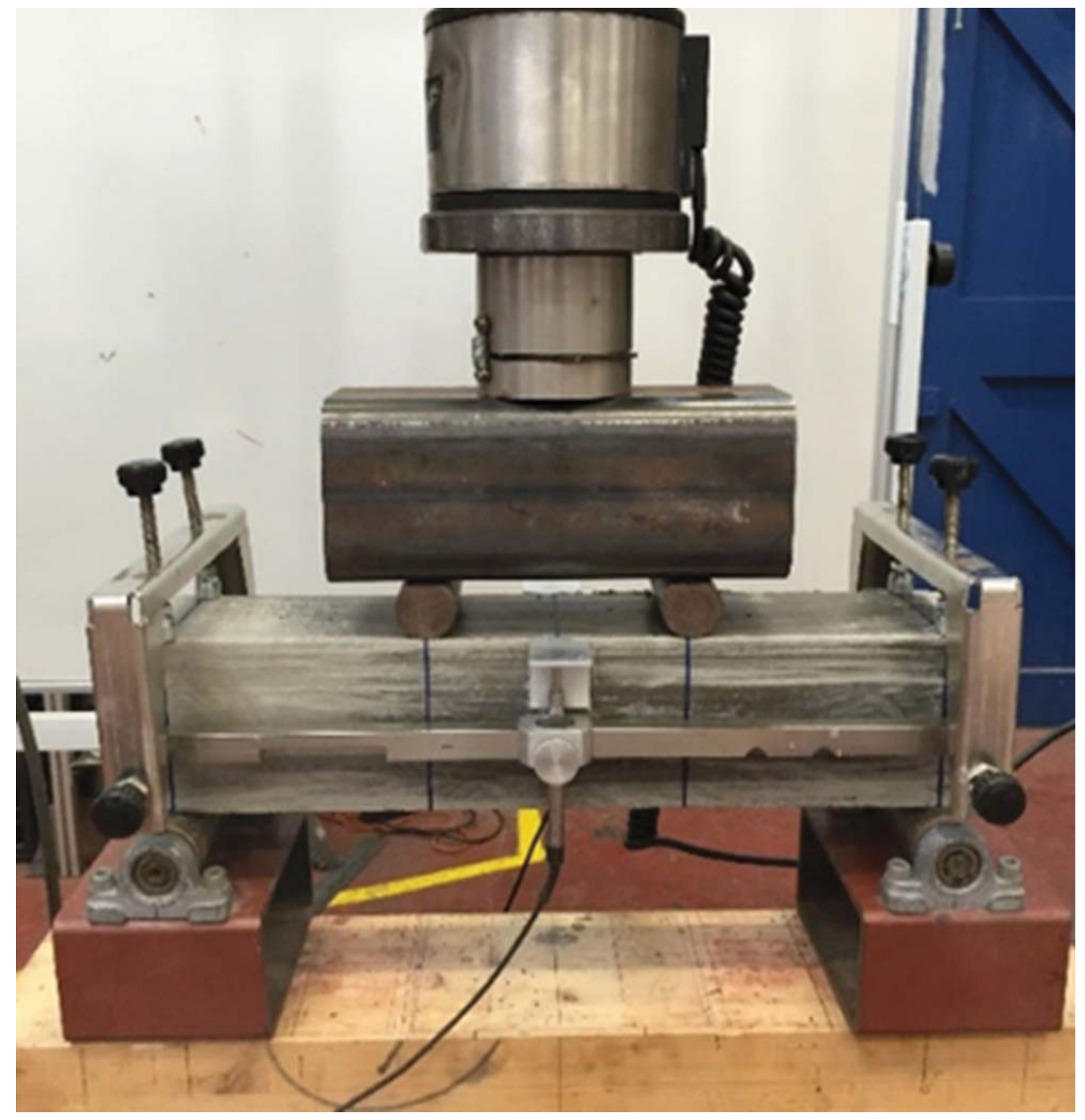




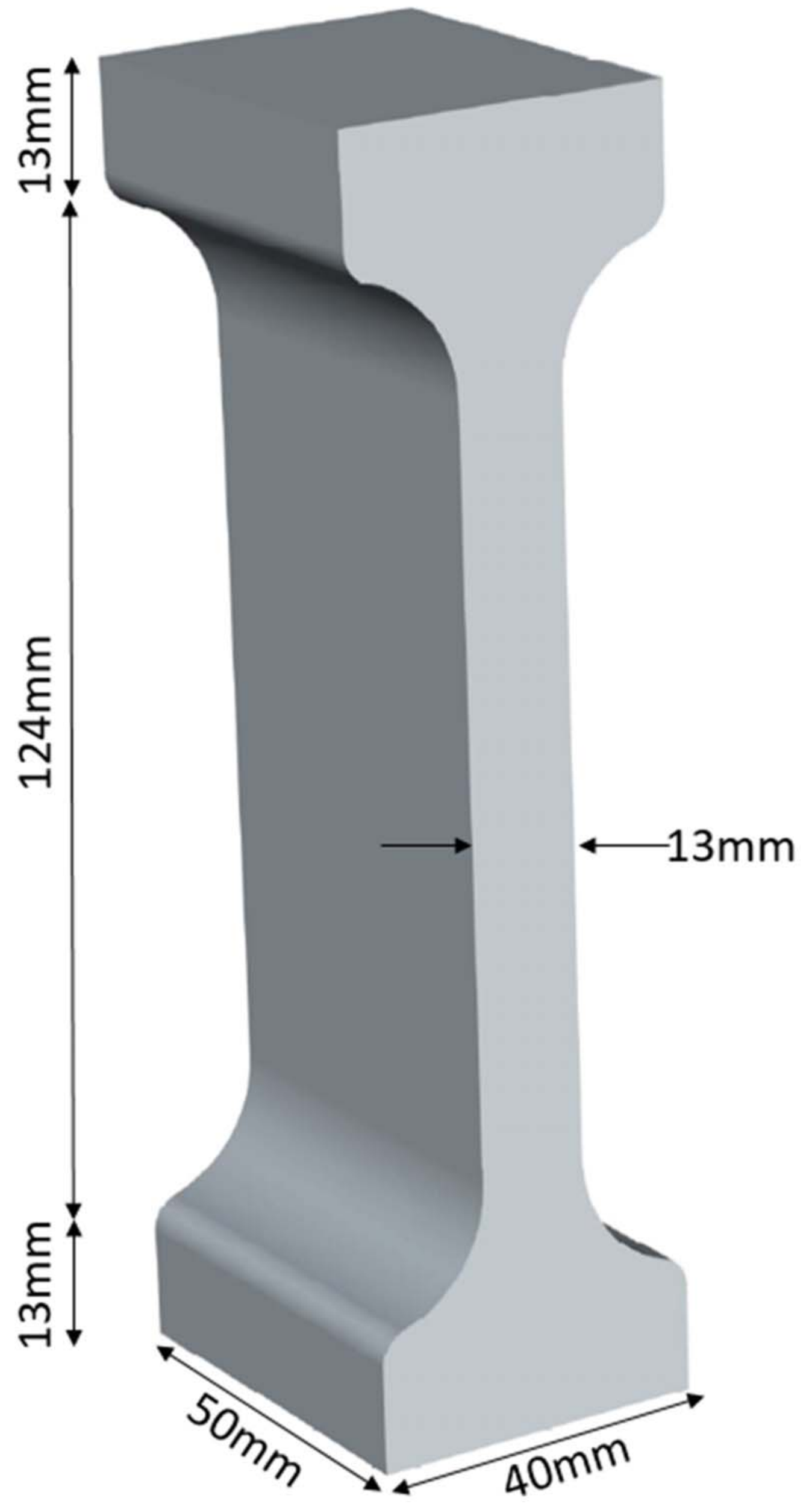




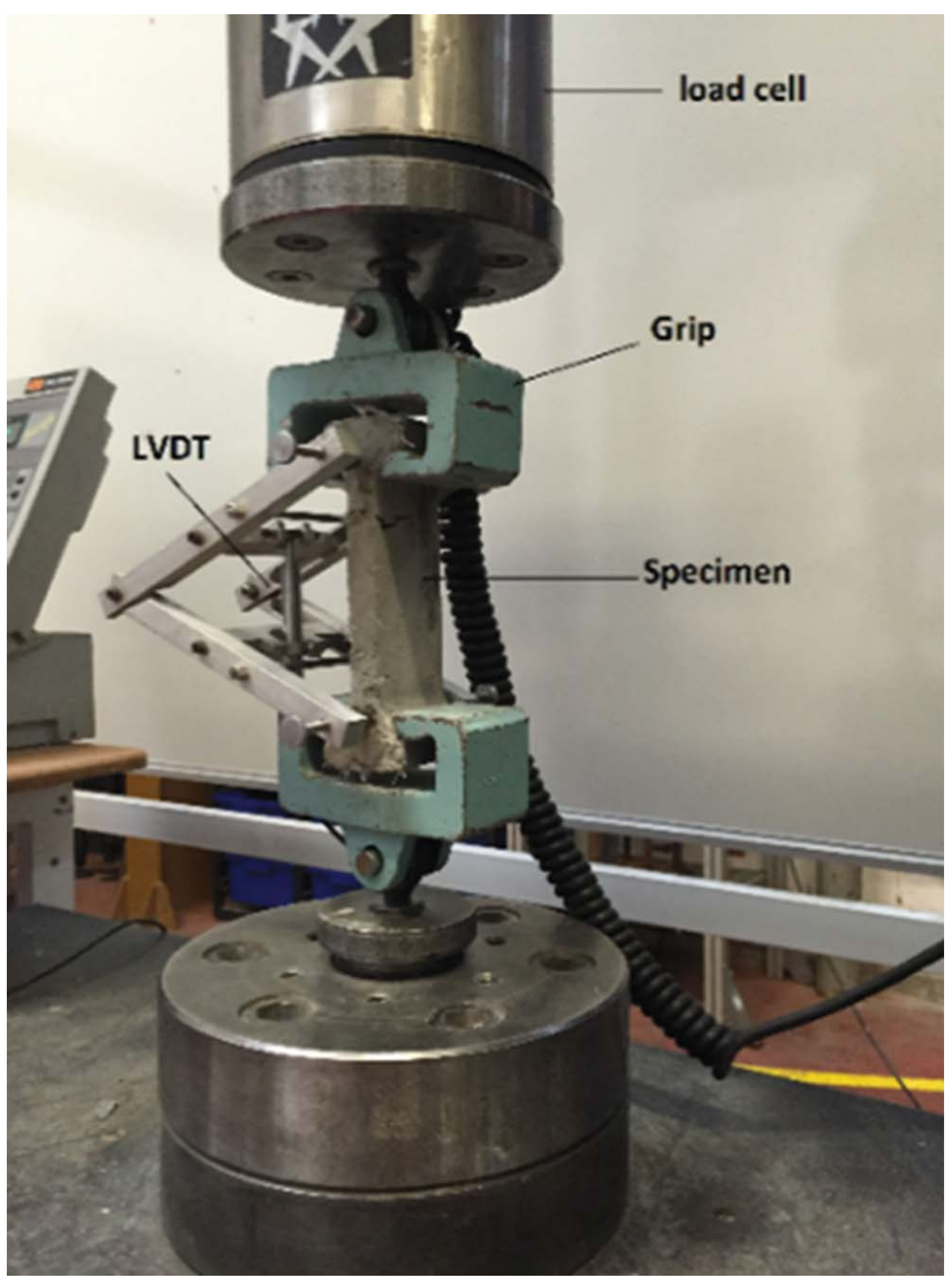




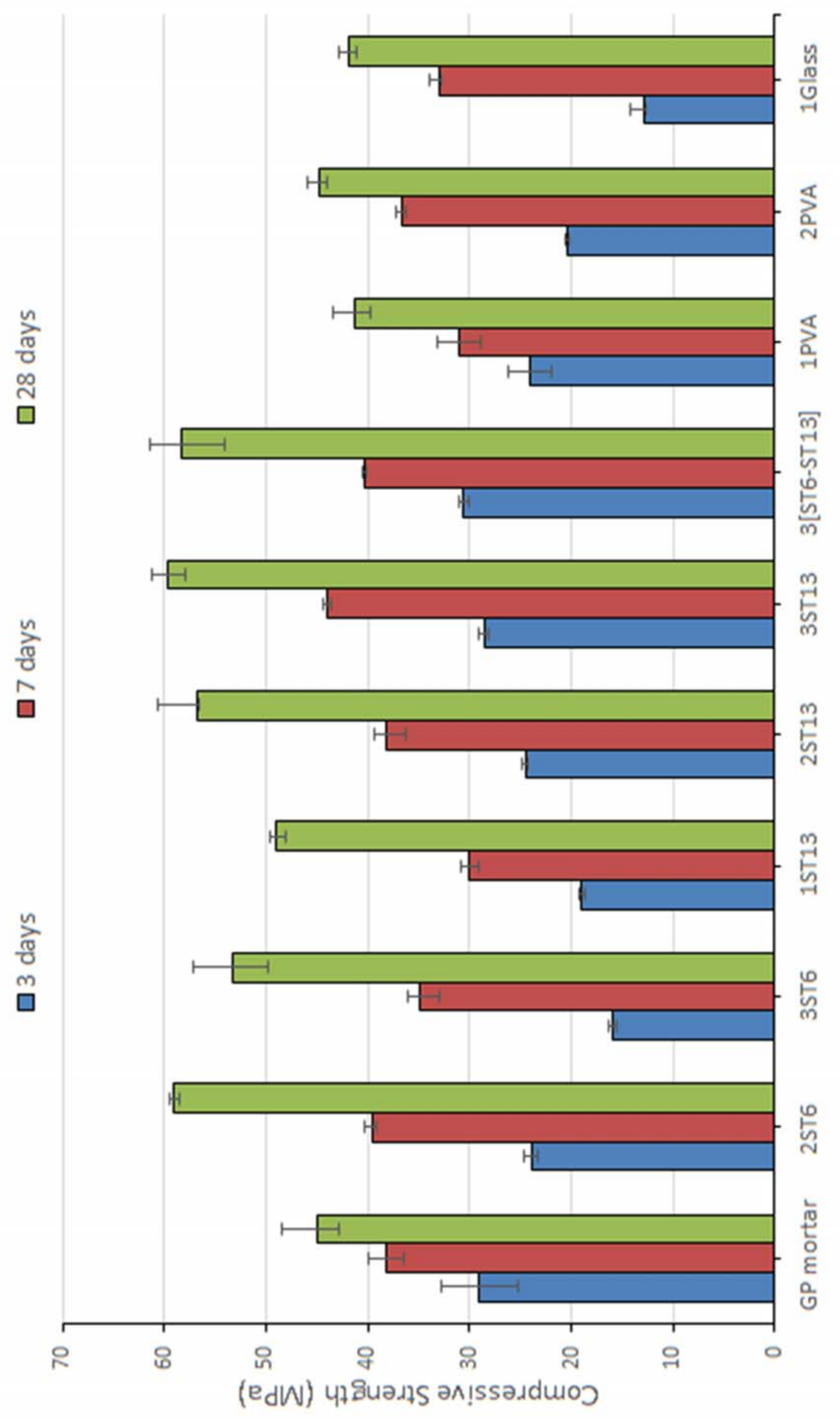




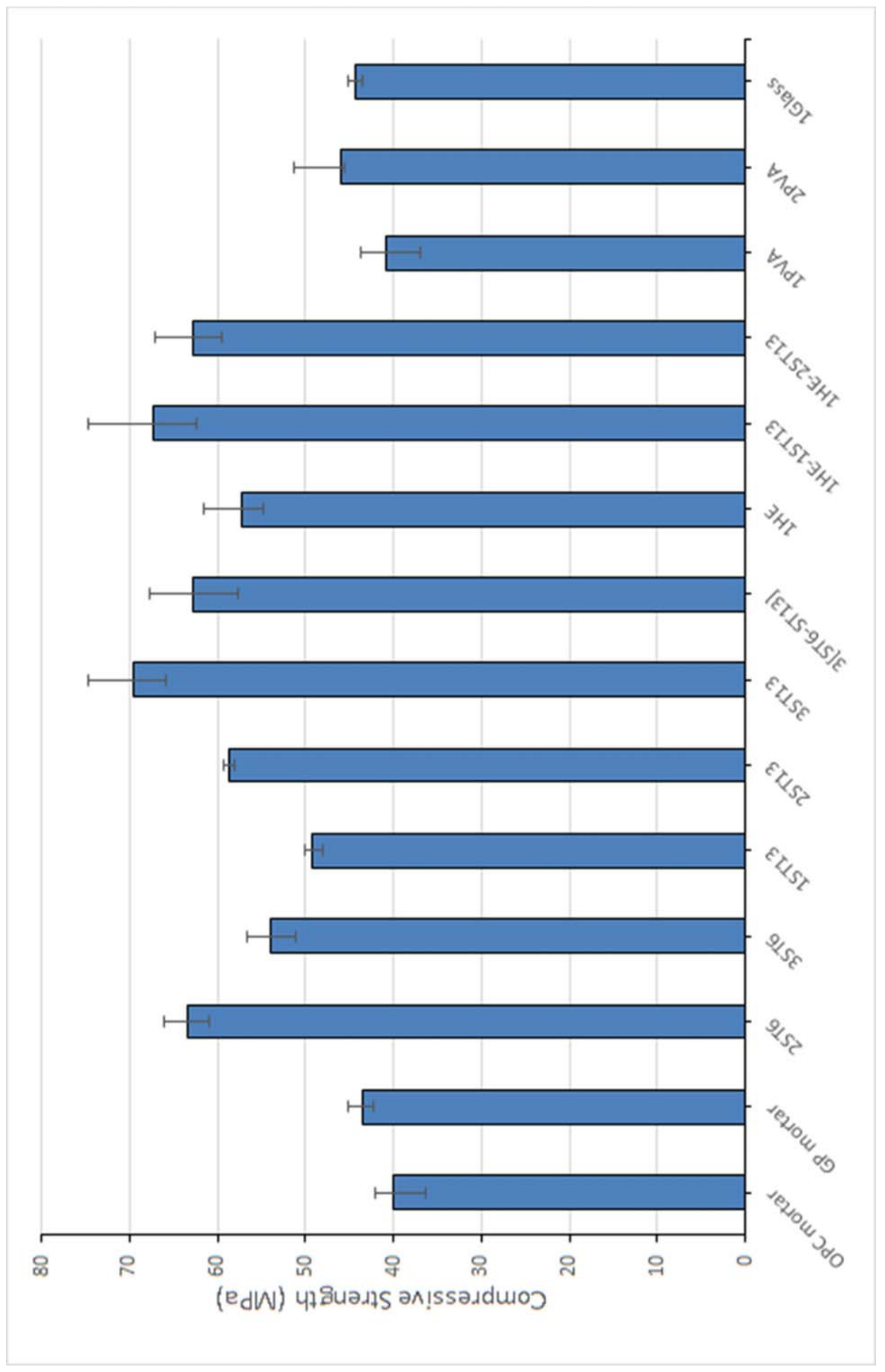




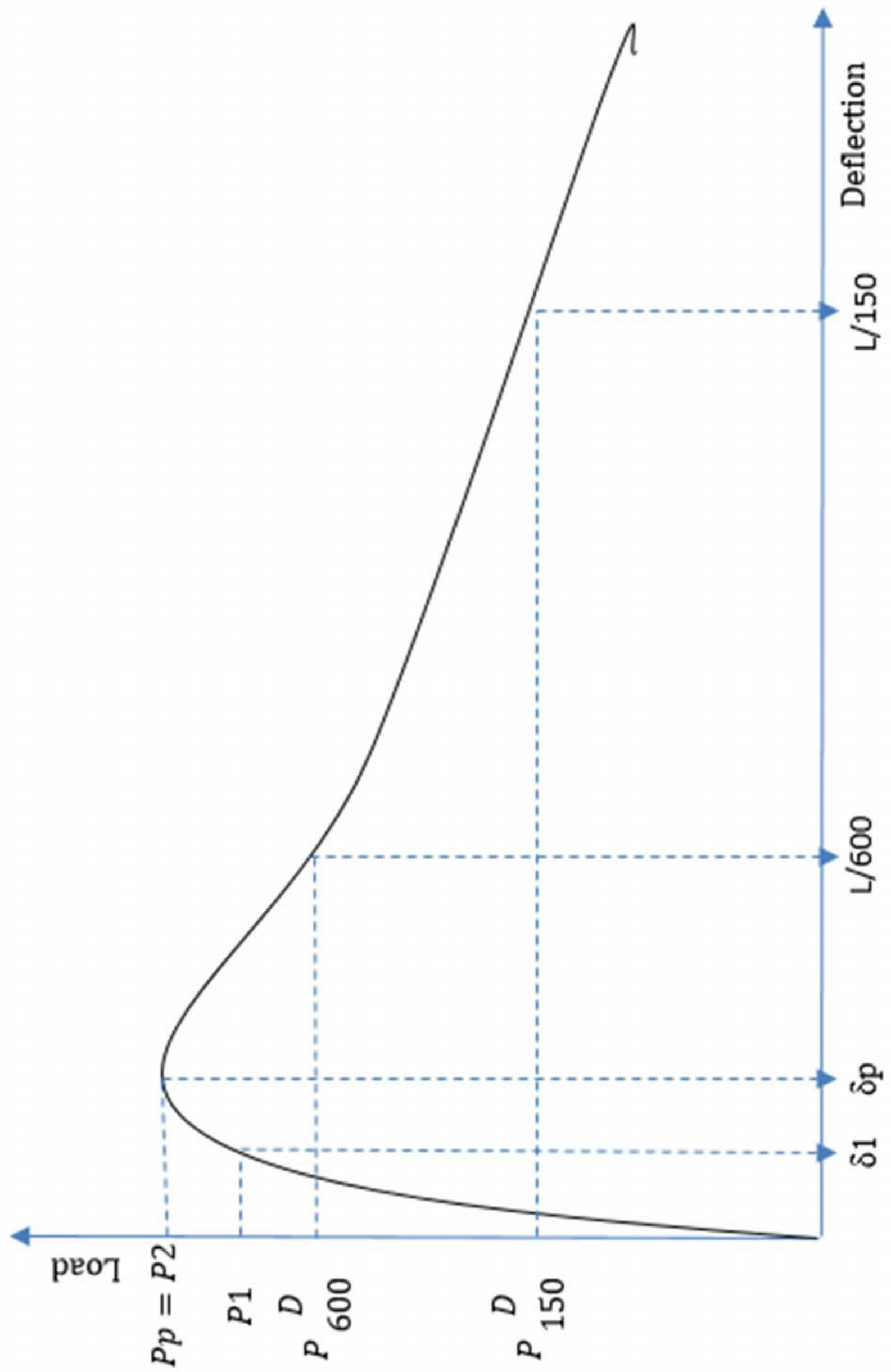




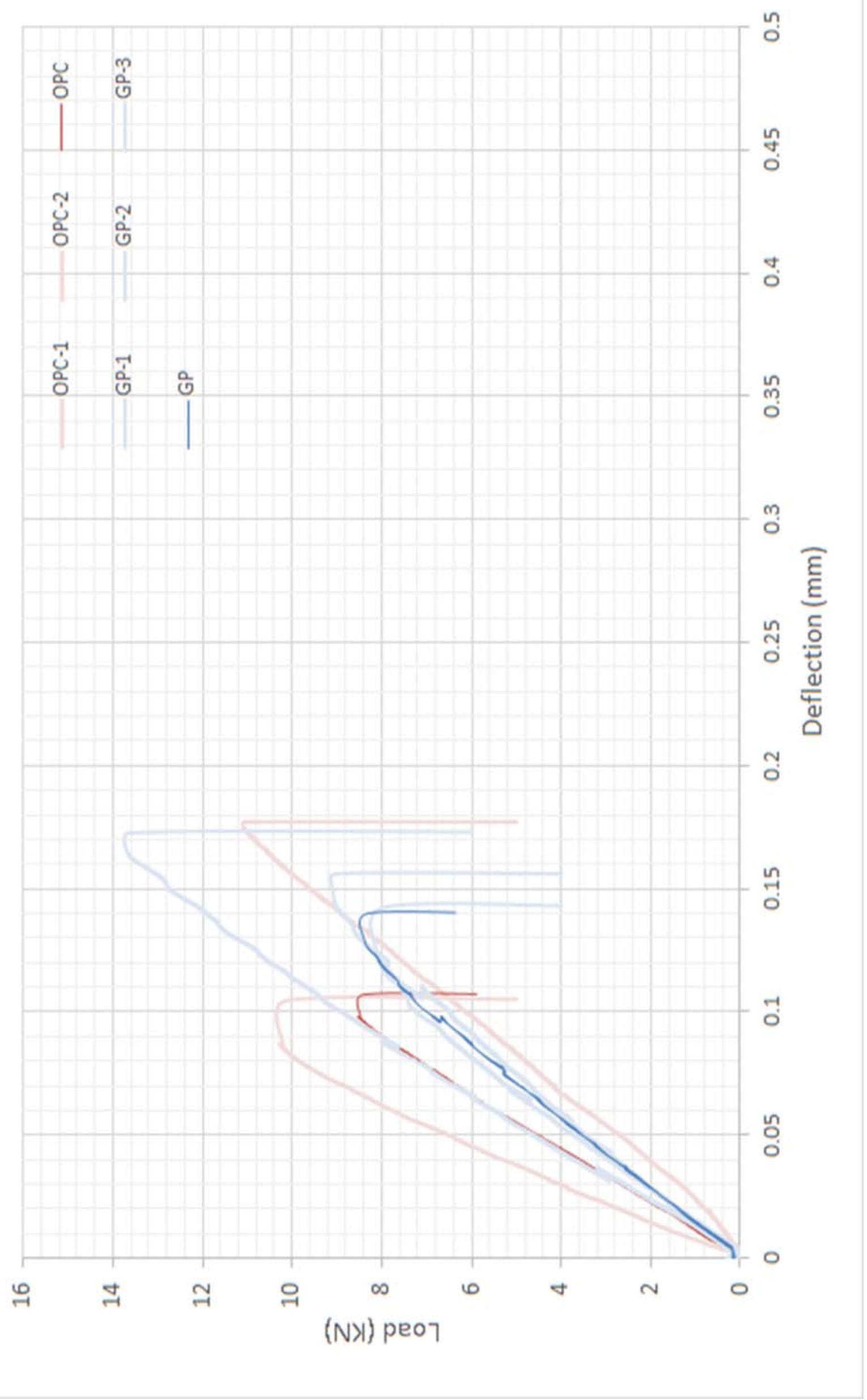




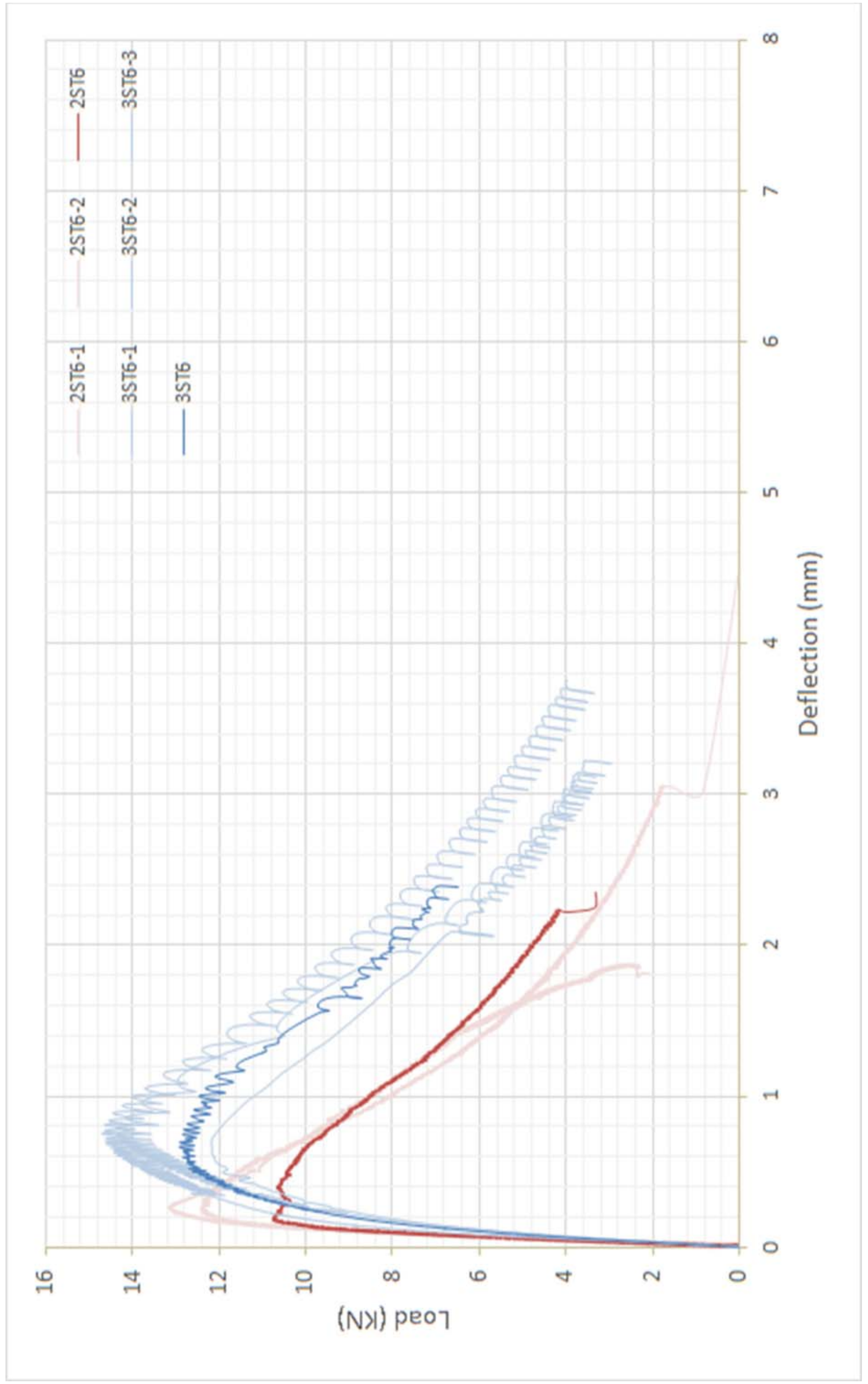




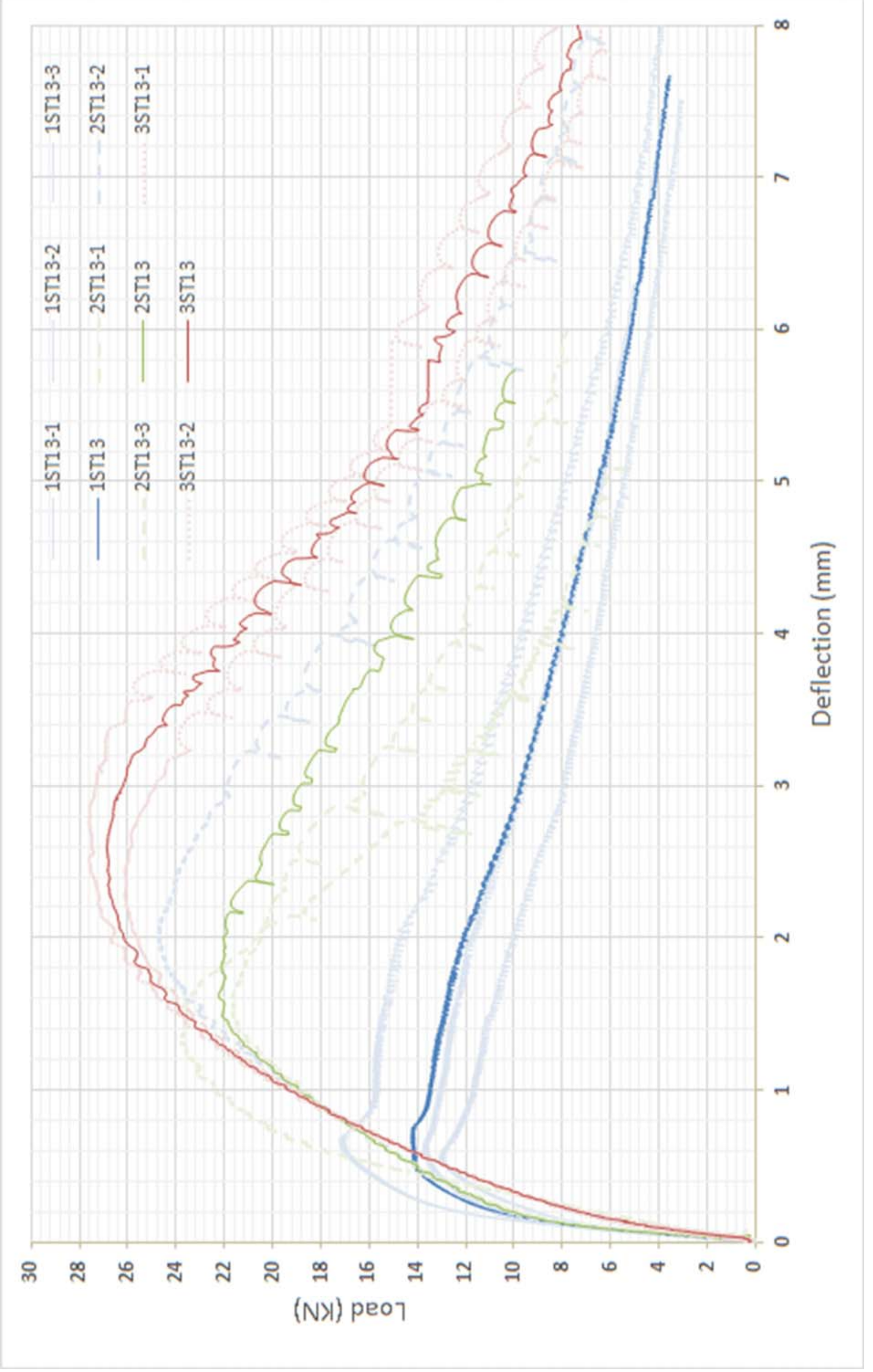




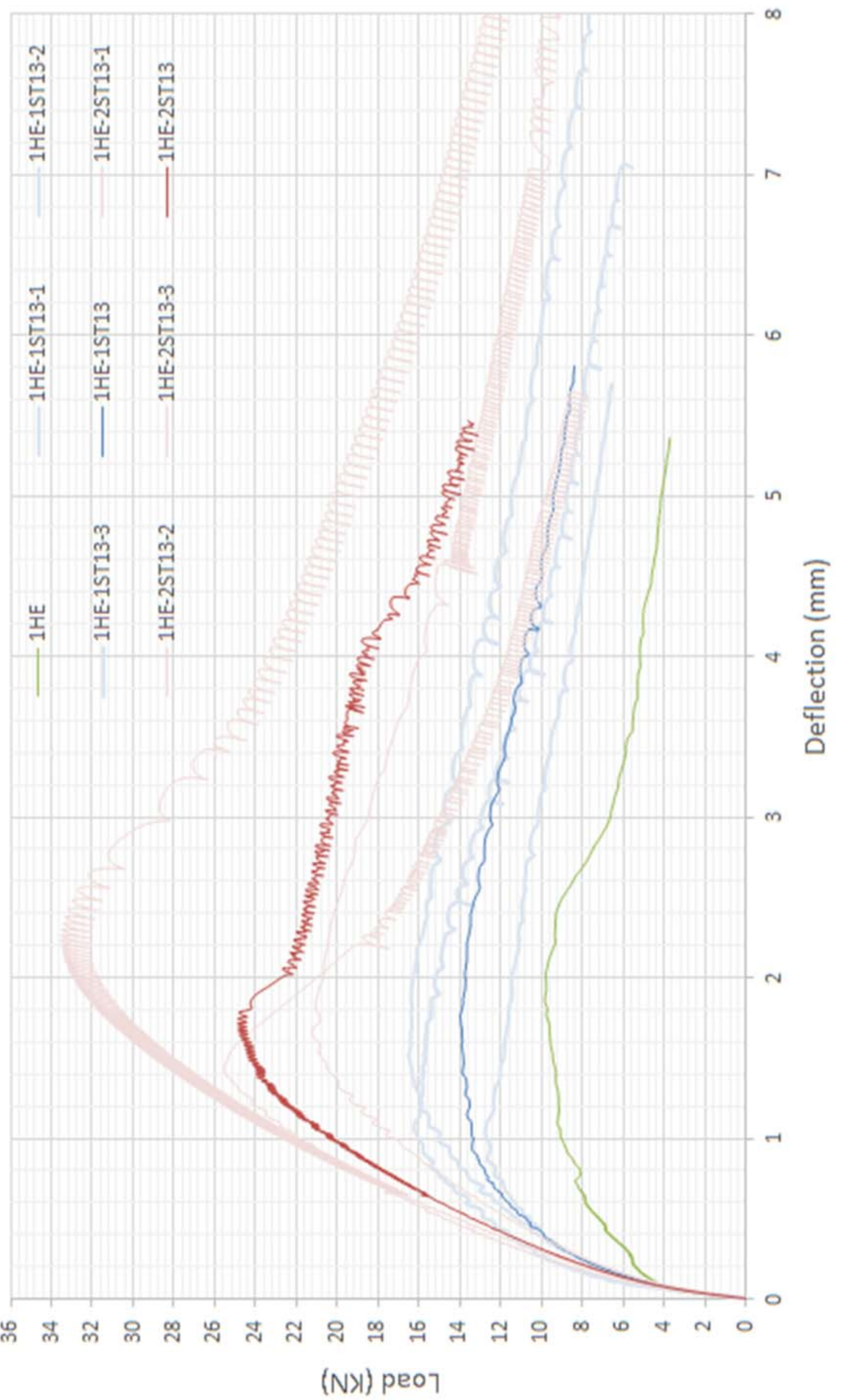




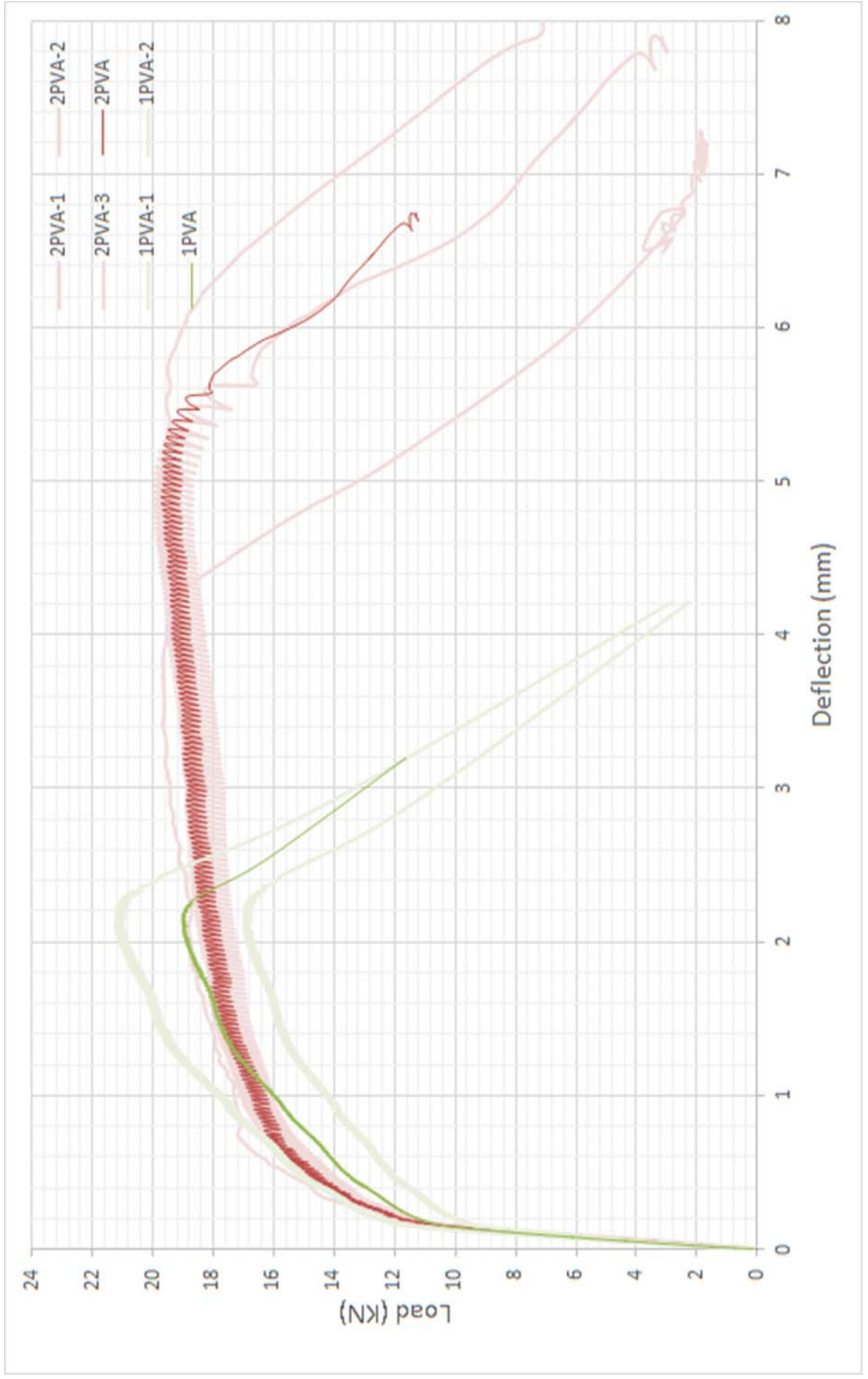




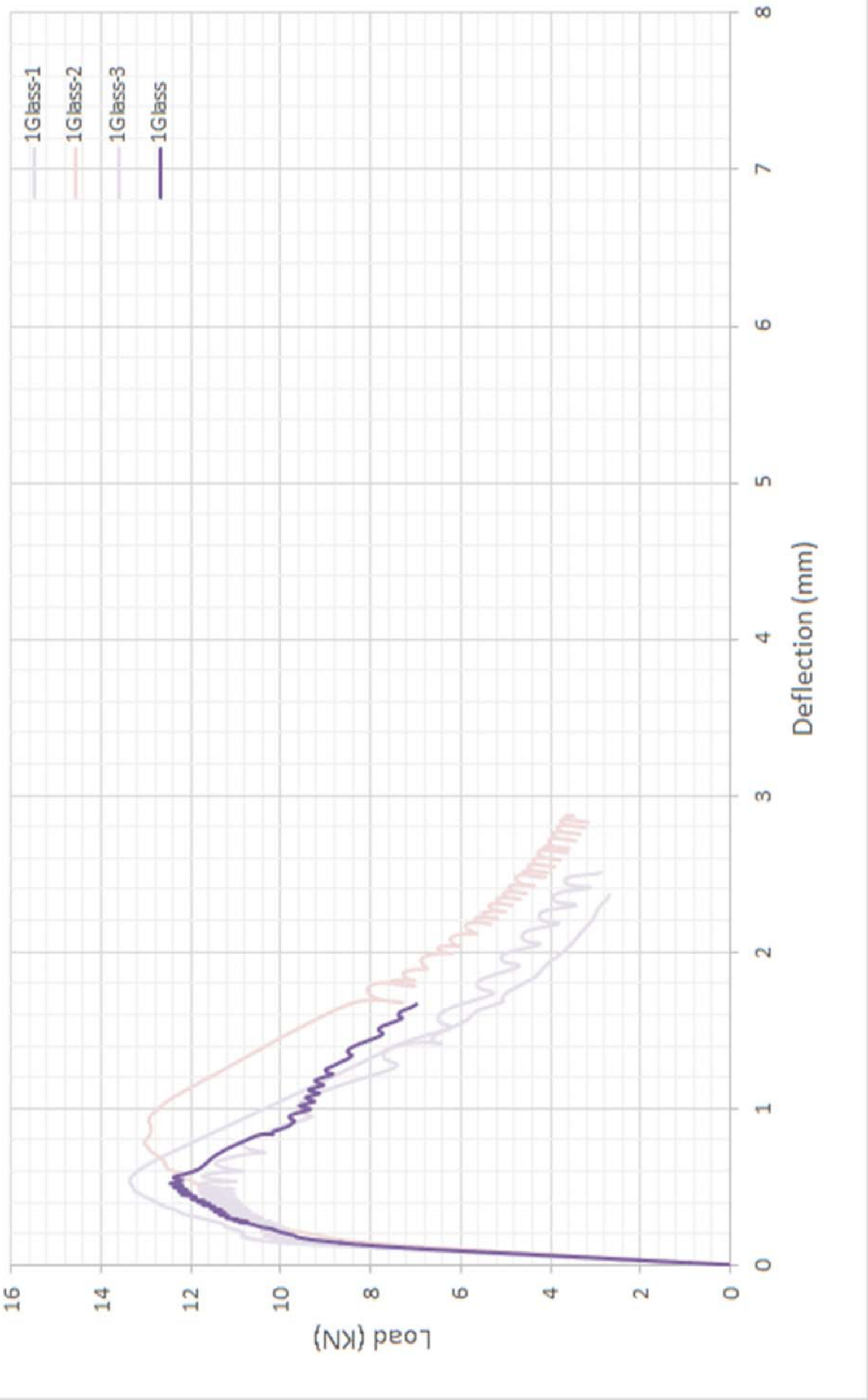




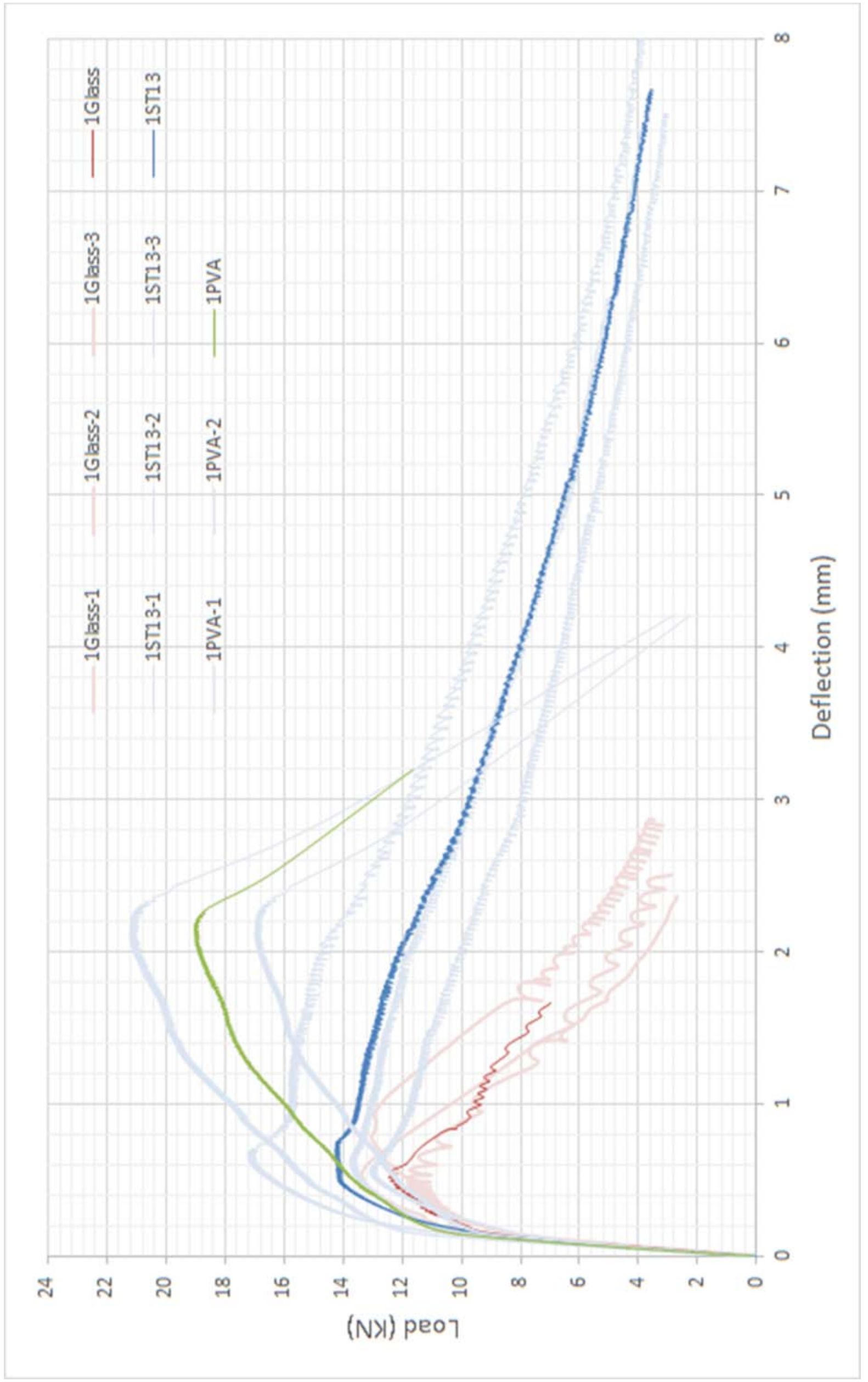




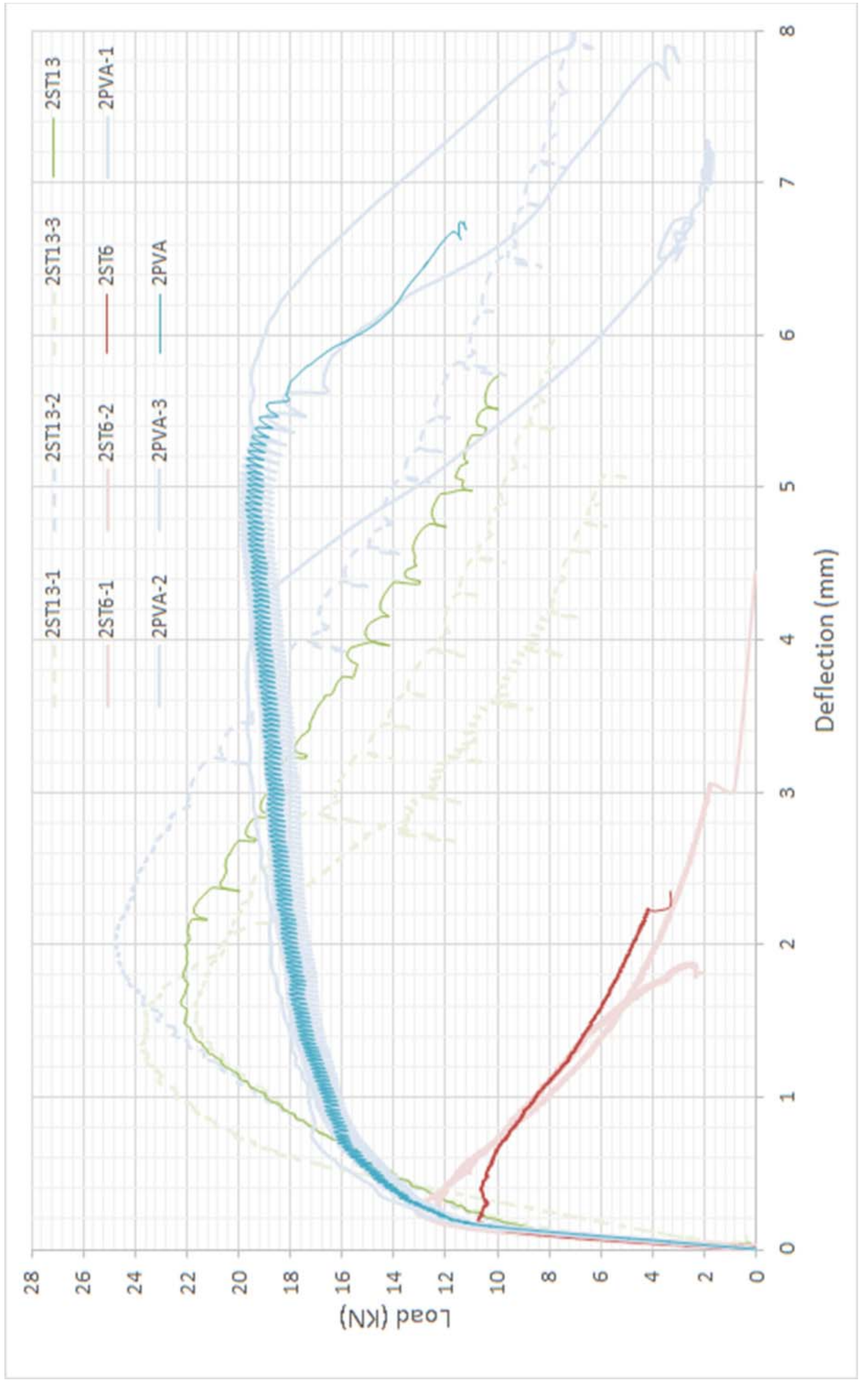




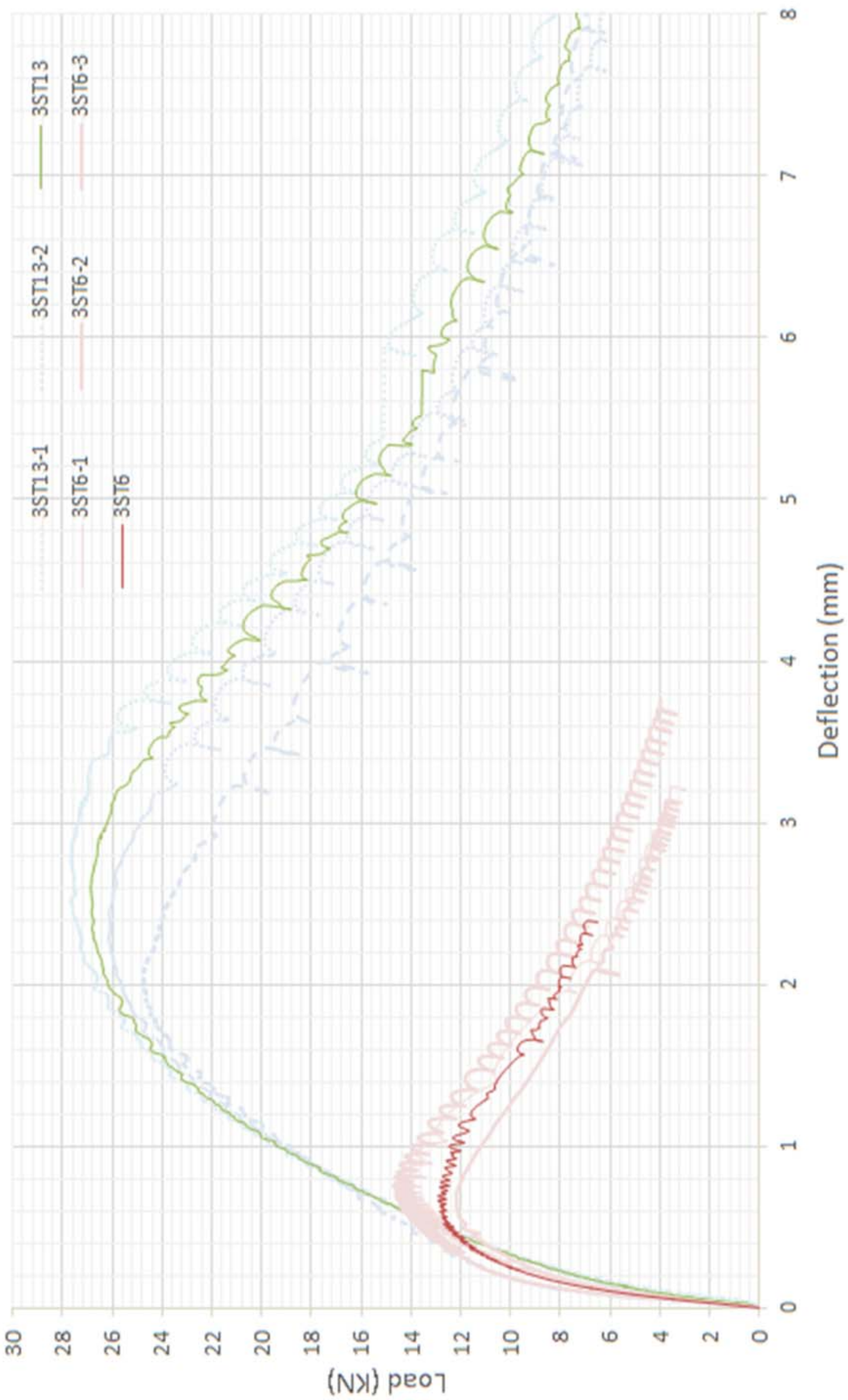




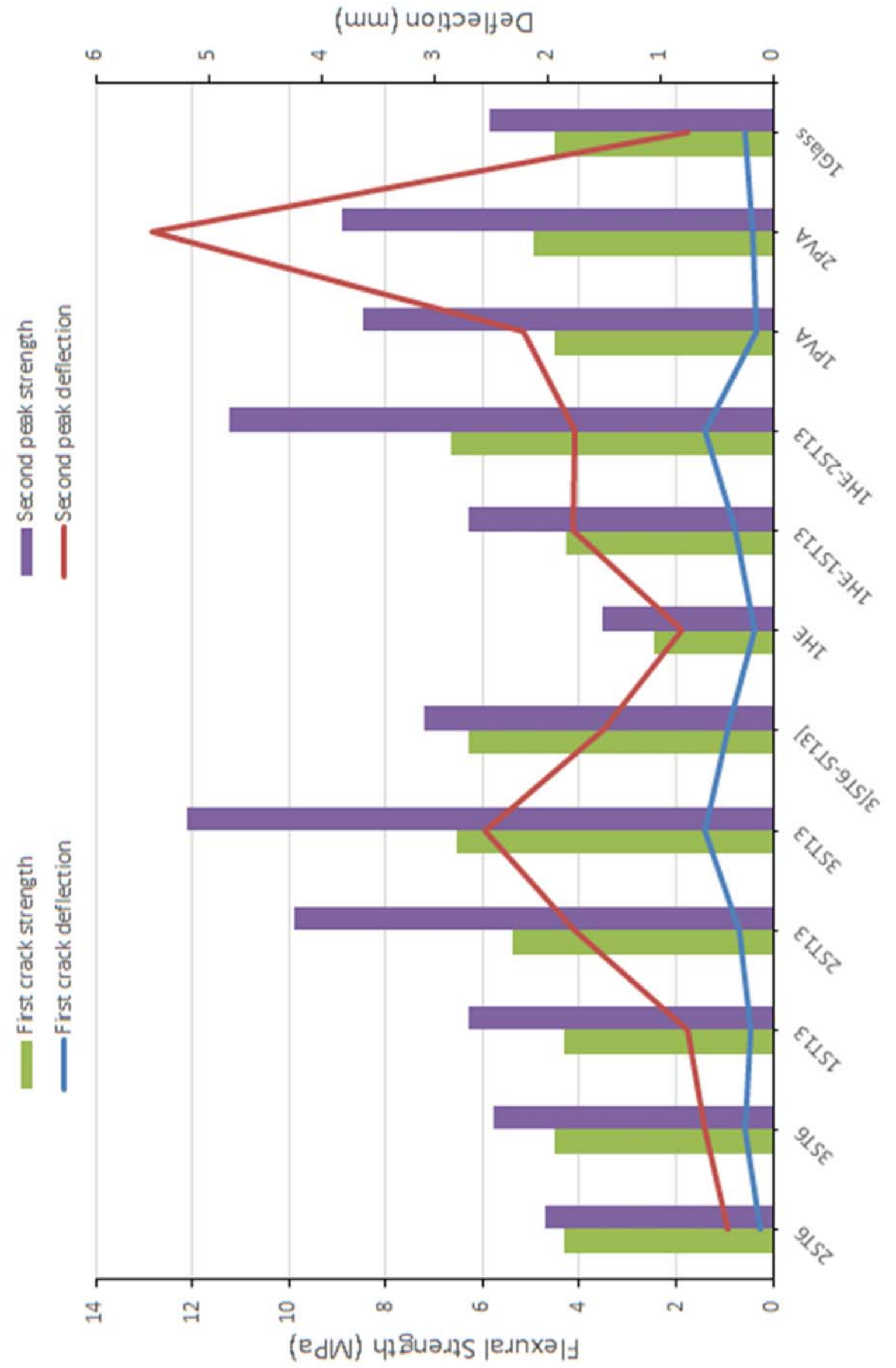




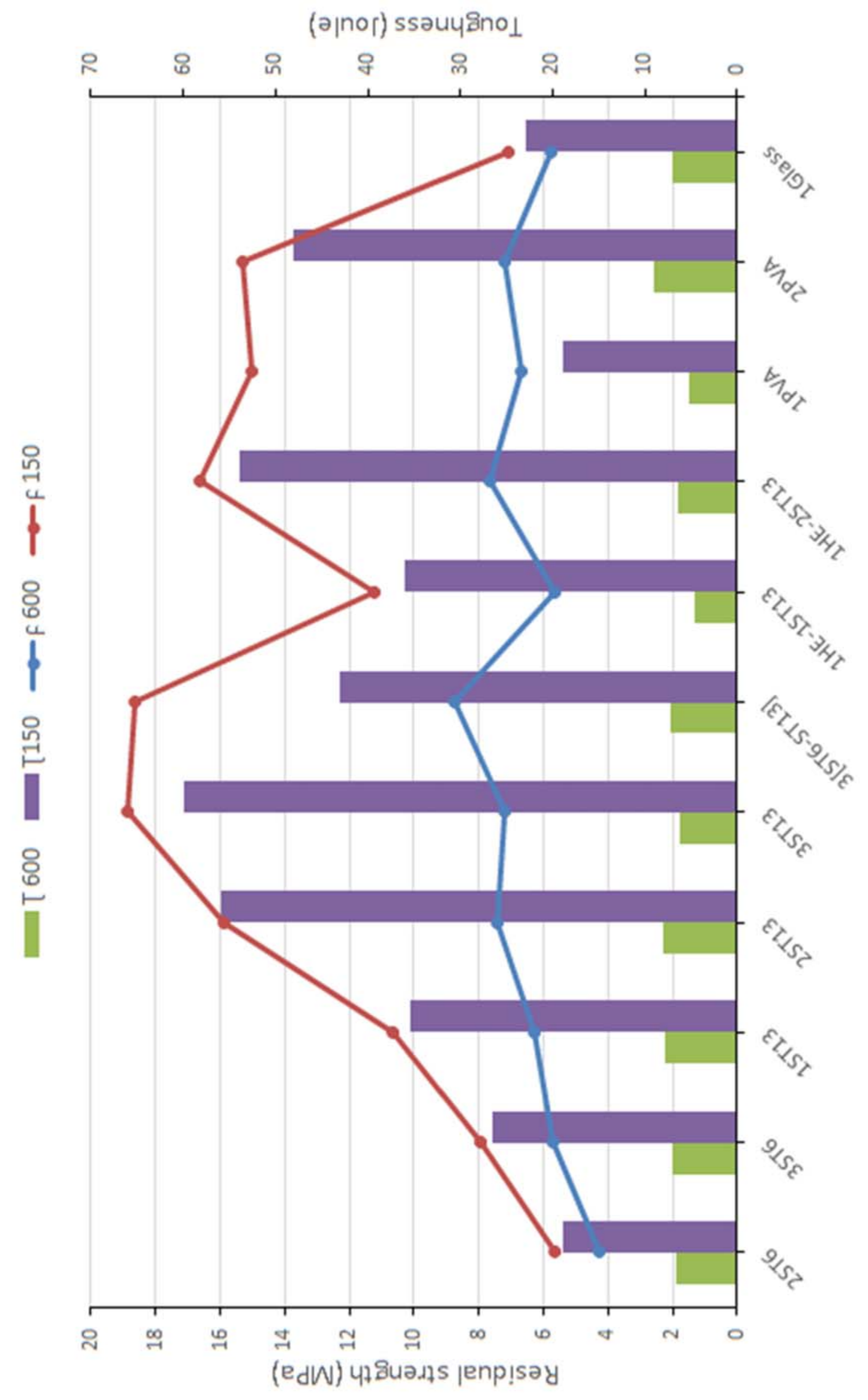




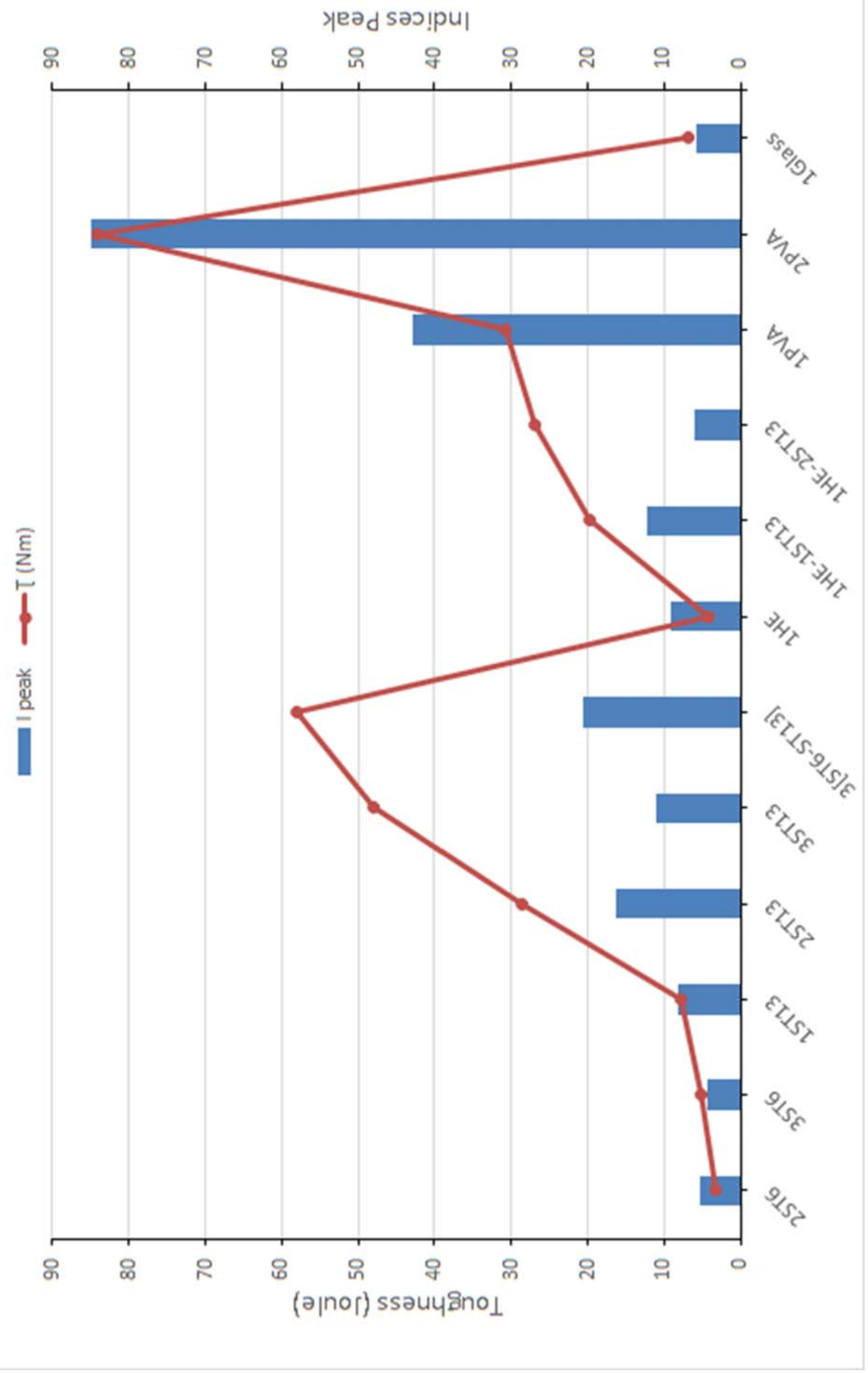




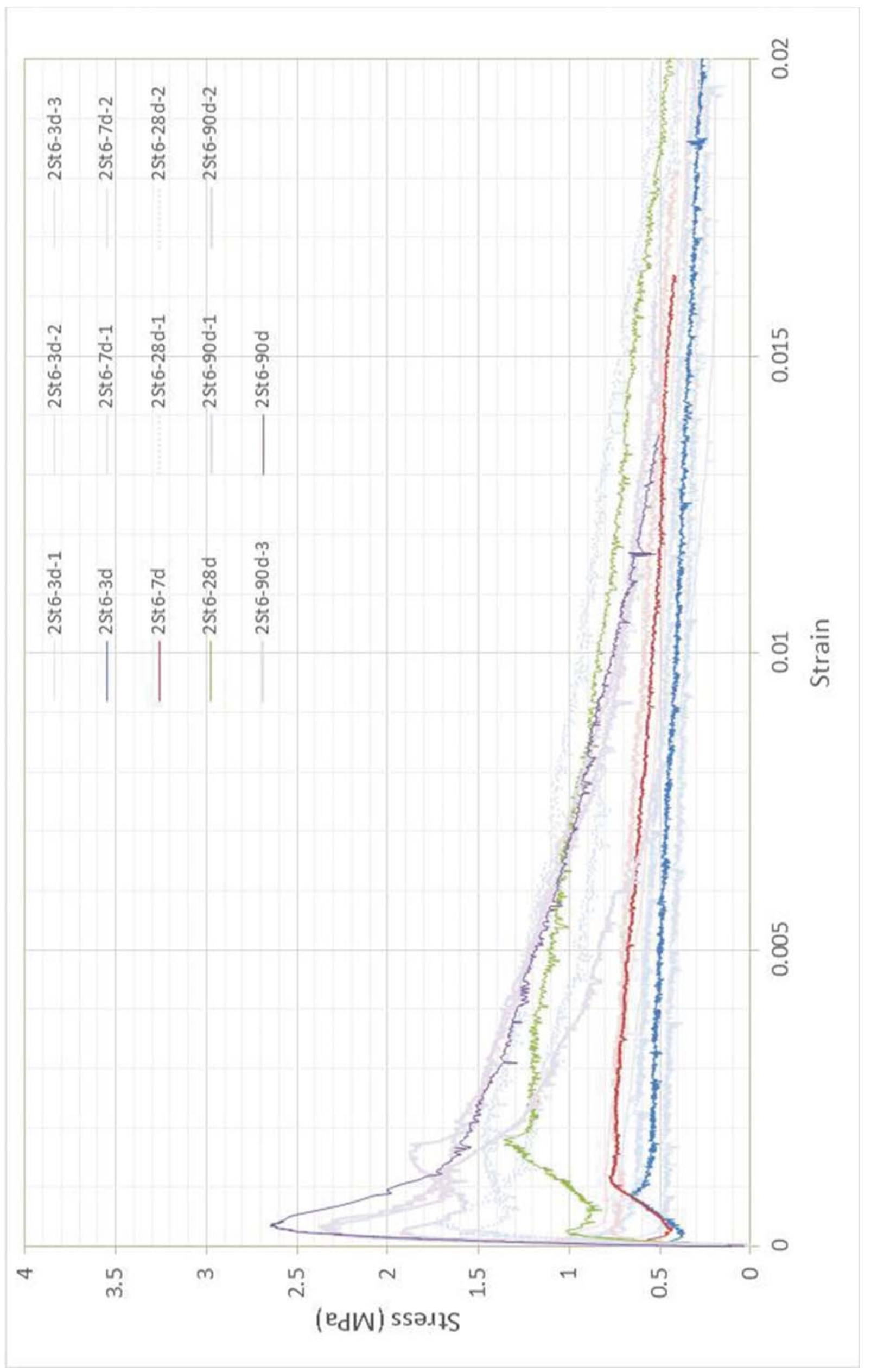




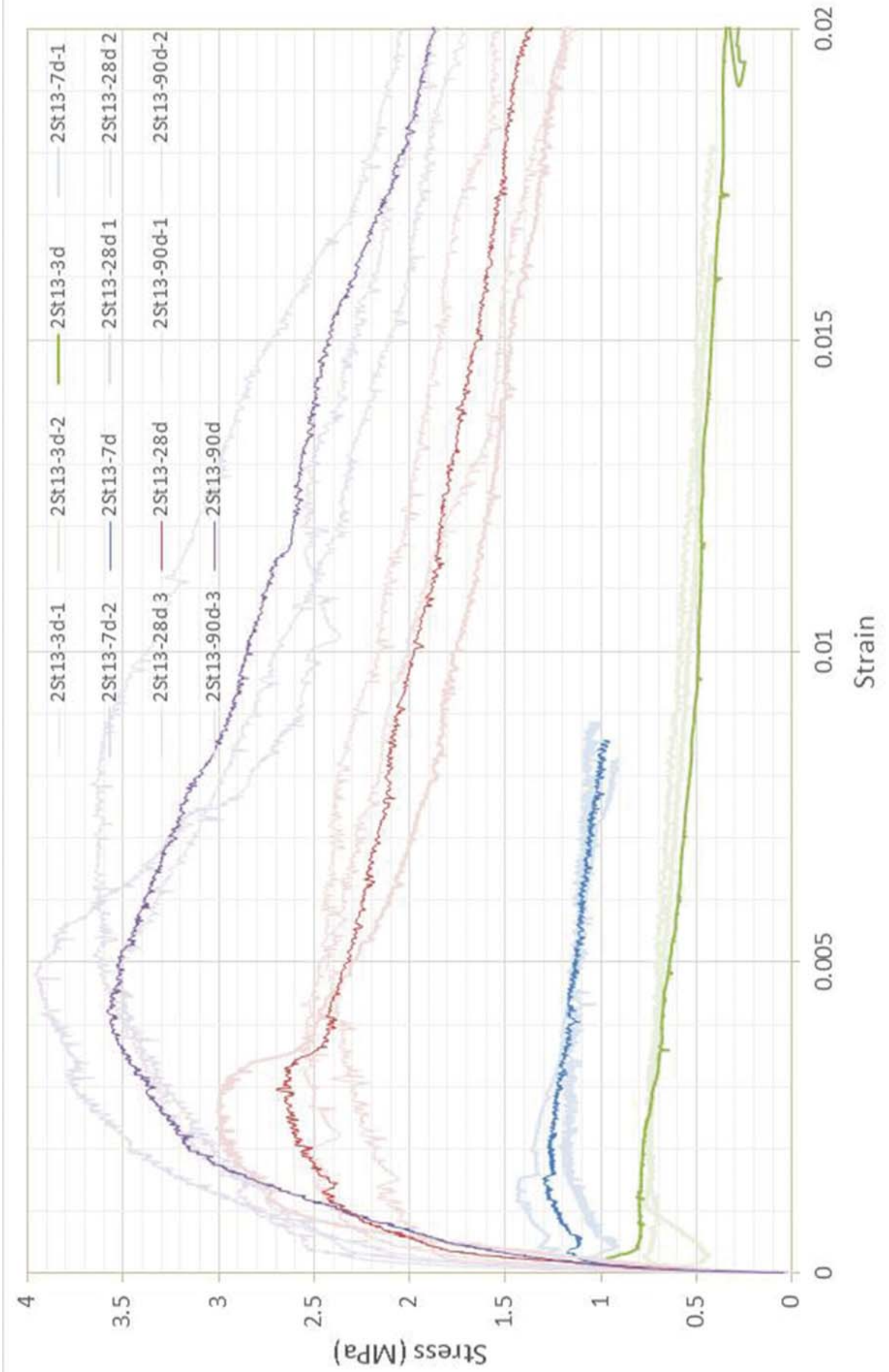




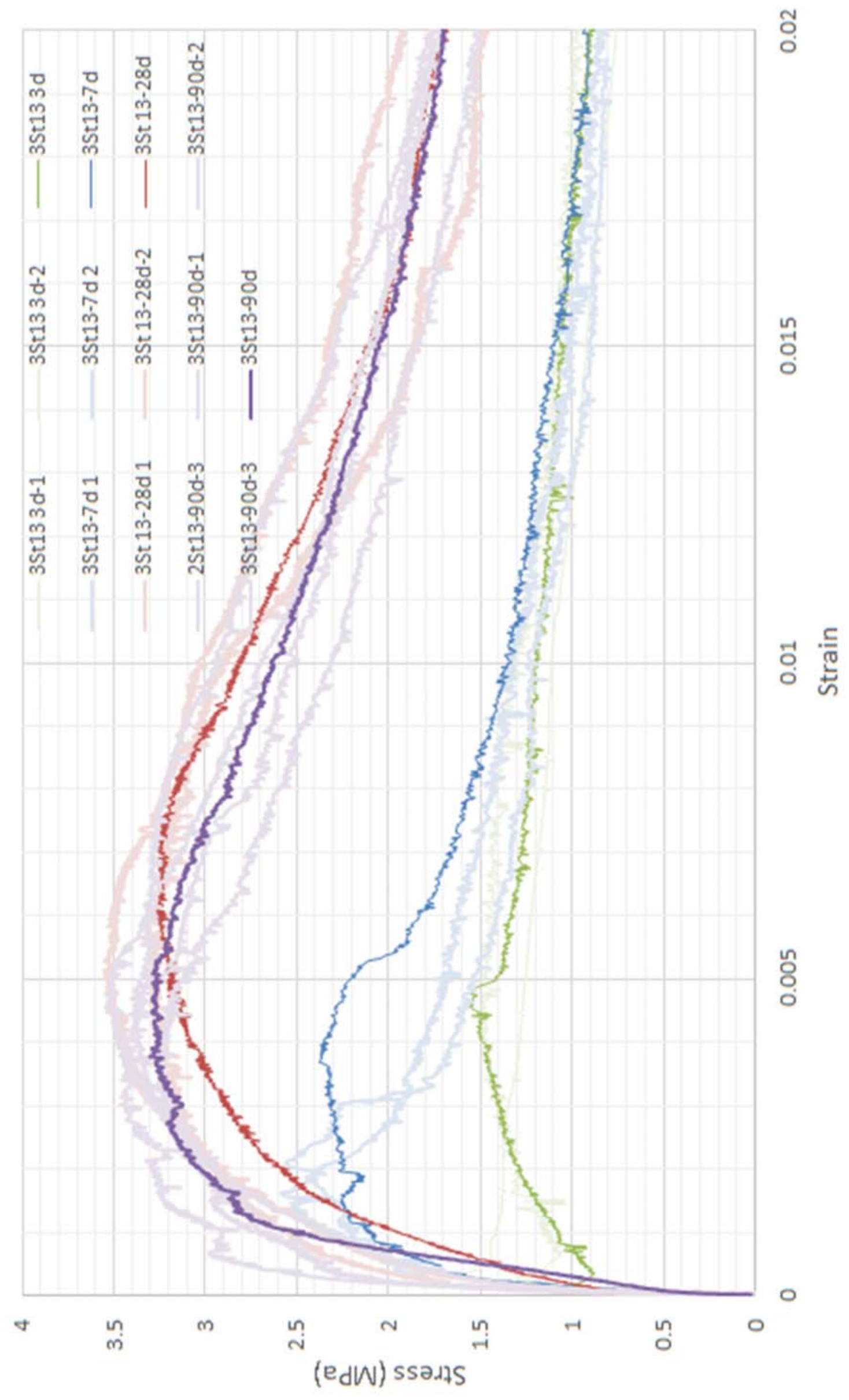




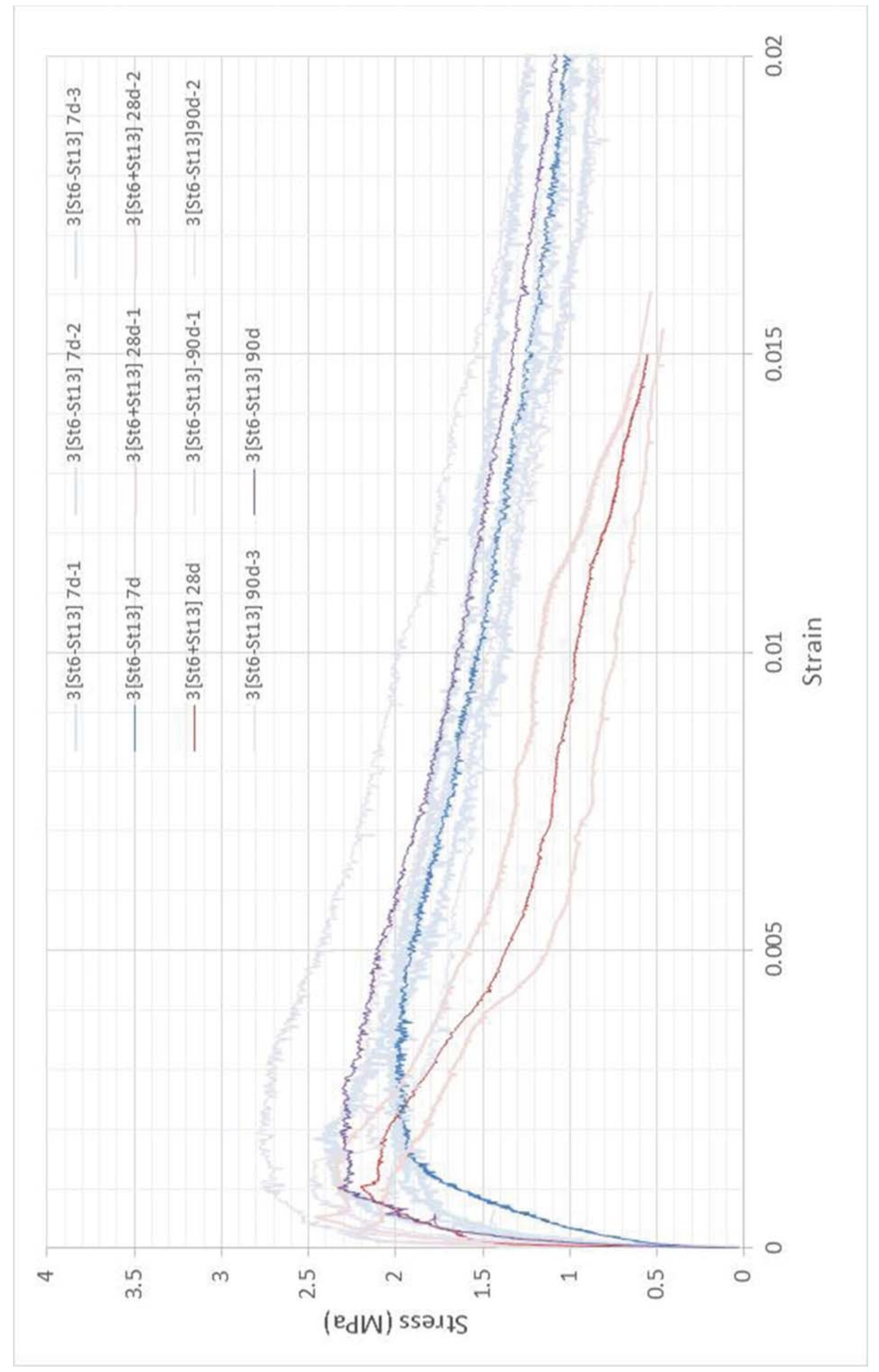




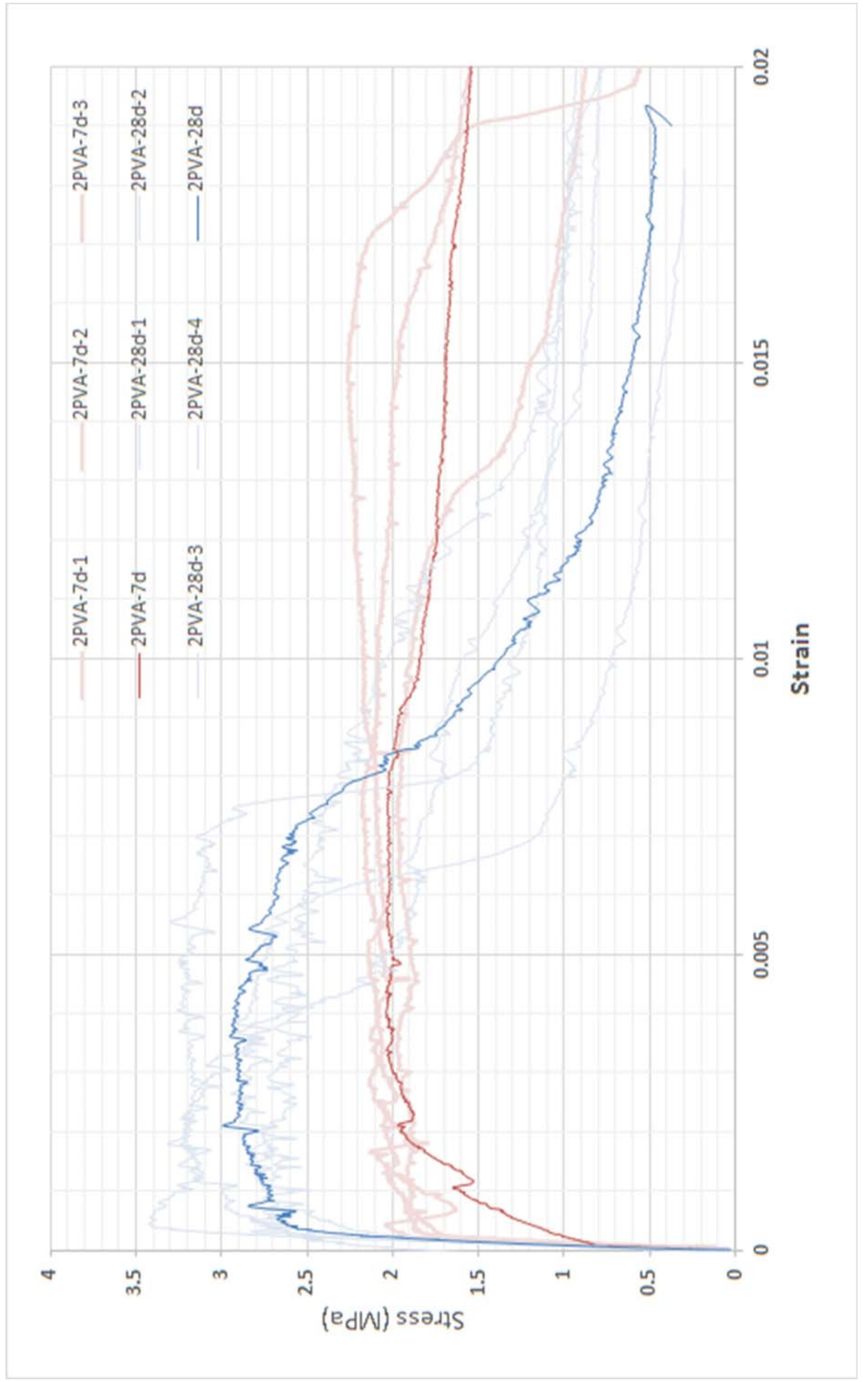




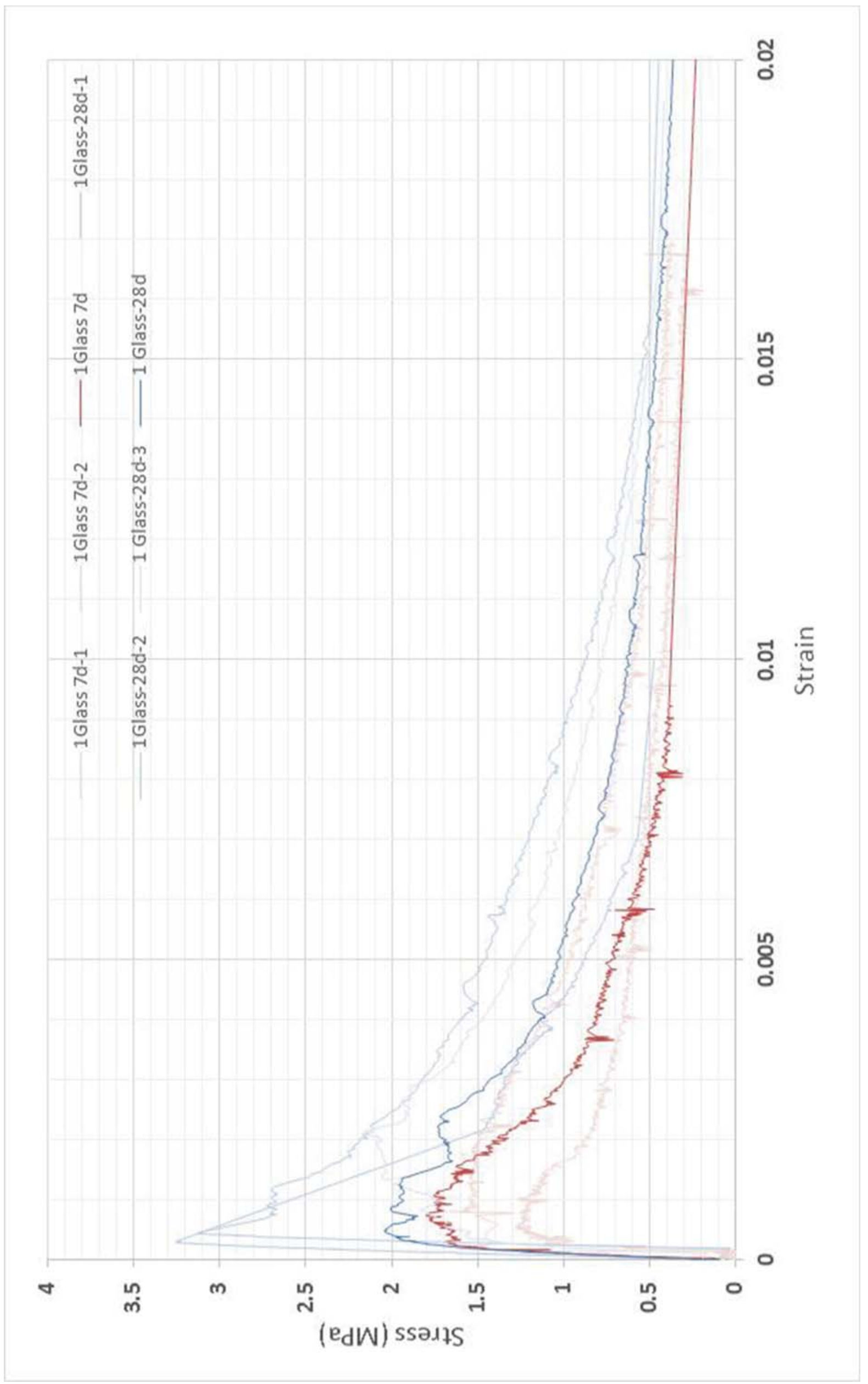




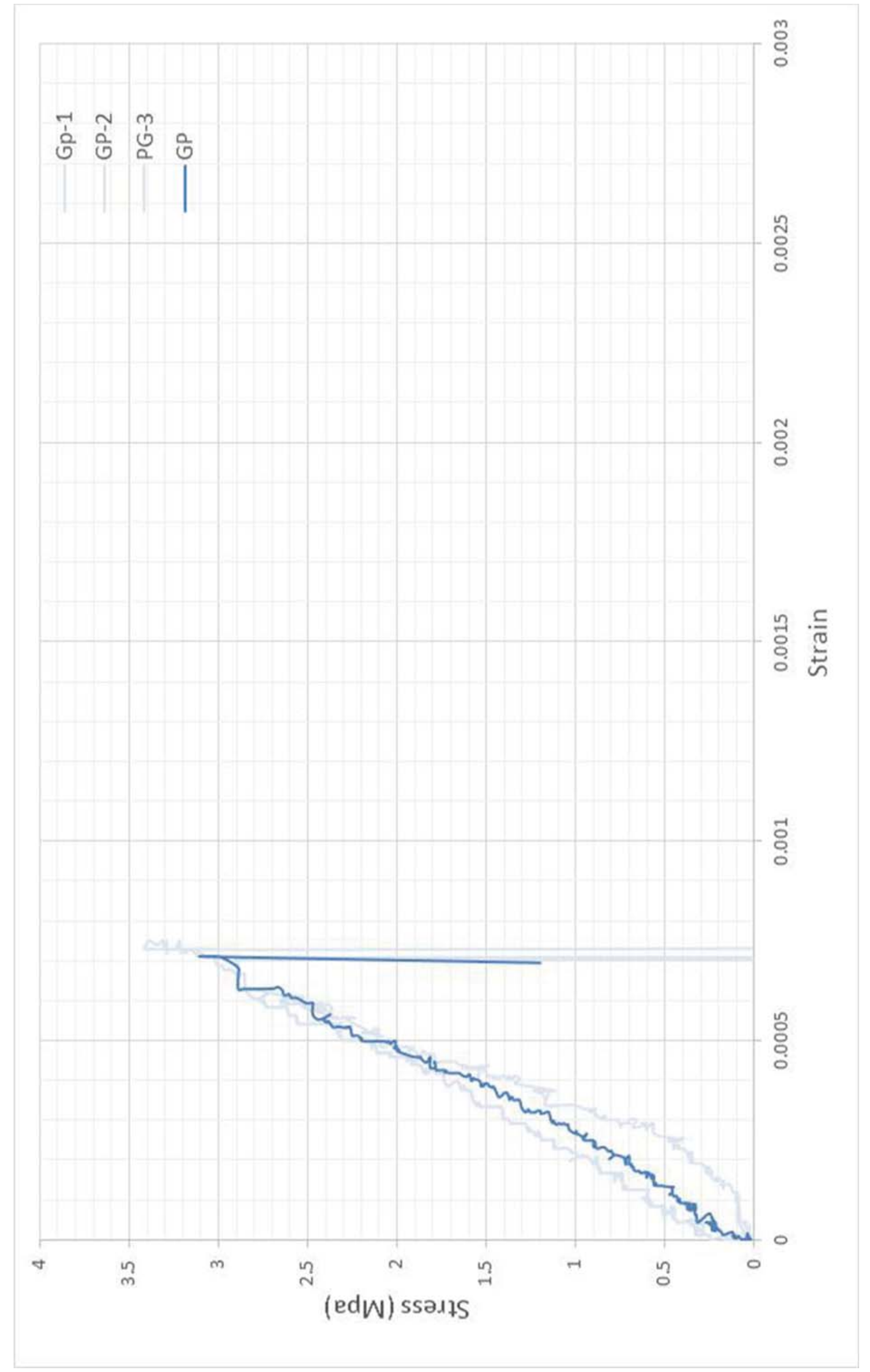




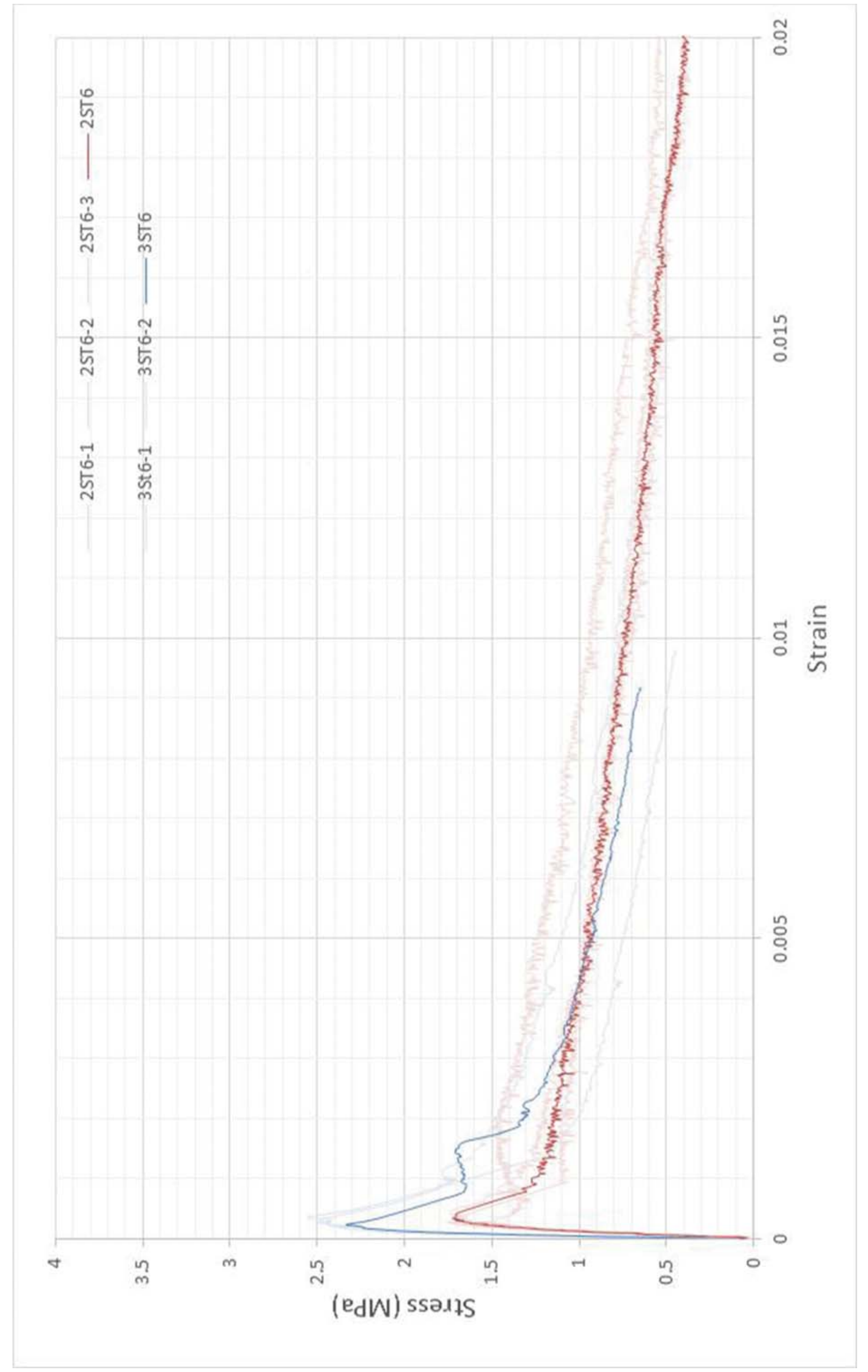




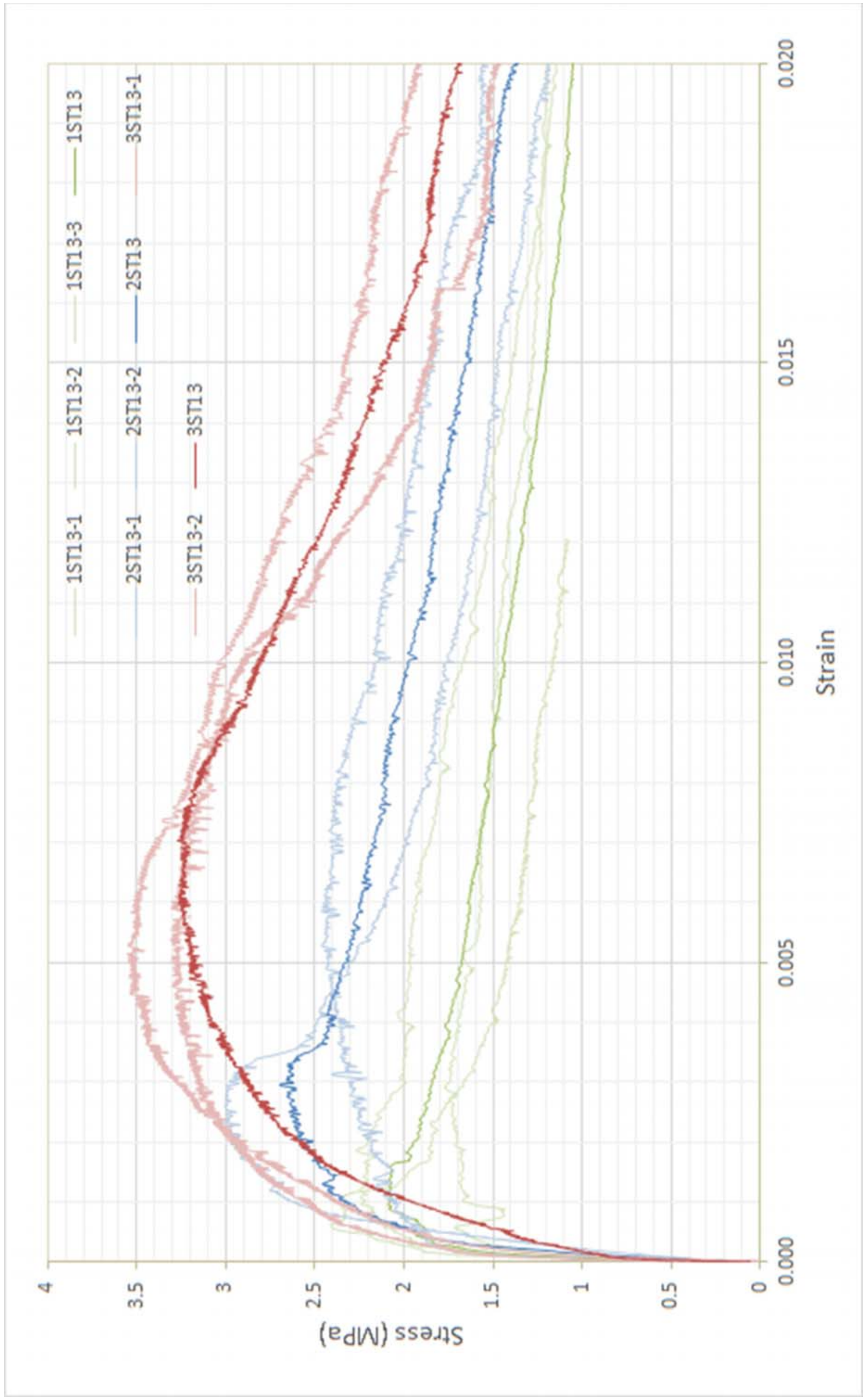




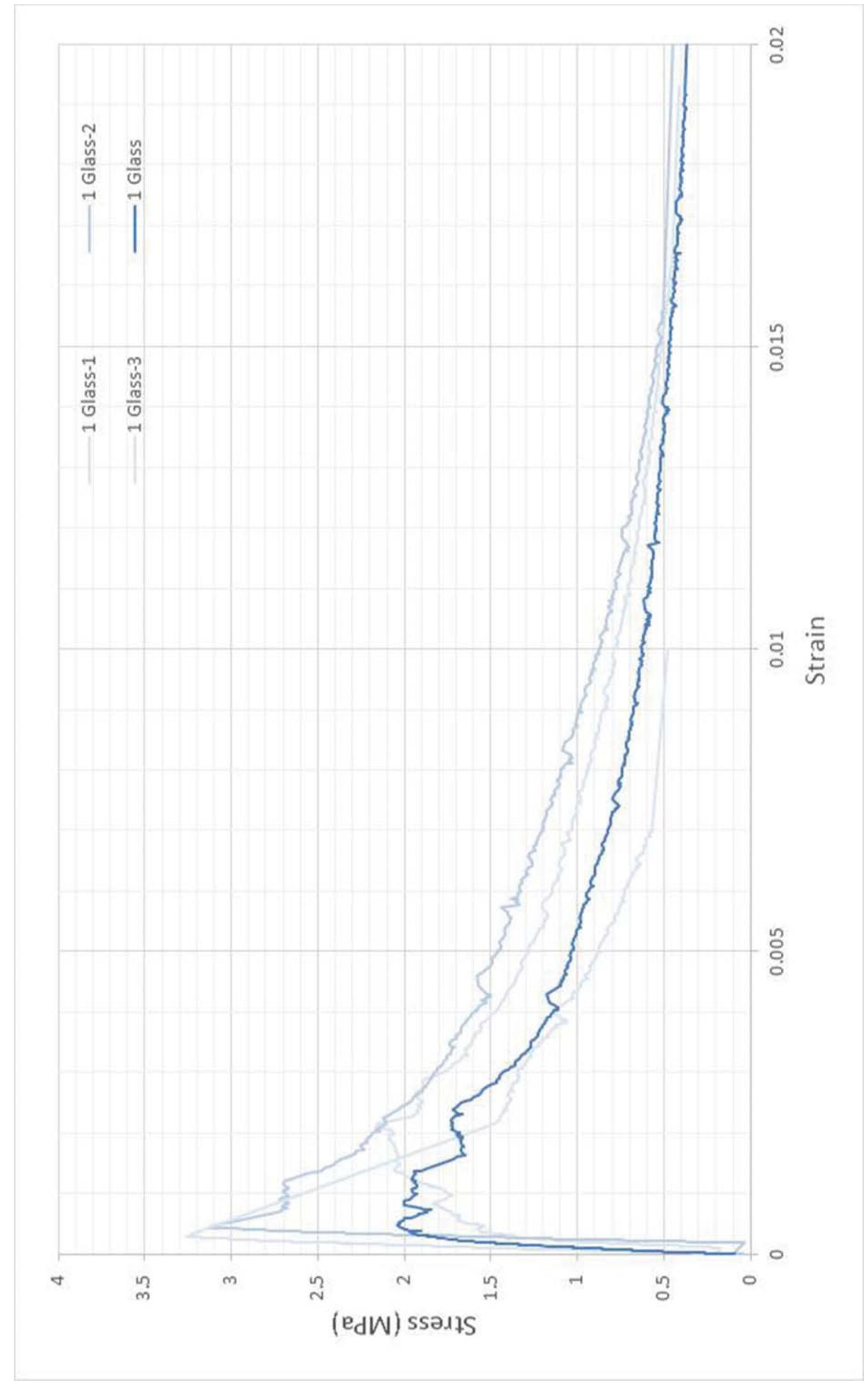




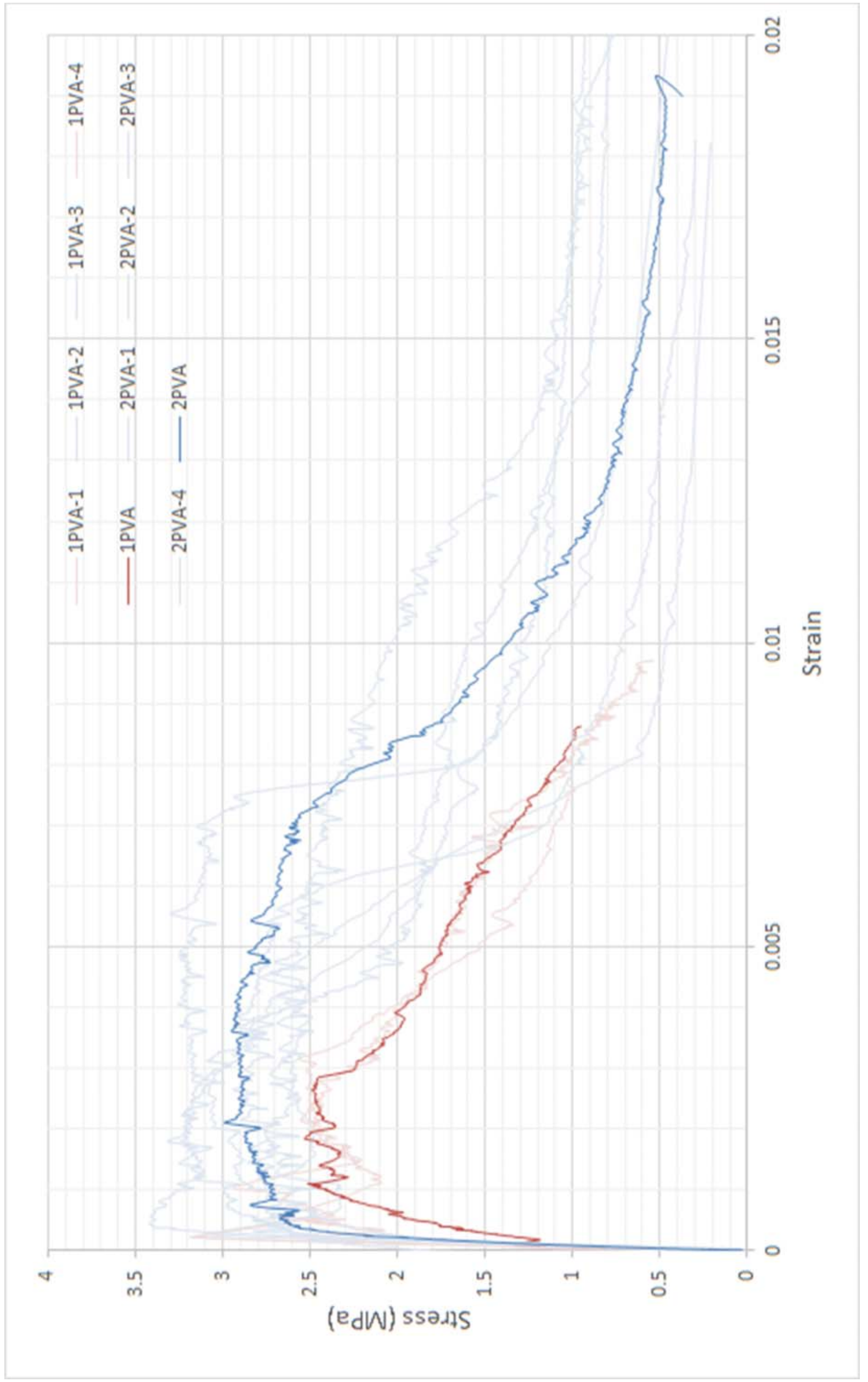




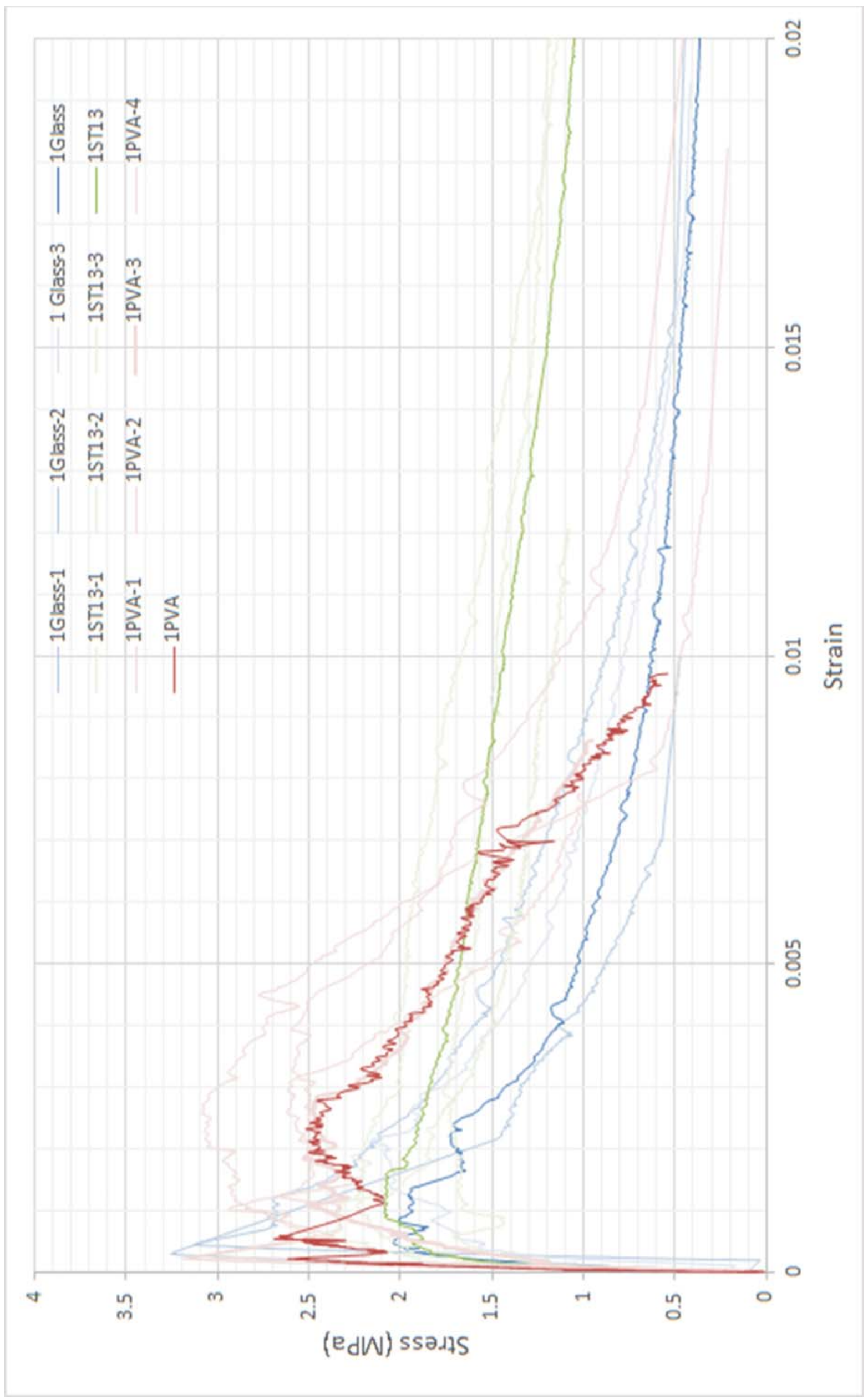




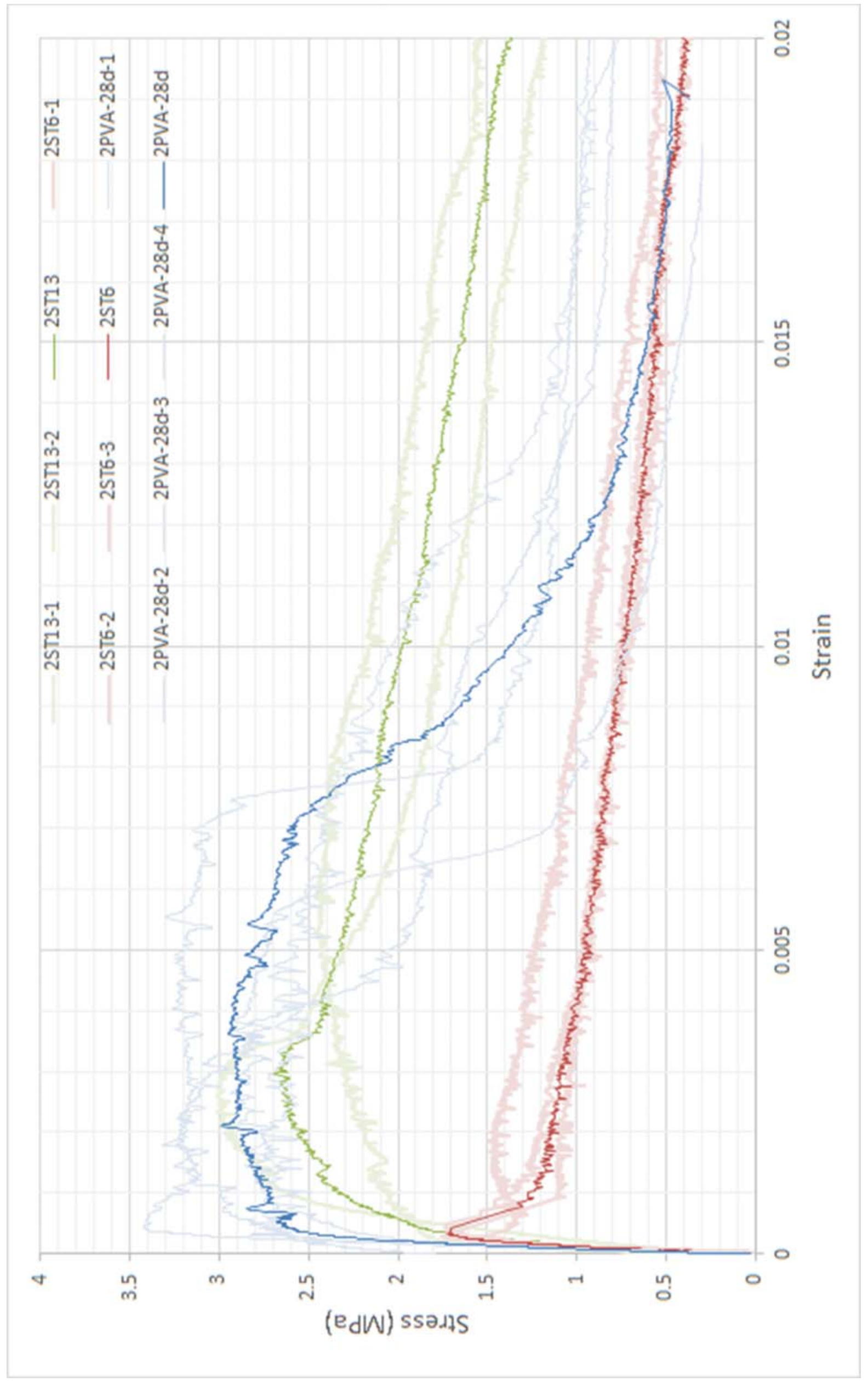




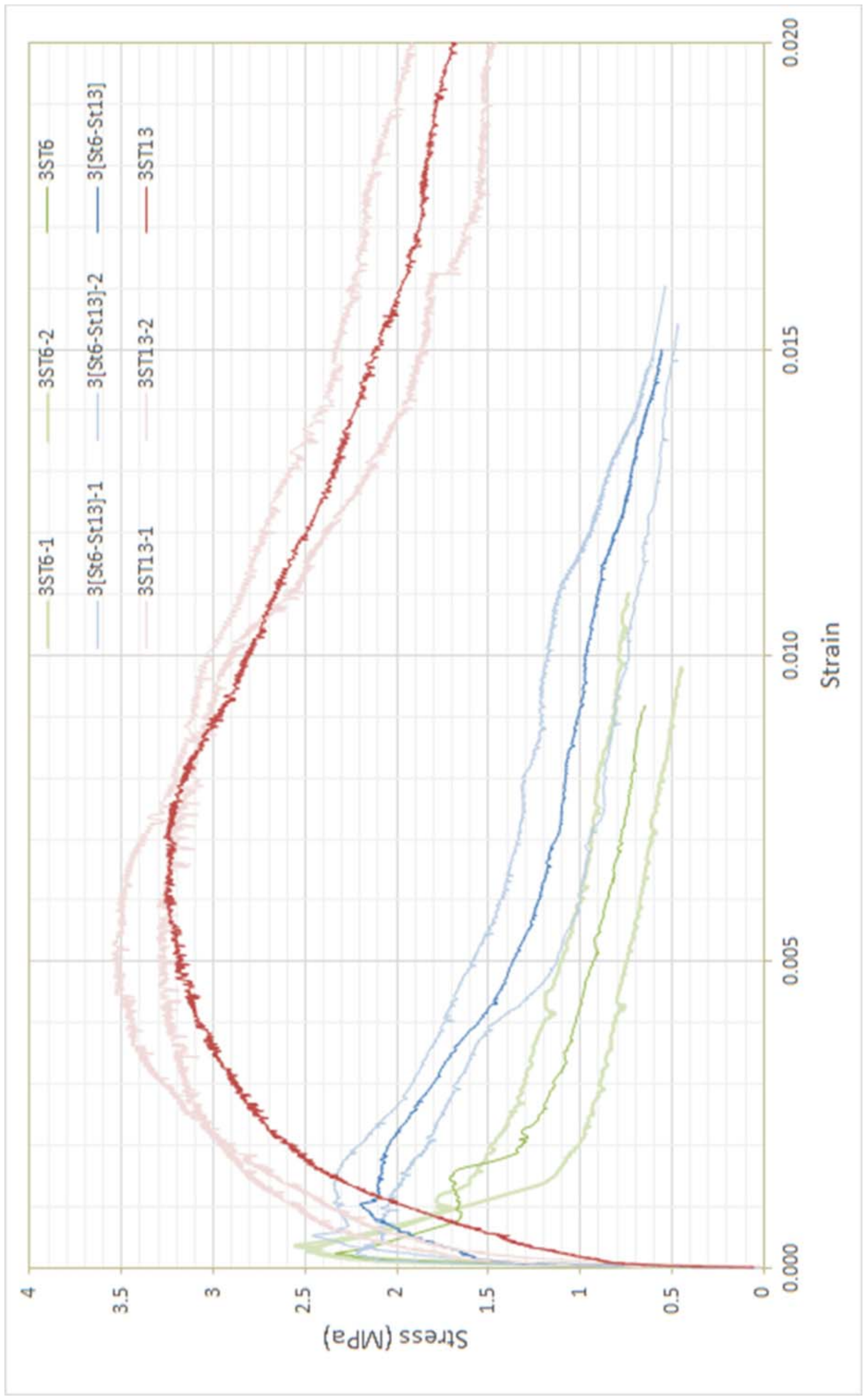




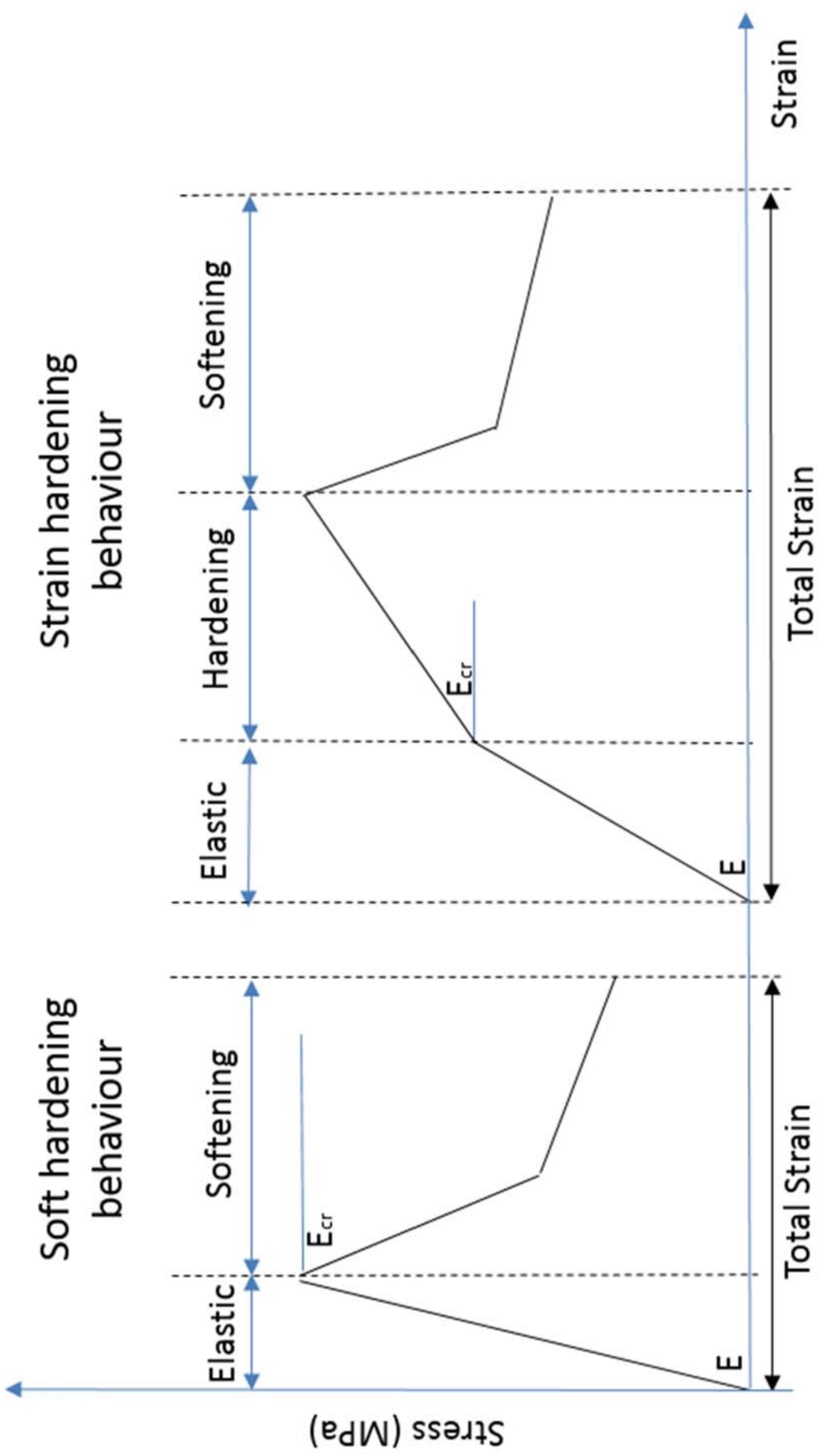




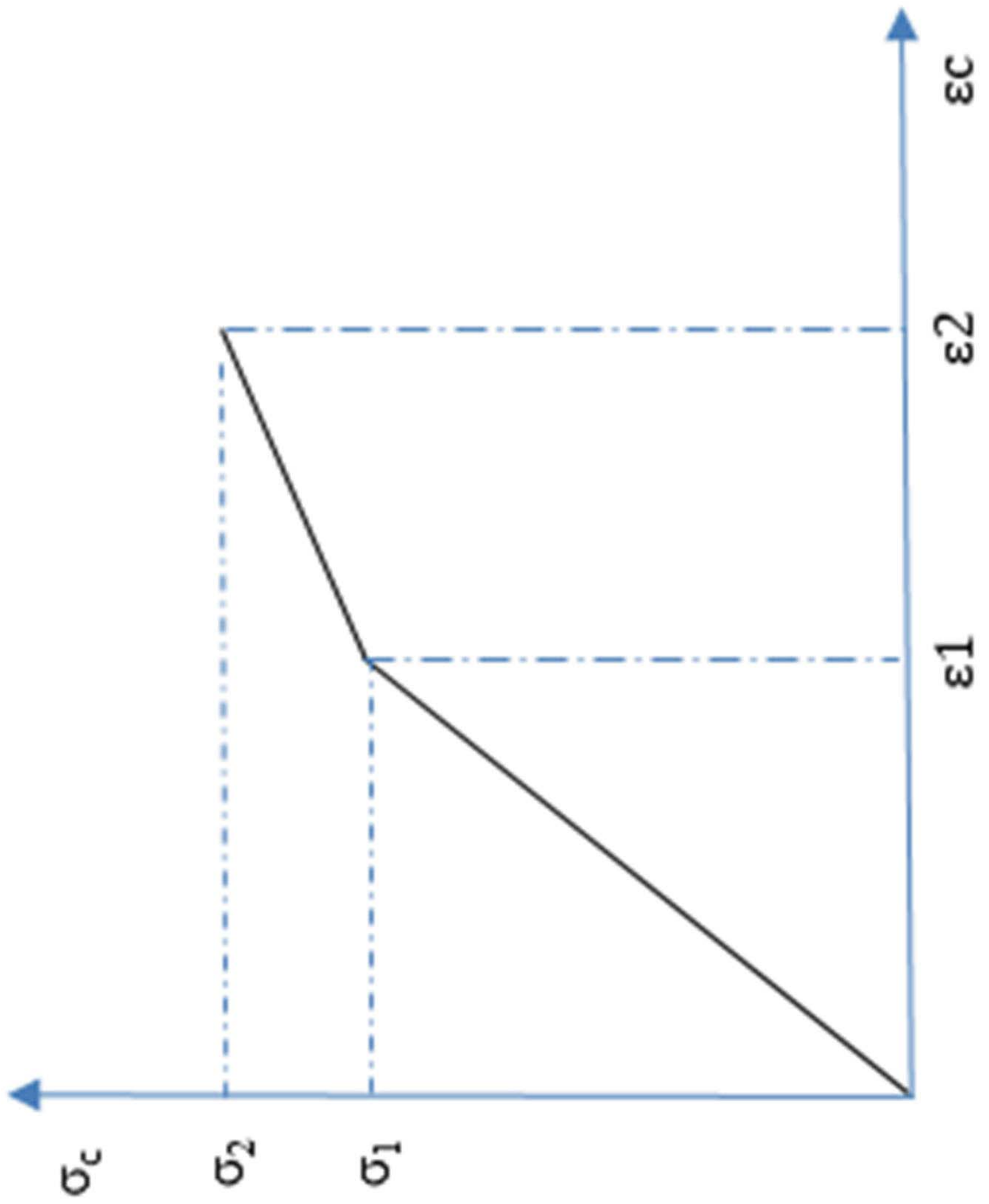




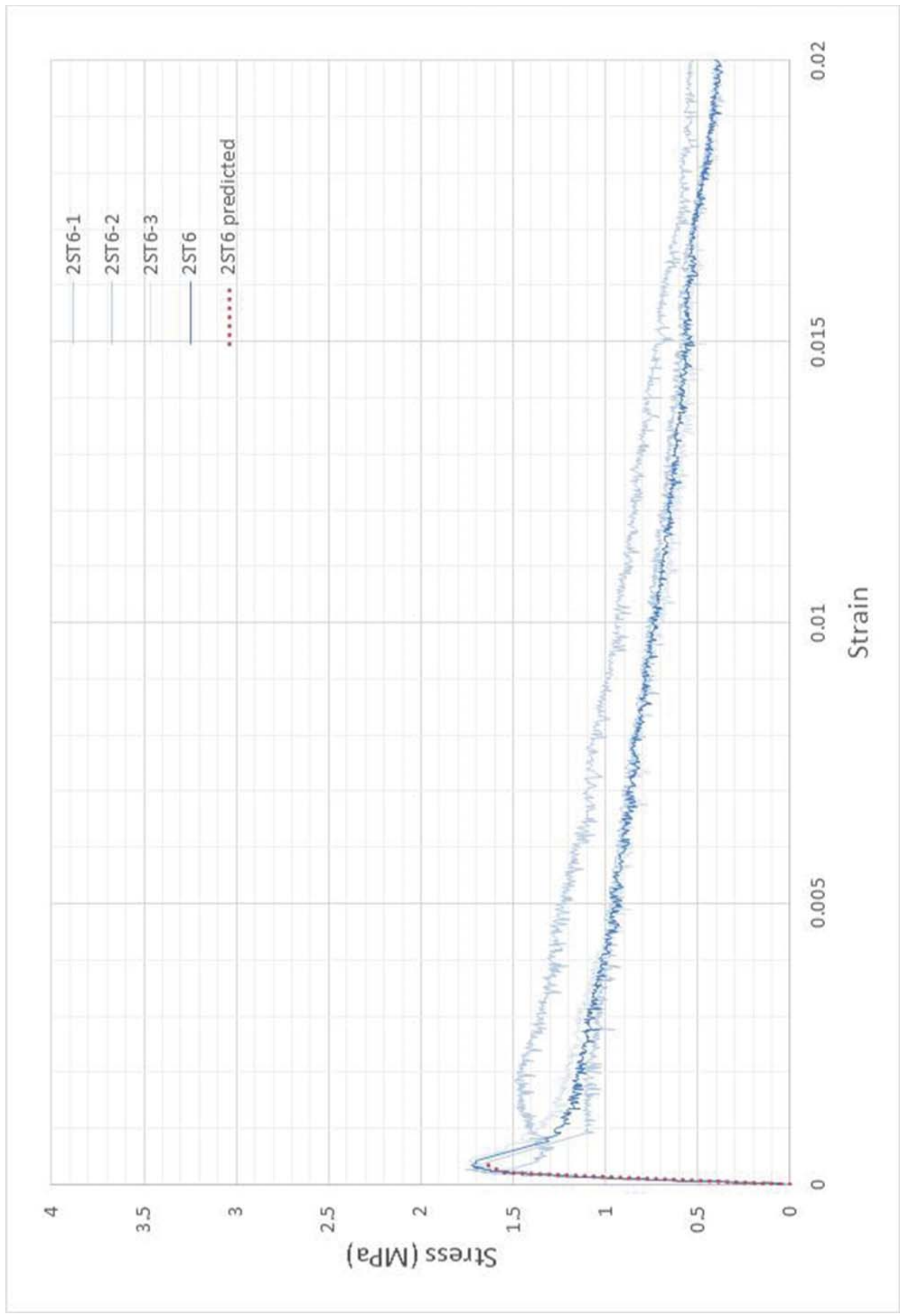




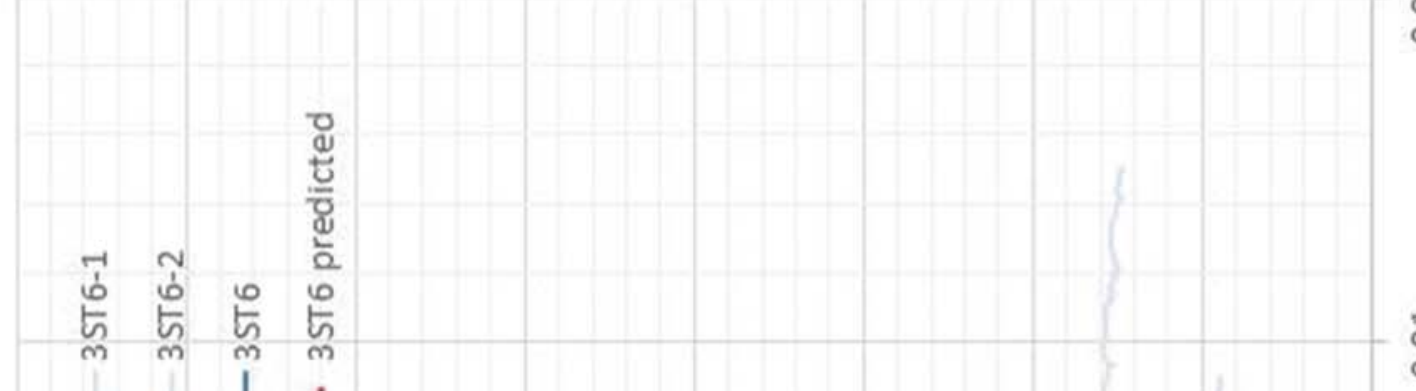

뭉.

$\stackrel{\infty}{\circ}$

응 $\frac{5}{\circ}$

8
0
0

응

ง

n

m ก

ก

N

n

ท

n

o

(edw) ssarts 


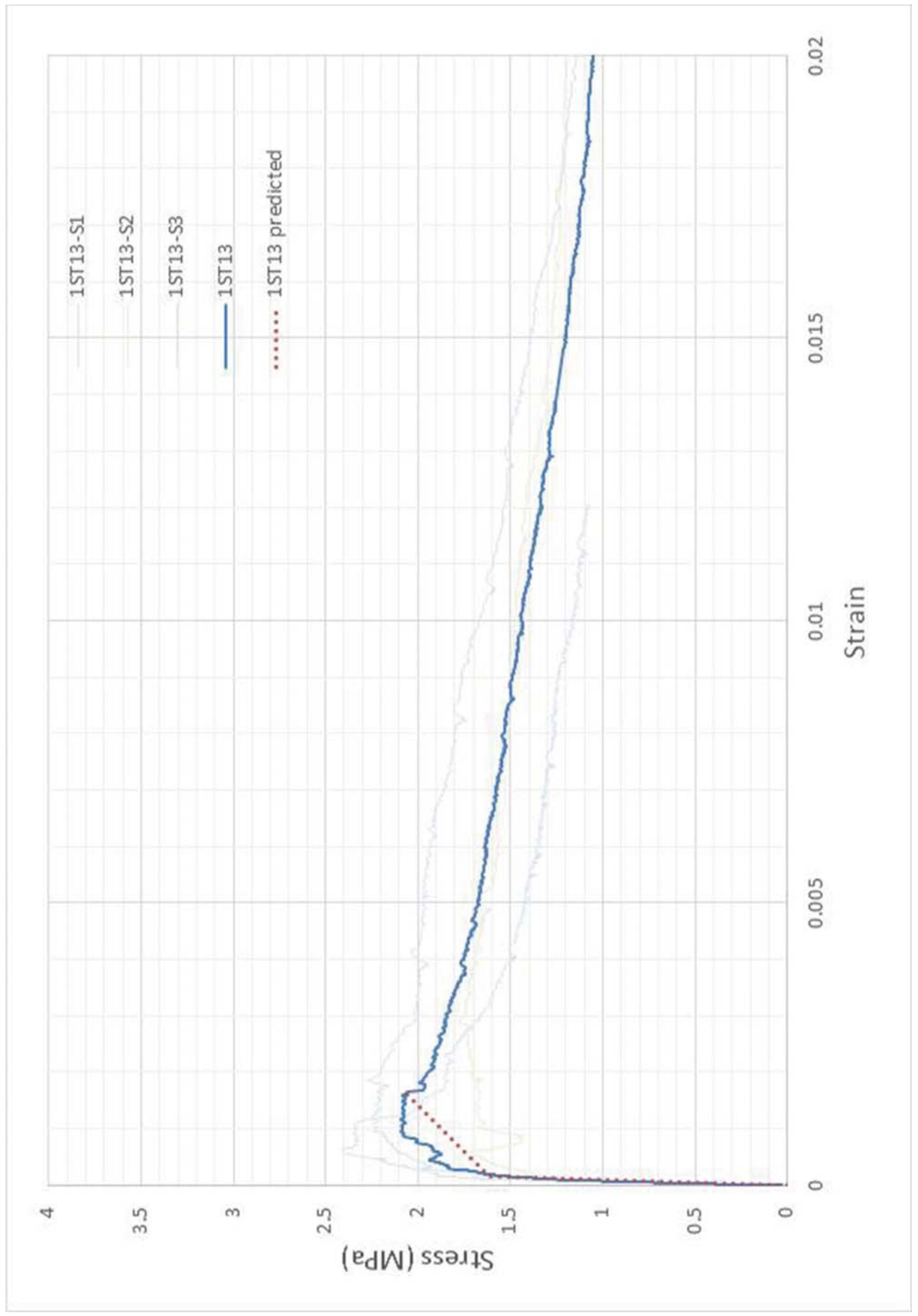




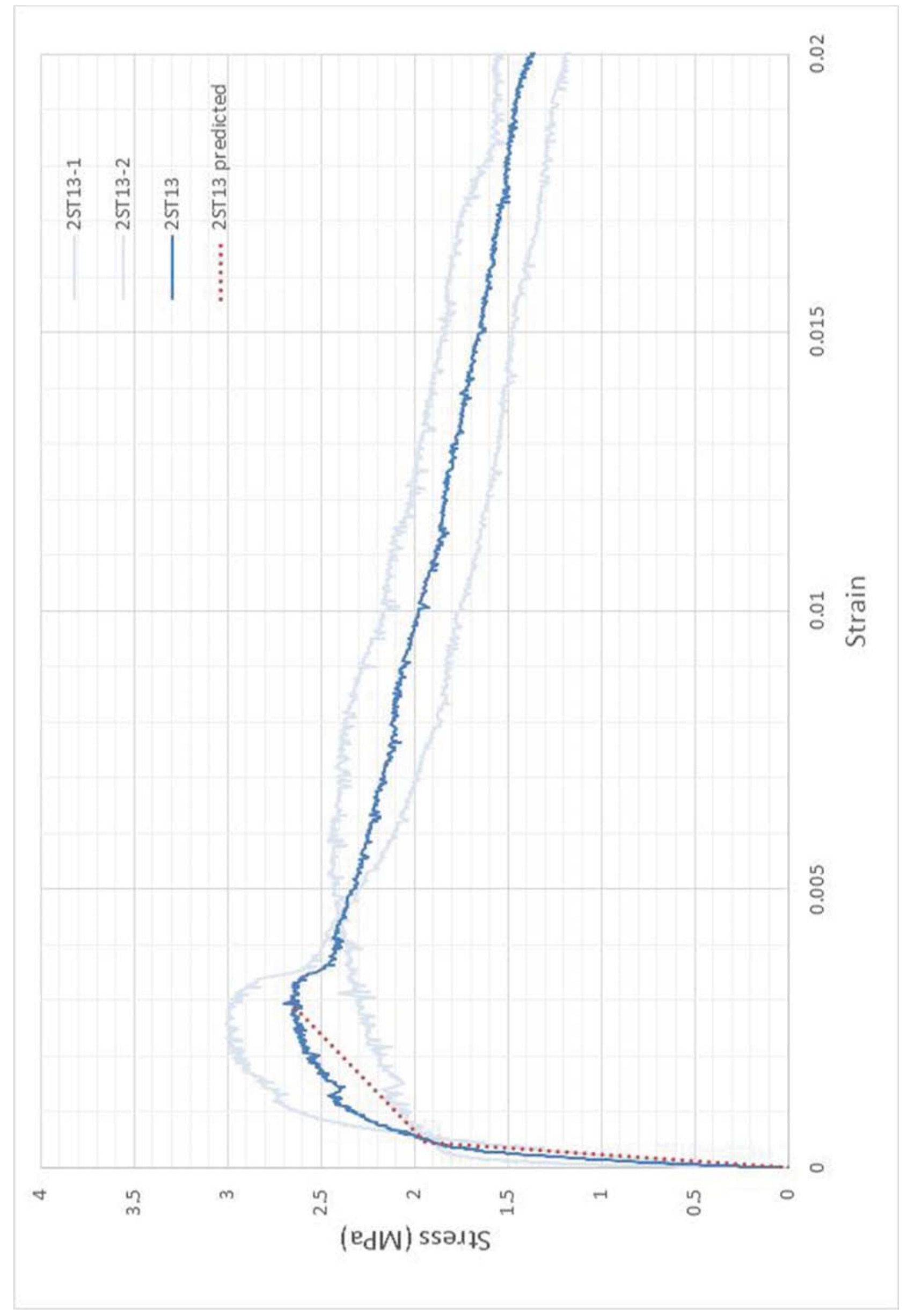




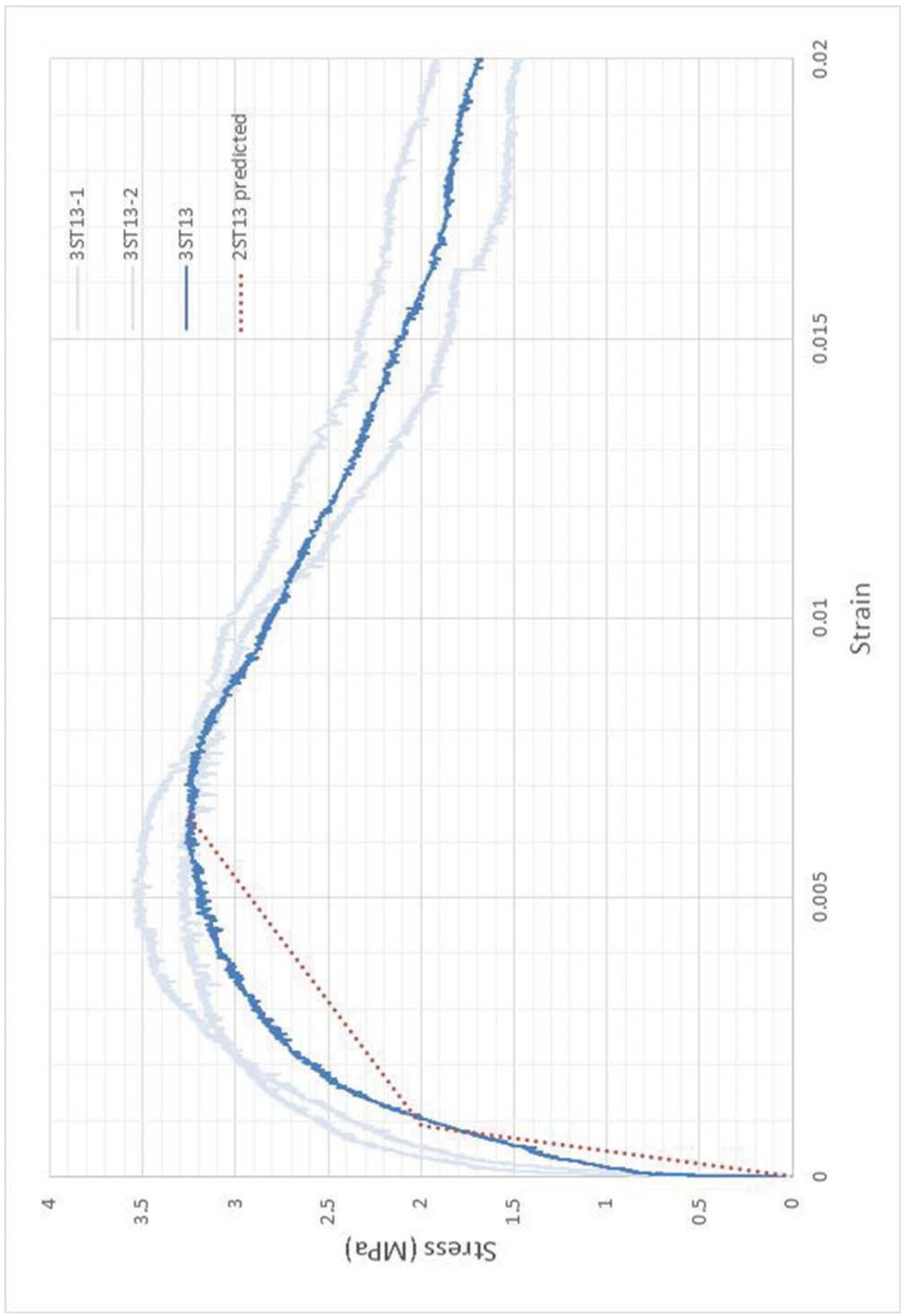




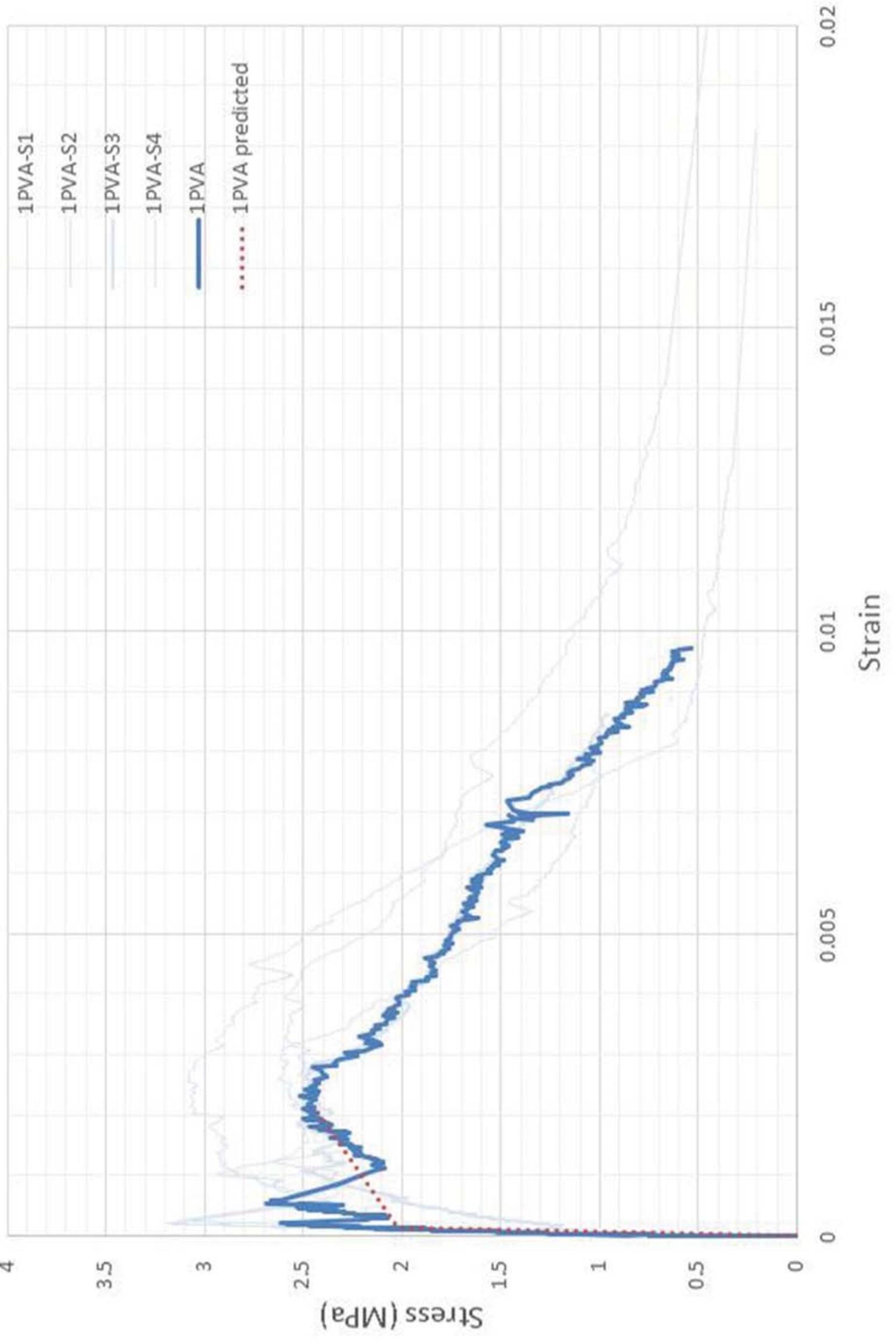




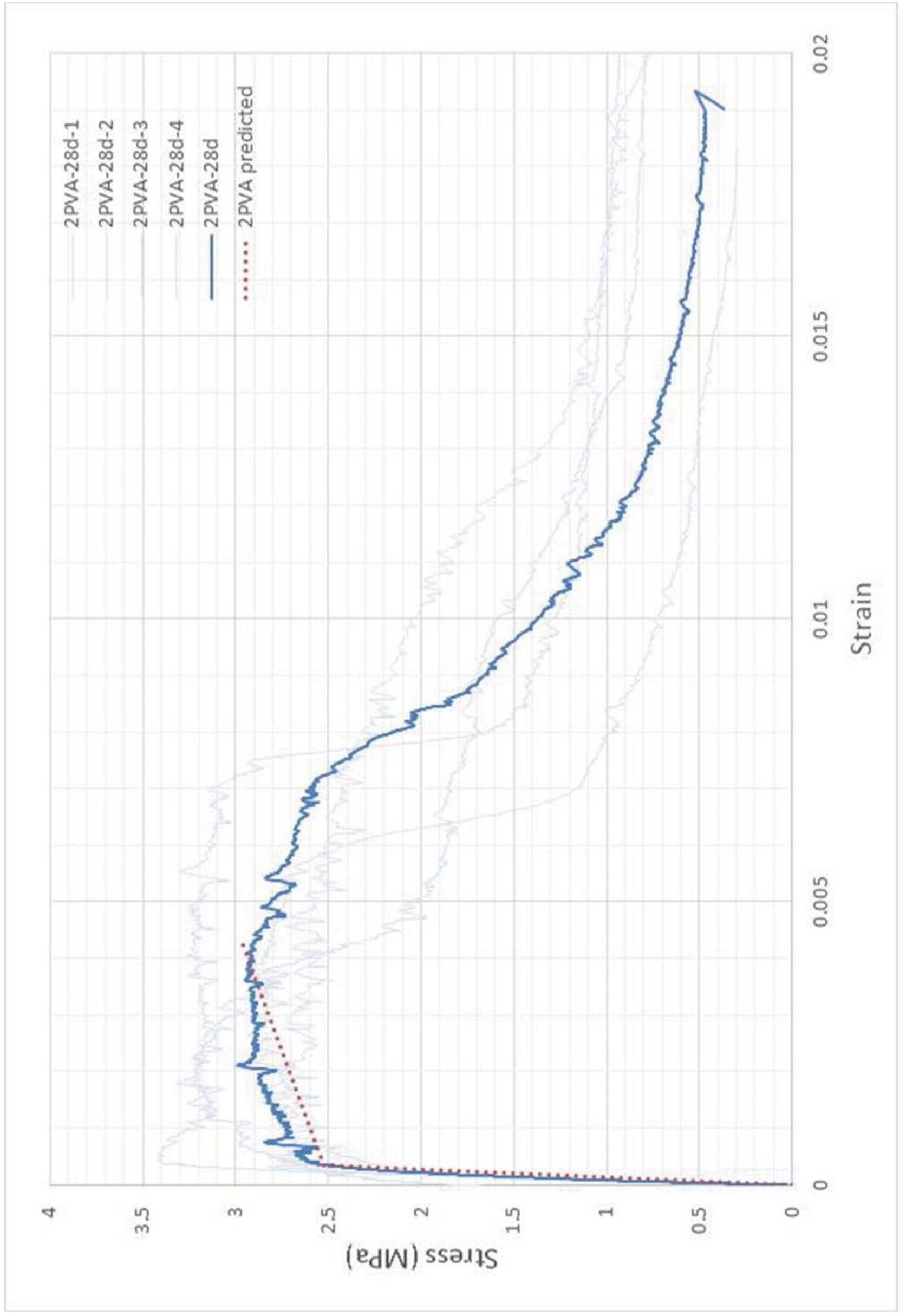




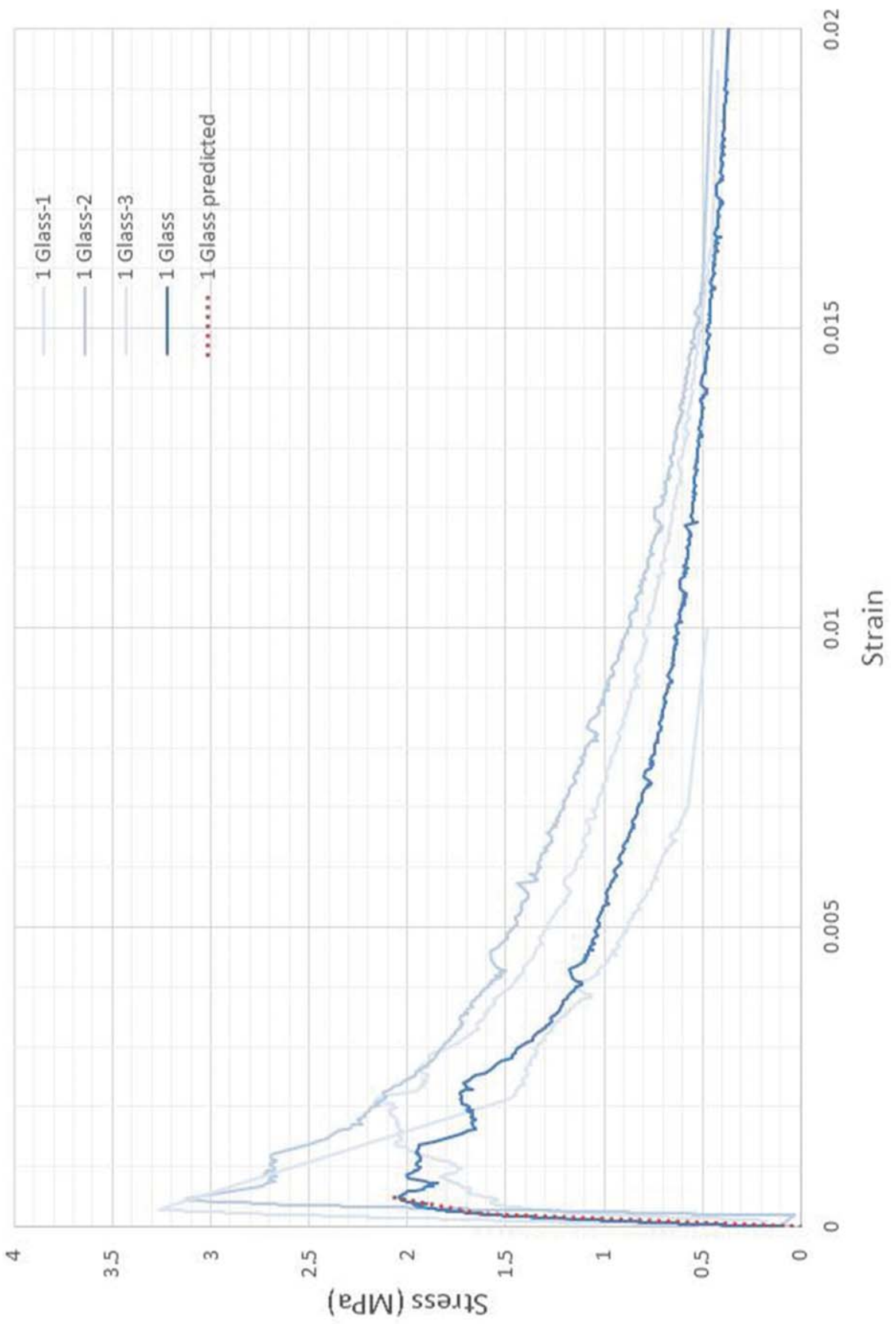




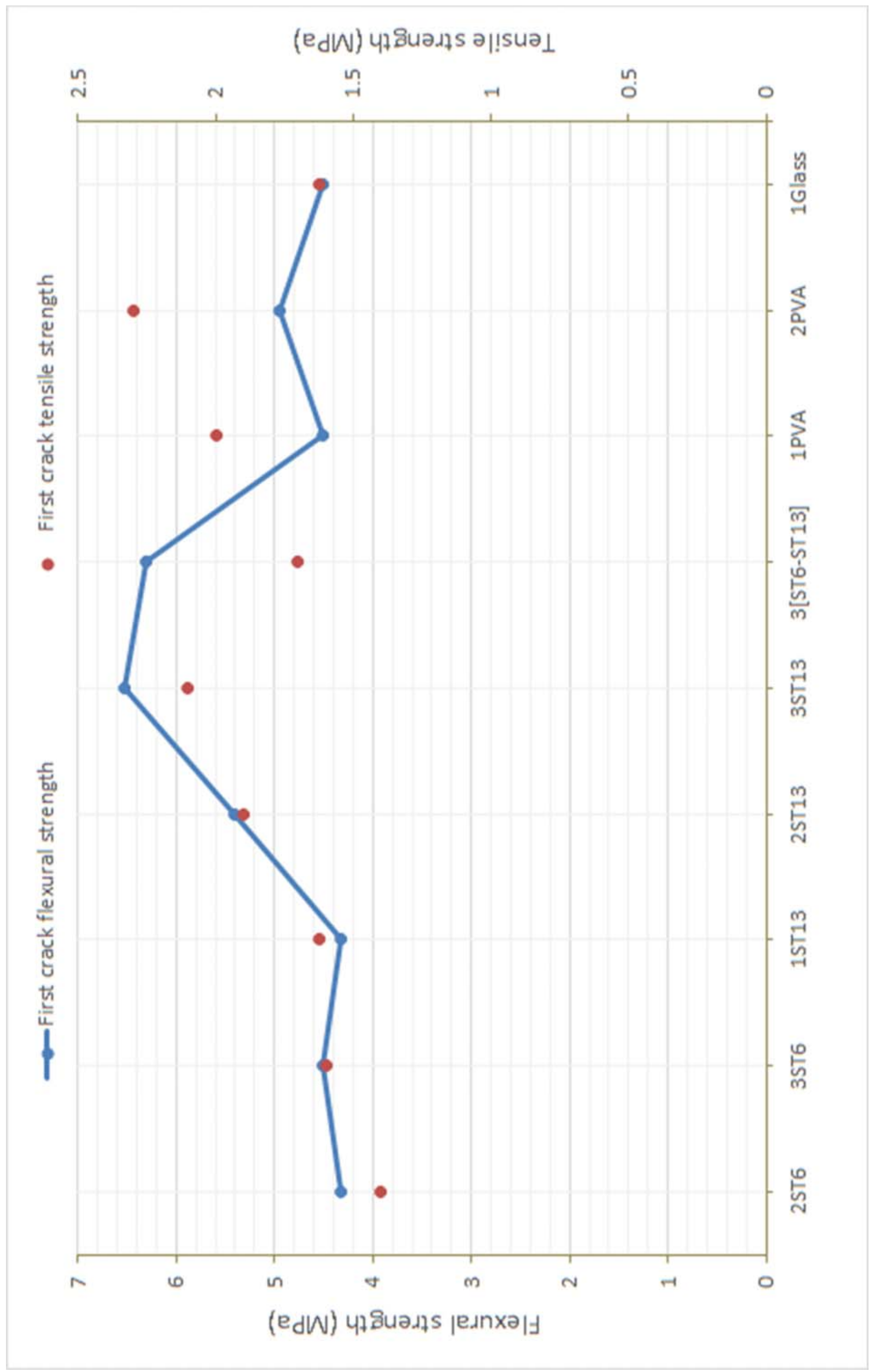




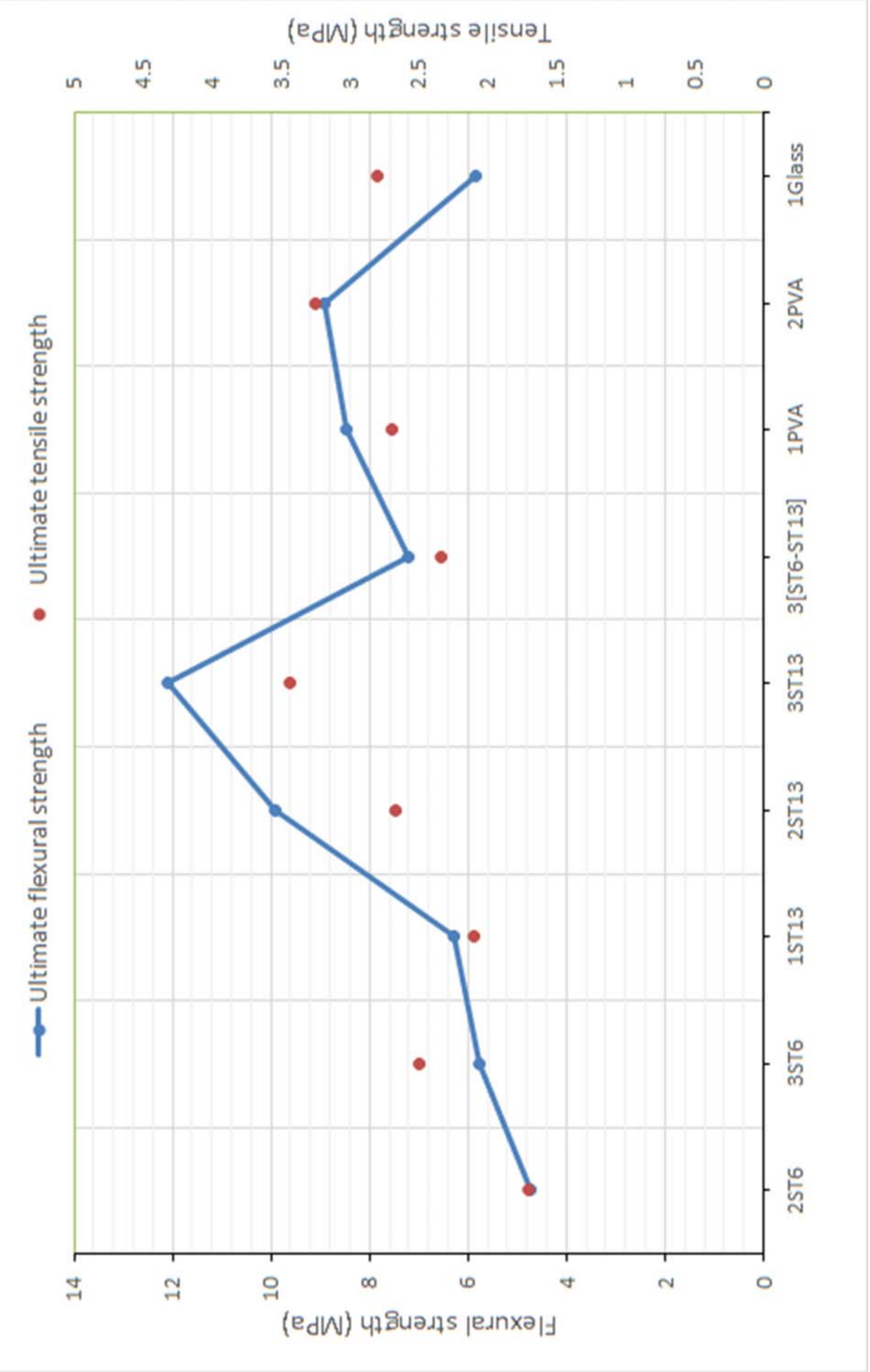




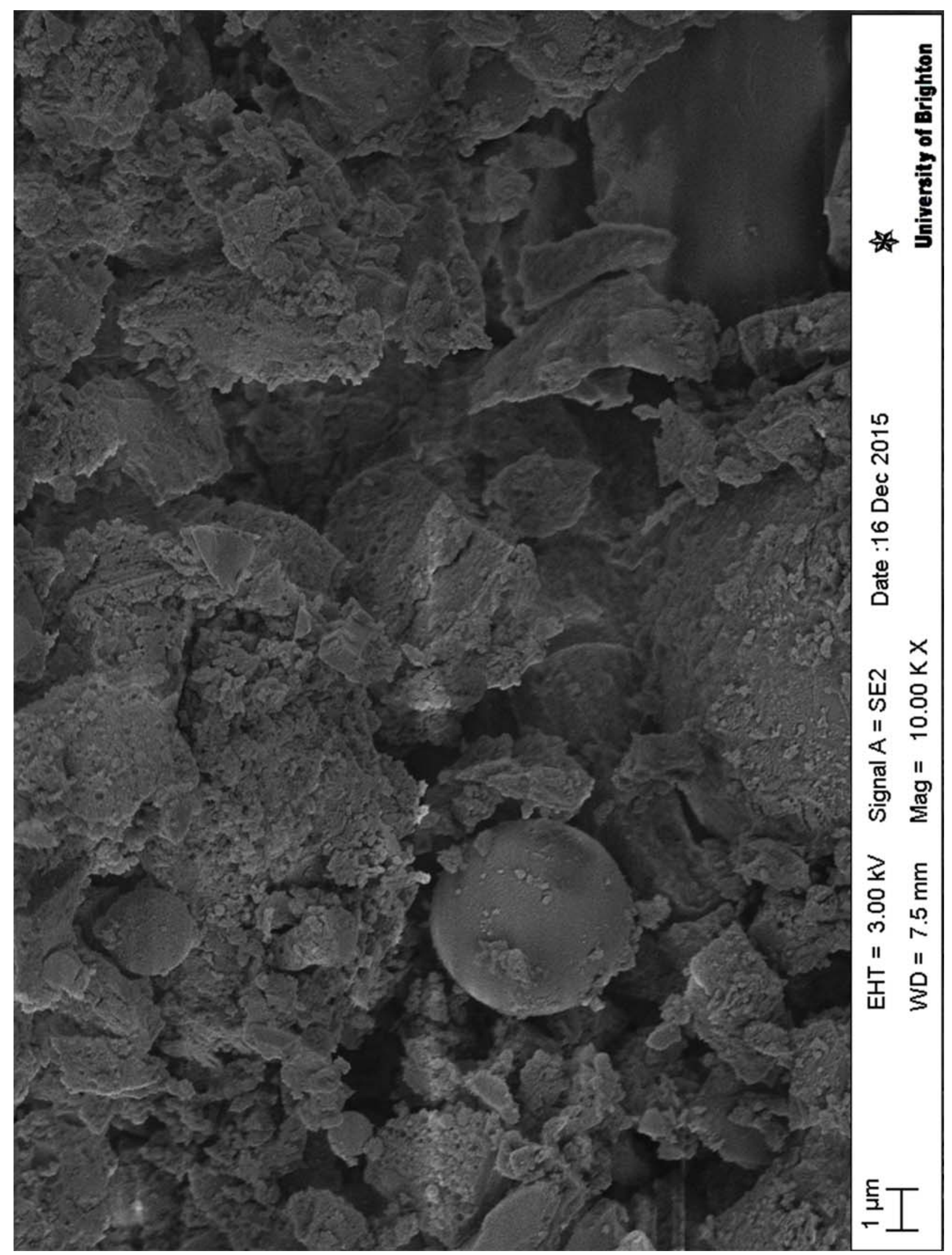




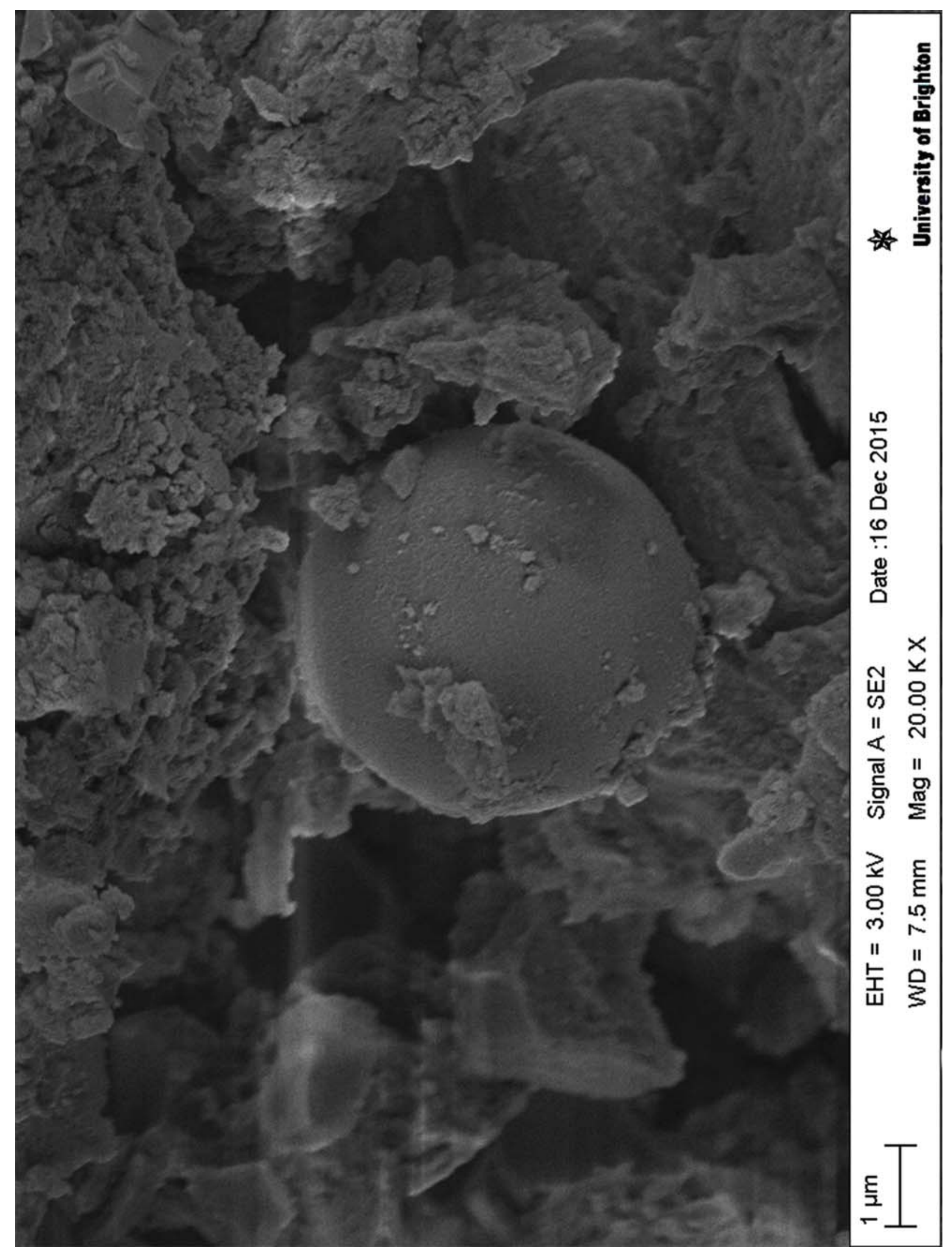




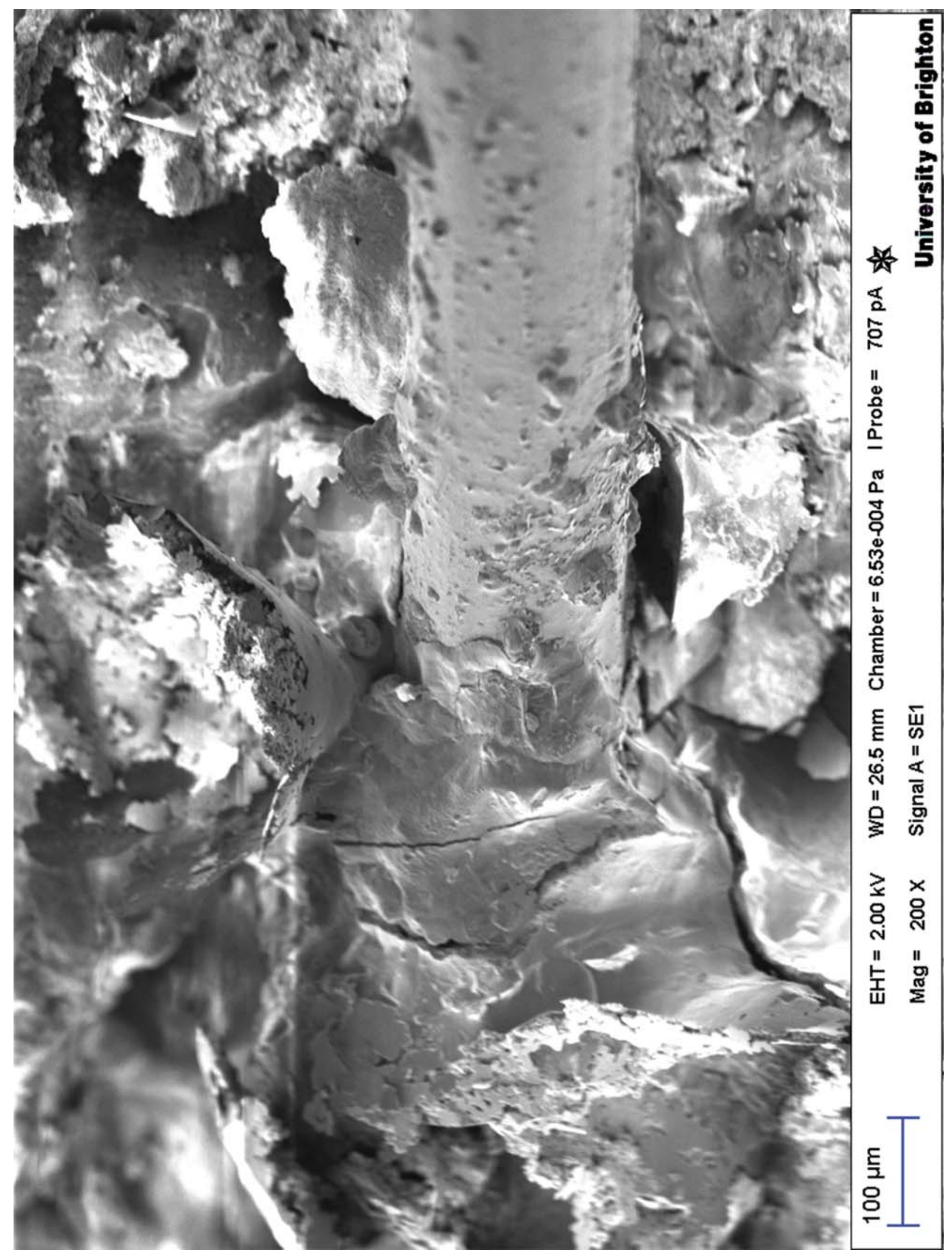




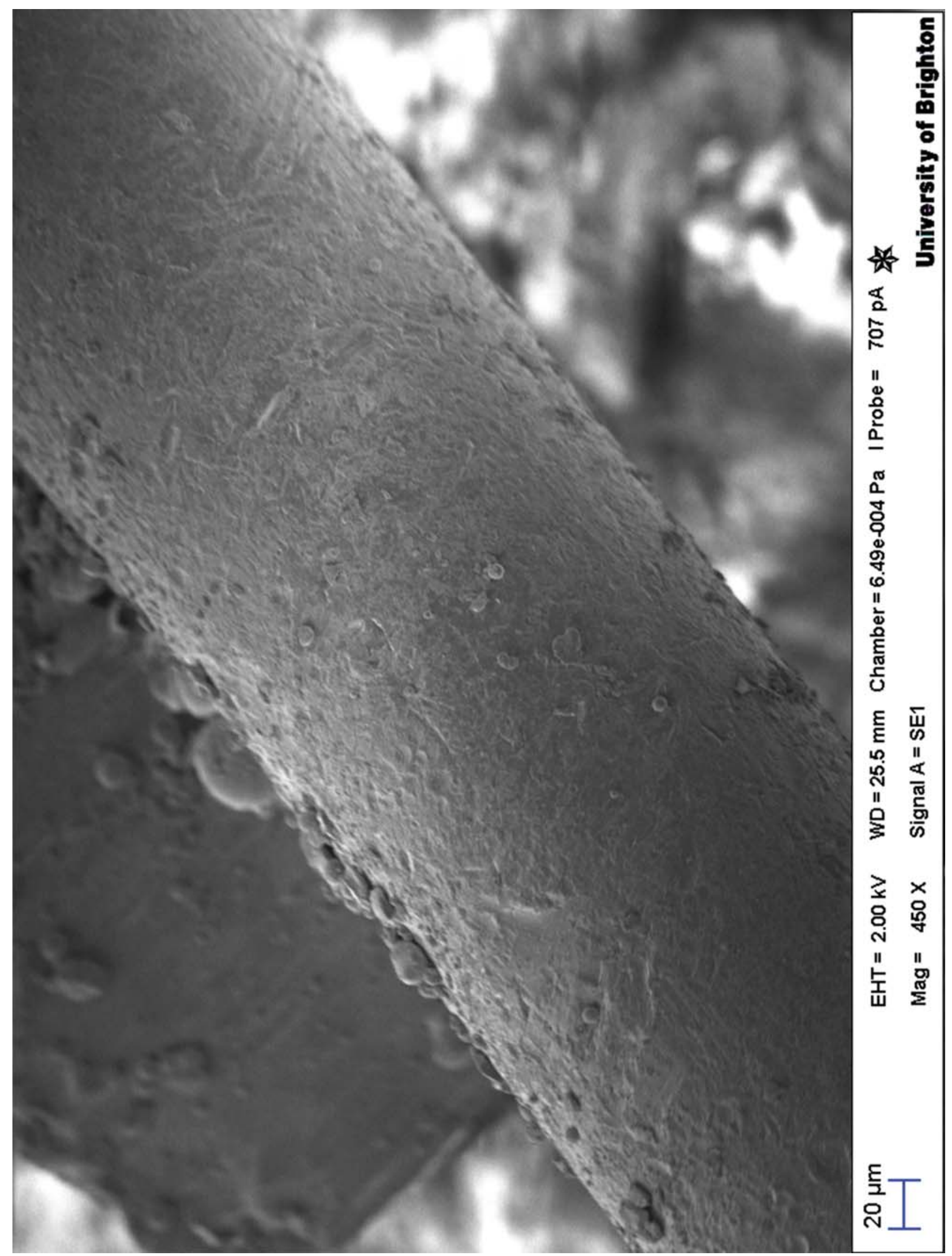




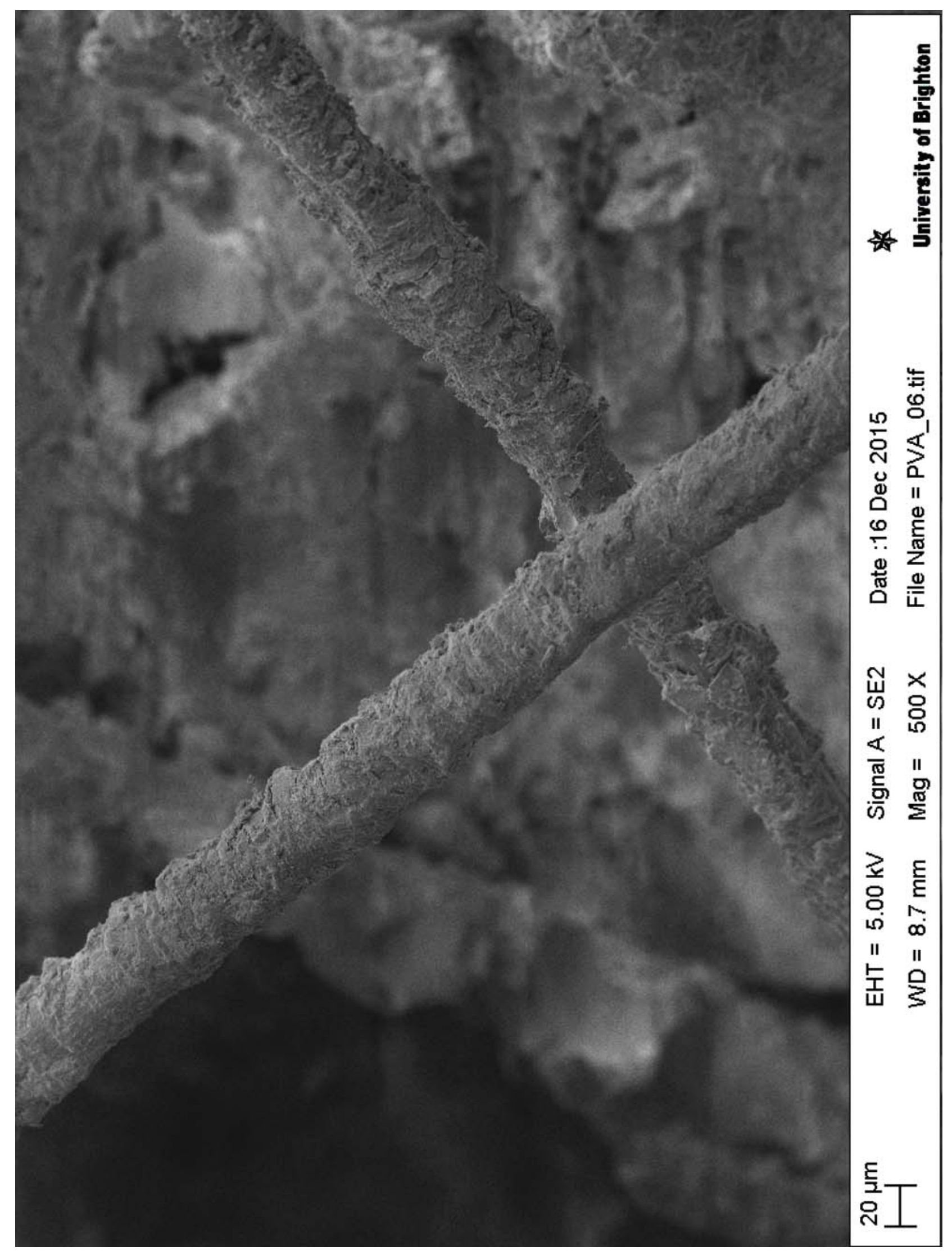




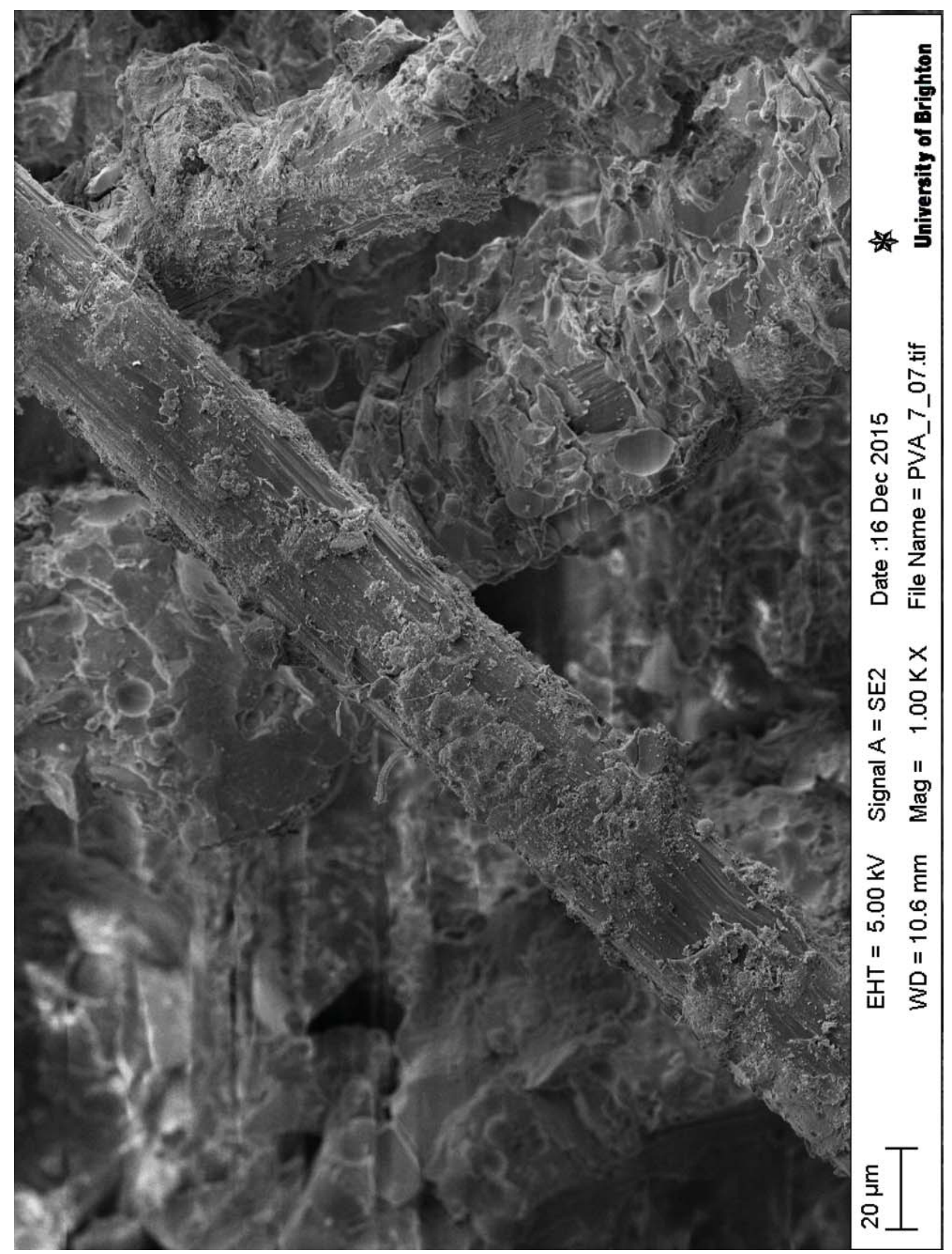




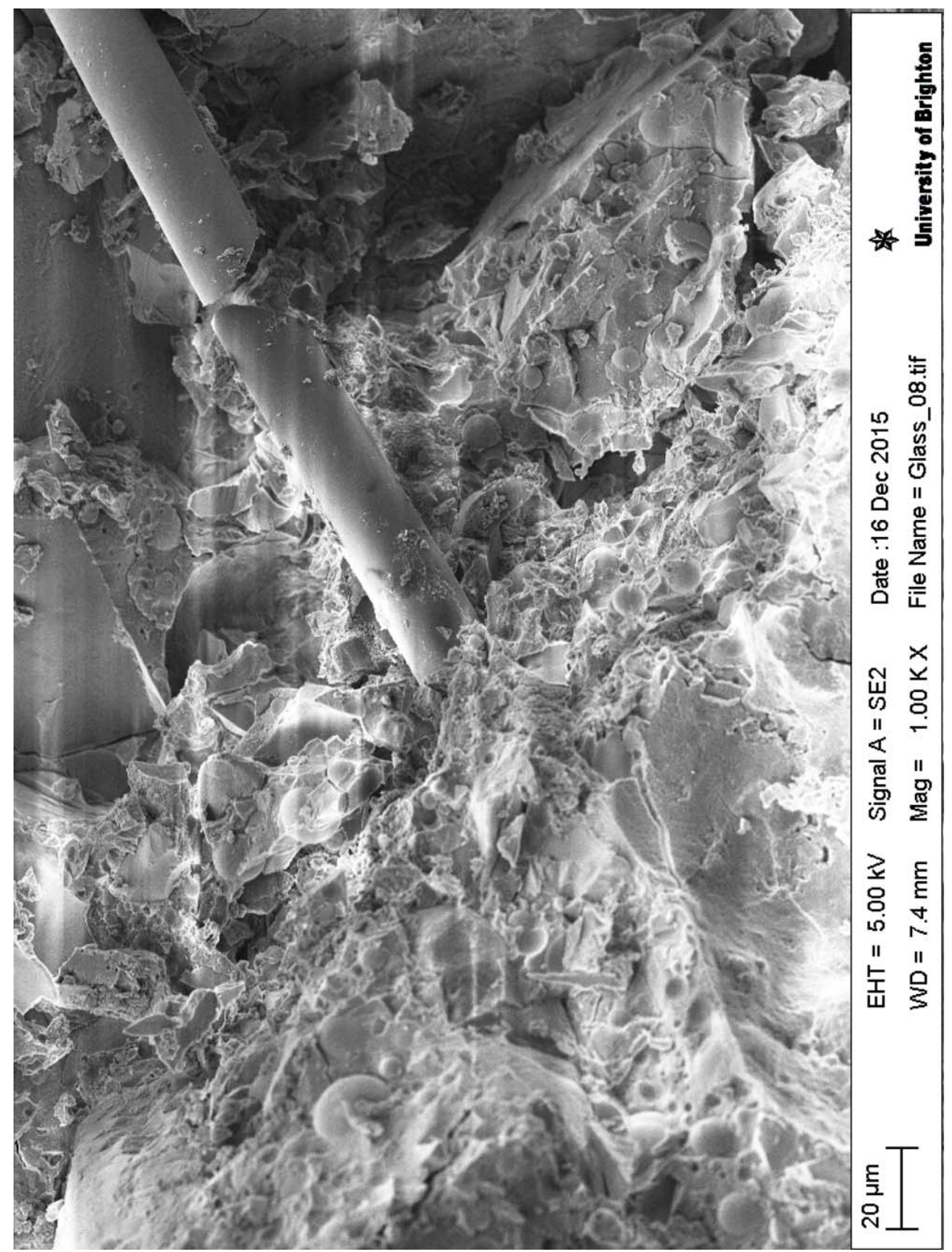




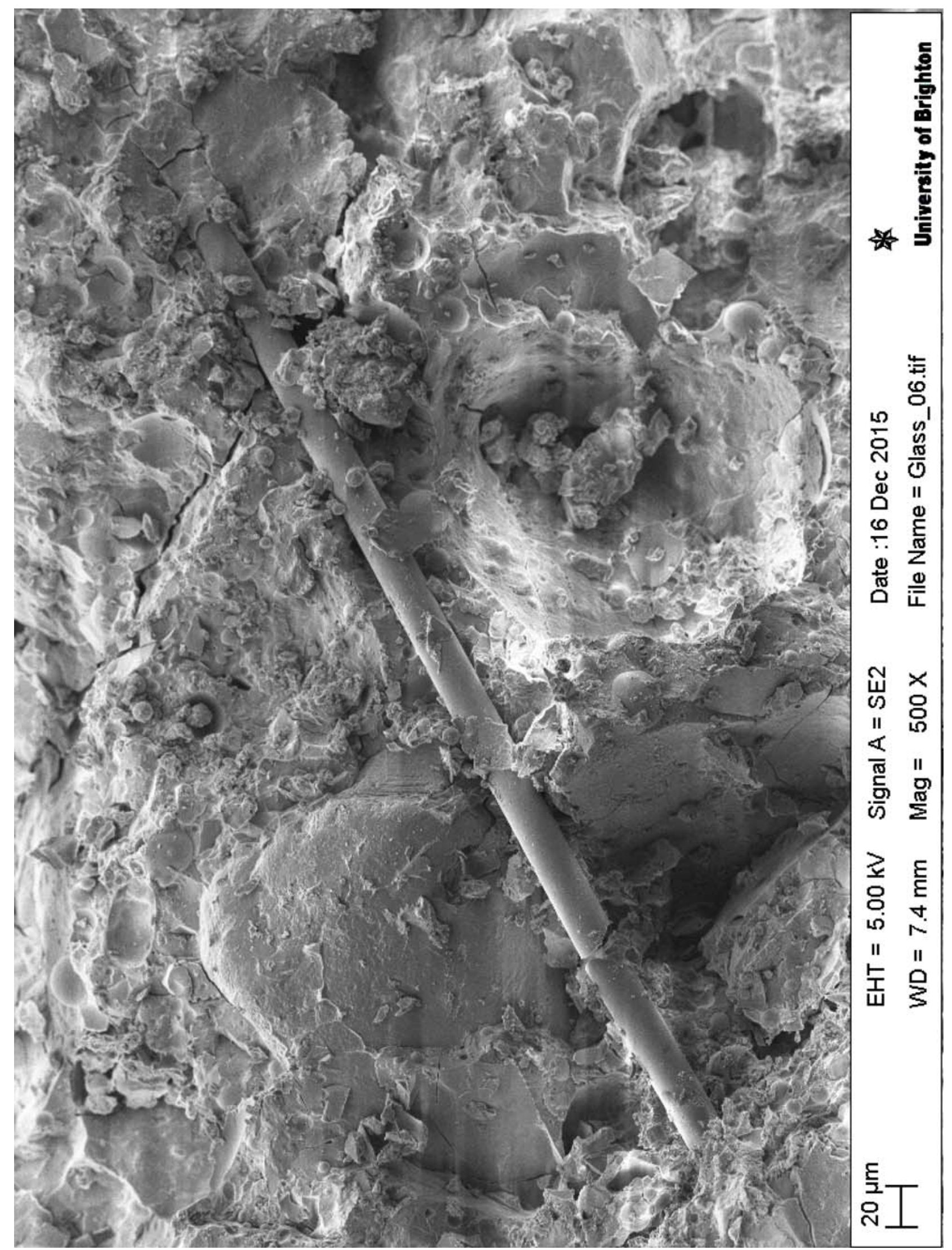




\section{List of tables}

Table 1. Mixture compositions of fibre reinforced geopolymer concrete

\begin{tabular}{ccccccccc}
\hline Mix ID & $\begin{array}{c}\text { OPC } \\
\left(\mathbf{K g} / \mathbf{m}^{3}\right)\end{array}$ & $\begin{array}{c}\text { FA/ } \\
\text { Binder }\end{array}$ & $\begin{array}{c}\text { GGBS/ } \\
\text { Binder }\end{array}$ & $\begin{array}{c}\text { SF/ } \\
\text { Binder }\end{array}$ & $\begin{array}{c}\text { Sand } \\
\left(\mathbf{K g} / \mathbf{m}^{3}\right)\end{array}$ & $\begin{array}{c}\mathbf{K}_{2} \mathbf{S i O}_{3} / \\
\text { Binder }\end{array}$ & $\begin{array}{c}\text { Water/ } \\
\text { Binder }\end{array}$ & $\begin{array}{c}\text { Fibre } \\
\mathbf{V}_{\mathbf{f}}(\mathbf{\%})\end{array}$ \\
\hline OPC mortar & 650 & - & - & - & 1525 & - & 0.35 & 0 \\
GP mortar & - & 0.5 & 0.4 & 0.1 & 1052 & 0.12 & 0.25 & 0 \\
2ST6 & - & 0.5 & 0.4 & 0.1 & 1052 & 0.12 & 0.25 & 2 \\
3ST6 & - & 0.5 & 0.4 & 0.1 & 1052 & 0.12 & 0.25 & 3 \\
1ST13 & - & 0.5 & 0.4 & 0.1 & 1052 & 0.12 & 0.25 & 1 \\
2ST13 & - & 0.5 & 0.4 & 0.1 & 1052 & 0.12 & 0.25 & 2 \\
3ST13 & - & 0.5 & 0.4 & 0.1 & 1052 & 0.12 & 0.25 & 3 \\
3[ST6-ST13] & - & 0.5 & 0.4 & 0.1 & 1052 & 0.12 & 0.25 & 3 \\
1HE & - & 0.5 & 0.4 & 0.1 & 1052 & 0.12 & 0.25 & 1 \\
1HE-1ST13 & - & 0.5 & 0.4 & 0.1 & 1052 & 0.12 & 0.25 & 2 \\
1HE-2ST13 & - & 0.5 & 0.4 & 0.1 & 1052 & 0.12 & 0.25 & 3 \\
1PVA & - & 0.5 & 0.4 & 0.1 & 1052 & 0.12 & 0.25 & 1 \\
2PVA & - & 0.5 & 0.4 & 0.1 & 1052 & 0.12 & 0.25 & 2 \\
1Glass & - & 0.5 & 0.4 & 0.1 & 1052 & 0.12 & 0.25 & 1 \\
\hline
\end{tabular}

Table 2. Fibre properties used in this study

\begin{tabular}{cccccccc}
\hline Fibre type & Geometry & $\begin{array}{c}\text { Length } \\
(\mathbf{m m})\end{array}$ & $\begin{array}{c}\text { Diameter } \\
(\mathbf{m m})\end{array}$ & $\begin{array}{c}\text { Aspect ratio } \\
(\mathbf{L} / \mathbf{D})\end{array}$ & $\begin{array}{c}\text { Fibre strength } \\
(\mathbf{M P a})\end{array}$ & $\begin{array}{c}\text { Density } \\
\left(\mathbf{K g} / \mathbf{m}^{\mathbf{3}}\right)\end{array}$ & $\begin{array}{c}\mathbf{E} \\
(\mathbf{G P a})\end{array}$ \\
\hline Steel (ST6) & Micro & 6 & 0.16 & 37.5 & 2250 & 7850 & 200 \\
Steel (ST13) & Micro & 13 & 0.16 & 81.25 & 2250 & 7850 & 200 \\
Steel (HE1050) & Macro & 50 & 1 & 50 & 1150 & 7850 & 200 \\
Glass & Micro & 13 & 0.13 & 100 & 1620 & 2700 & 74 \\
PVA & Micro & 12 & 0.015 & 800 & $1560 \pm 325$ & 1300 & 29.5 \\
\hline
\end{tabular}

Table 3. Flexural response of fibre reinforced geopolymer composite

\begin{tabular}{|c|c|c|c|c|c|c|c|c|c|c|c|c|c|}
\hline & & 2ST6 & 3ST6 & 1ST13 & 2ST13 & 3ST13 & $\begin{array}{l}\text { 3[ST6- } \\
\text { ST13] }\end{array}$ & $1 \mathrm{HE}$ & $\begin{array}{c}\text { 1HE- } \\
\text { 1ST13 }\end{array}$ & $\begin{array}{c}\text { 1HE- } \\
2 \mathrm{ST} 13\end{array}$ & 1PVA & 2PVA & 1Glass \\
\hline \multirow{3}{*}{$\begin{array}{l}\text { First } \\
\text { crack }\end{array}$} & $P_{1}(k N)$ & 9.60 & 10.00 & 9.60 & 12.00 & 14.50 & 14.00 & 5.50 & 9.50 & 14.80 & 10 & 11.00 & 10.00 \\
\hline & $\delta_{1}(\mathrm{~mm})$ & 0.15 & 0.25 & 0.20 & 0.30 & 0.60 & 0.40 & 0.17 & 0.34 & 0.60 & 0.14 & 0.22 & 0.24 \\
\hline & T(joule) & 0.60 & 1.25 & 0.96 & 1.76 & 4.34 & 2.80 & 0.47 & 1.62 & 4.44 & 0.72 & 0.99 & 1.20 \\
\hline $\begin{array}{c}\mathrm{L} / 600= \\
0.75 \mathrm{~mm}\end{array}$ & $\mathbf{P}_{600}^{100}(\mathrm{kN})$ & 9.50 & 12.70 & 14.00 & 16.50 & 16.00 & 19.40 & 7.50 & 12.50 & 17.00 & 14.9 & 16.00 & 12.80 \\
\hline \multirow{4}{*}{$\begin{array}{c}\text { Second } \\
\text { peak }\end{array}$} & $P_{p}(k N)$ & 10.50 & 12.80 & 14.00 & 22.00 & 26.90 & 16.00 & 7.80 & 14.00 & 25.00 & 18.8 & 19.80 & 13.00 \\
\hline & $\delta_{2}(\mathrm{~mm})$ & 0.22 & 0.60 & 0.75 & 1.75 & 2.55 & 1.5 & 0.80 & 1.77 & 1.75 & 2.22 & 5.50 & 0.75 \\
\hline & F(MPa) & 4.73 & 5.76 & 6.30 & 9.90 & 12.11 & 7.20 & 3.51 & 6.30 & 11.25 & 8.46 & 8.91 & 5.85 \\
\hline & $\mathbf{T}_{\mathrm{P}}$ (joule) & 3.17 & 5.30 & 7.78 & 28.56 & 48.00 & 25.35 & 4.30 & 19.70 & 27.00 & 30.87 & 84.00 & 6.90 \\
\hline $\begin{array}{c}\mathrm{L} / \mathbf{1 5 0}= \\
\mathbf{3 m m}\end{array}$ & $\mathbf{P}_{150}^{100}(\mathrm{kN})$ & 3.00 & 5.00 & 9.70 & 18.80 & 26.00 & 22.00 & -- & 12.50 & 20.00 & 11.63 & 18.00 & 3.00 \\
\hline
\end{tabular}


Table 4. Ultimate tensile strength versus curing time

\begin{tabular}{ccccc}
\hline \multirow{2}{*}{ Mix ID } & \multicolumn{4}{c}{ Tensile strength (MPa) } \\
\cline { 2 - 5 } 2ST6 & 3 days & 7 days & 28 days & 90 days \\
\hline \multirow{3}{*}{ 3ST6 } & 0.70 & 0.86 & 1.60 & 2.33 \\
& 0.70 & 0.76 & 1.73 & 2.65 \\
& 0.69 & 0.90 & 1.80 & 2.38 \\
\cline { 2 - 5 } & NA & 0.88 & 2.55 & NA \\
1ST13 & NA & 0.79 & 2.33 & NA \\
& NA & 1.00 & 2.40 & NA \\
\cline { 2 - 5 } & 1.60 & NA & 2.40 & NA \\
\multirow{2}{*}{ ST13 } & 1.40 & NA & 1.80 & NA \\
& 1.80 & NA & 2.20 & NA \\
\cline { 2 - 5 } 3ST13 & 0.79 & 1.45 & 2.46 & 3.46 \\
& 1.01 & 1.22 & 3.01 & 3.27 \\
& 0.80 & 1.20 & 2.57 & 3.40 \\
\hline \multirow{3}{*}{ 3ST6-ST13] } & 1.73 & 2.50 & 3.55 & 3.67 \\
& 1.68 & 2.59 & 3.31 & 3.97 \\
& 1.66 & 2.55 & 3.40 & 3.54 \\
\hline \multirow{2}{*}{ 1PVA } & NA & 2.03 & 2.23 & 2.34 \\
& NA & 2.46 & 2.46 & 2.79 \\
& NA & 2.06 & 2.20 & 2.51 \\
\hline \multirow{2}{*}{ 2PVA } & 1.60 & 2.00 & 2.50 & NA \\
& 1.40 & 1.80 & 2.60 & NA \\
& 1.80 & 2.30 & 3.00 & NA \\
\cline { 2 - 5 } 1Glass & NA & 2.26 & 3.24 & NA \\
& NA & 2.14 & 3.43 & NA \\
& NA & 2.00 & 3.80 & NA \\
\hline & NA & 1.28 & 3.13 & NA \\
& NA & 1.68 & 3.26 & NA \\
& NA & 1.80 & 2.04 & NA \\
\hline
\end{tabular}

Table 5. Bond characteristics of fibre reinforced geopolymer concrete

\begin{tabular}{cccccccccc}
\hline $\begin{array}{c}\text { Modulus of } \\
\text { Elasticity }\end{array}$ & 2ST6 & 3ST6 & 1ST13 & 2ST13 & 3ST13 & 3[ST6-ST13] & 1PVA & 2PVA & 1Glass \\
\hline E (MPa) & 9855 & 19978 & 9804 & 16064 & 24885 & 13636 & 16129 & 23974 & 15353 \\
$\mathbf{E}_{\text {cr }}$ (MPa) & -- & -- & 431 & 304 & 317 & 665 & 235 & 4414 & 353 \\
\hline
\end{tabular}

Table 6. Proposed stress-strain relationships for FRGC

\begin{tabular}{|c|c|c|c|}
\hline \multirow[t]{2}{*}{ Mix ID } & \multirow{2}{*}{$\begin{array}{c}\text { First crack } \\
\text { Stress }\end{array}$} & \multicolumn{2}{|c|}{ Ultimate strength } \\
\hline & & Strain & Stress \\
\hline 2ST6 & $\sigma_{1}=0.24 \cdot(1.6-\mathrm{h}) \cdot \mathrm{f}_{\mathrm{ctm}, \mathrm{fl}}$ & $\varepsilon_{2}=\varepsilon_{1}+0.02 \%$ & $\sigma_{2}=0.35 \cdot f_{\text {fl,ult }}$ \\
\hline 3ST6 & $\sigma_{1}=0.24 \cdot(1.6-\mathrm{h}) \cdot \mathrm{f}_{\mathrm{ctm}, \mathrm{fl}}$ & $\varepsilon_{2}=\varepsilon_{1}+0.015 \%$ & $\sigma_{2}=0.38 \cdot f_{\mathrm{fl}, \mathrm{ult}}$ \\
\hline 1ST13 & $\sigma_{1}=0.24 \cdot(1.6-\mathrm{h}) \cdot \mathrm{f}_{\mathrm{ctm}, \mathrm{fl}}$ & $\varepsilon_{2}=\varepsilon_{1}+0.015 \%$ & $\sigma_{2}=0.32 \cdot f_{\mathrm{fl}, \mathrm{ult}}$ \\
\hline $2 \mathrm{ST} 13$ & $\sigma_{1}=0.24 \cdot(1.6-\mathrm{h}) \cdot \mathrm{f}_{\mathrm{ctm}, \mathrm{fl}}$ & $\varepsilon_{2}=\varepsilon_{1}+0.25 \%$ & $\sigma_{2}=0.26 \cdot f_{\mathrm{fl}, \mathrm{ult}}$ \\
\hline 3ST13 & $\sigma_{1}=0.20 \cdot(1.6-\mathrm{h}) \cdot \mathrm{f}_{\mathrm{ctm}, \mathrm{fl}}$ & $\varepsilon_{2}=\varepsilon_{1}+0.55 \%$ & $\sigma_{2}=0.26 \cdot f_{\mathrm{fl}, \mathrm{ult}}$ \\
\hline 1PVA & $\sigma_{1}=0.20 \cdot(1.6-\mathrm{h}) \cdot \mathrm{f}_{\mathrm{ctm}, \mathrm{fl}}$ & $\varepsilon_{2}=\varepsilon_{1}+0.20 \%$ & $\sigma_{2}=0.28 \cdot f_{\text {fl, ult }}$ \\
\hline 2PVA & $\sigma_{1}=0.34 \cdot(1.6-\mathrm{h}) \cdot \mathrm{f}_{\mathrm{ctm}, \mathrm{fl}}$ & $\varepsilon_{2}=\varepsilon_{1}+0.40 \%$ & $\sigma_{2}=0.32 \cdot f_{\mathrm{fl}, \mathrm{ult}}$ \\
\hline 1Glass & $\sigma_{1}=0.24 \cdot(1.6-\mathrm{h}) \cdot \mathrm{f}_{\mathrm{ctm}, \mathrm{fl}}$ & $\varepsilon_{2}=\varepsilon_{1}+0.025 \%$ & $\sigma_{2}=0.36 \cdot f_{\text {fl, ult }}$ \\
\hline
\end{tabular}

